DESIRE FERREIRA COELHO

\title{
O PAPEL DA COMPOSIÇÃO DE ÁCIDOS GRAXOS DA DIETA NA LIPECTOMIA E NAS DOENÇAS INFLAMATÓRIAS INTESTINAIS.
}

Tese apresentada ao Programa de PósGraduação em Biologia Celular e Tecidual do Instituto de Ciências Biomédicas da Universidade de São Paulo, para obtenção do Título de Doutor em Ciências. 
DESIRE FERREIRA COELHO

\section{O PAPEL DA COMPOSIÇÃO DE ÁCIDOS GRAXOS DA DIETA NA LIPECTOMIA E NAS DOENÇAS INFLAMATÓRIAS INTESTINAIS.}

Tese apresentada ao Departamento de Biologia Celular e do Desenvolvimento do Instituto de Ciências Biomédicas da Universidade de São Paulo, para obtenção do Título de Doutor em Ciências.

Área de concentração: Biologia Celular e Tecidual

Orientador: Prof. Dr. Antonio Herbert Lancha Junior

Versão original

São Paulo

2013 
DADOS DE CATALOGAÇÃO NA PUBLICAÇÃO (CIP)

Serviço de Biblioteca e Informação Biomédica do

Instituto de Ciências Biomédicas da Universidade de São Paulo

(C) reprodução total

Coelho, Desire Ferreira.

O papel da composição de ácidos graxos da dieta na lipectomia e nas doenças inflamatórias intestinais / Desire Ferreira Coelho. -- São Paulo, 2013.

Orientador: Prof. Dr. Antonio Helbert Lancha Junior.

Tese (Doutorado) - Universidade de São Paulo. Instituto de Ciências Biomédicas. Departamento de Biologia Celular e do Desenvolvimento. Área de concentração: Biologia Celular e Tecidual. Linha de pesquisa: Metabolismo de lipídios.

Versão do título para o inglês: The role of different dietary fatty acids on lipectomy and inflammatory bowel diseases.

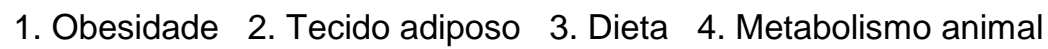
5. Fisiologia I. Prof. Dr. Lancha Junior, Antonio Helbert

II. Universidade de São Paulo. Instituto de Ciências Biomédicas.

Programa de Pós-Graduação em Biologia Celular e Tecidual III. Título. 
Candidato(a): $\quad$ Desire Ferreira Coelho.

Título da Tese: $\quad$ O papel da composição de ácidos graxos da dieta na lipectomia e nas doenças inflamatórias intestinais.

Orientador(a): $\quad$ Prof. Dr. Antonio Helbert Lancha Junior.

A Comissão Julgadora dos trabalhos de Defesa da Tese de Doutorado, em sessão pública realizada a considerou
( ) Aprovado(a)
( ) Reprovado(a)

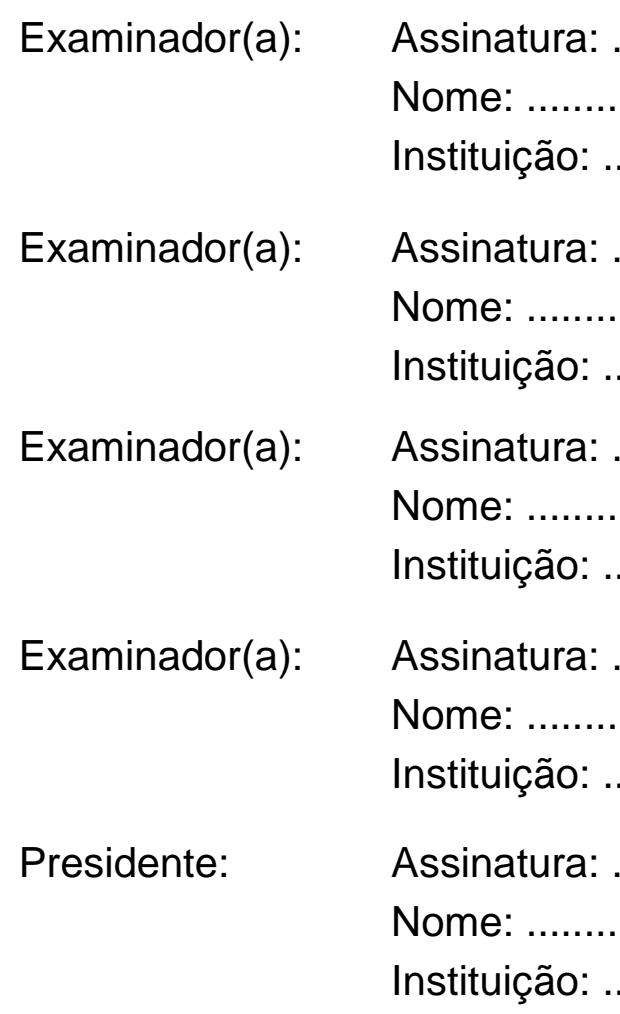




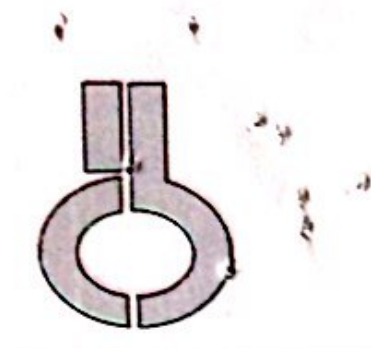

\section{UNIVERSIDADE DE SÃO PAULO INSTITUTO DE CIÊNCIAS BIOMÉDICAS}

\section{Certificado}

Certificamos que o protocolo registrado sob $\mathrm{n}^{\circ} 108$ nas fls. 92 do livro 02 para uso de animais em experimentação, sob a responsabilidade do $\operatorname{Prof}(a) \operatorname{Dr}(a)$ Antonio Herbert Lancha Junior, Coordenador(a) da Linha de pesquisa Efeito de diferentes tipos de gordura dietética na composição corporal, sensibilidade à insulina e marcadores inflamatórios de ratos submetidos à lipectomia do qual participam o(s) alunos Desire Ferreira Coelho, Daisy Diwan, está de acordo com os Principios Éticos de Experimentação Animal adotado pela Sociedade Brasileira de Ciência de Animais de Laboratório (SBCAL) e foi aprovado pela COMISSĀO DE ÉTICA NO USO DE ANIMAIS (CEUA) em 29.11.2010, com validade de 3 anos.

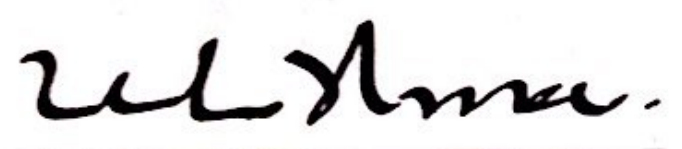

Prof.Dr.WOTHAN TAVARES DE LIMA

Coordenador CEUA - ICB/USP
São Paulo, 06 de dezembro de 2010.

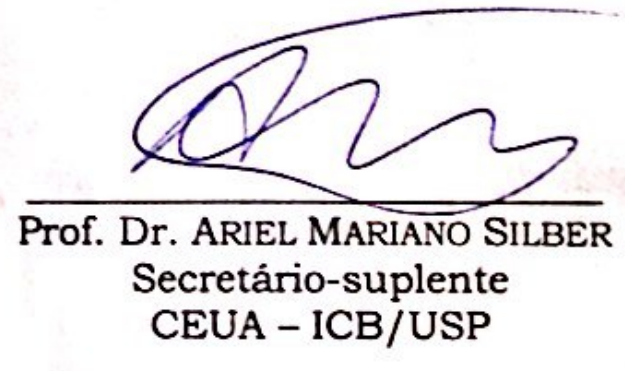




\section{AGRADECIMENTOS}

Ao finalizar esta etapa tão importante nada mais prazeroso do que a sensação de objetivo cumprido e poder agradecer a todos que em ajudaram direta, ou indiretamente, na conclusão deste trabalho. Nesses momentos percebo como tenho a sorte de ter ao meu lado pessoas tão especiais que me fazem crescer e amadurecer a cada dia e que não quero jamais perder a convivência.

Agradeço em primeiro lugar ao meu orientador, o Prof. Dr. Antônio Herbert Lancha Junior, pelo constante apoio desde o início de minha jornada científica/acadêmica, em 2001. São doze anos de muito aprendizado sobre a ciência e a vida. Obrigada!

A todos meus amigos do laboratório, por fazerem dele um lugar extremamente agradável. E, pelo constante aprendizado e diversão, agradeço em especial: Fabiana Benatti, Guilherme Artioli, Bruno Gualano e Hamilton Roschel, grandes amigos que admiro muito.

A Aline Tritto, Daisy Diwan, Fábio Médici e a todos que me auxiliaram no desenvolvimento deste projeto e sem os quais seria impossível conseguir finalizar este projeto.

Ao Prof. Dr. François Blachier e Annaïg Lan, meus professores franceses. Agradeço pela oportunidade de vivenciar um outro modo de encarar não apenas a pesquisa, mas a vida.

Gostaria de agradecer também aos funcionários do Instituto de Ciências Biomédicas e da Escola de Educação Física e Esporte da USP por toda ajuda que me foi dada. Em especial agradeço ao técnico do laboratório Vitor Procópio e às secretarias de Departamento Shirley Oliveira, Celiana Marchiori e Regina Valbom.

A Fundação de Amparo à Pesquisa do Estado de São Paulo (FAPESP) pelo apoio financeiro.

Por fim, agradeço a toda a minha família e, em especial aos meu pais, Dercindo e Célia, e aos meus avós, Lourdes Ferreira e Manoel Ferreira (in memorian) pelo apoio e amor incondicionais. Impossível escrever quão importantes vocês são na minha vida. Jamais conseguiria sonhar com uma família melhor. 


\section{RESUMO}

Coelho DF. O papel da composição de ácidos graxos da dieta na lipectomia e nas doenças inflamatórias intestinais. [tese (Doutorado em Ciências)]. São Paulo: Instituto de Ciências Biomédicas, Universidade de São Paulo; 2013.

A mudança no padrão alimentar e, especialmente, o aumento no consumo de dietas hiperlipídicas tem sido apontado como um dos principais responsáveis pelo aumento da incidência de doenças como obesidade e doenças inflamatórias intestinais. Porém, os lipídios podem atuar de maneira distinta nestas condições: enquanto uma dieta rica em gordura saturada (SAT) poderia exercer efeitos deletérios, uma dieta rica em gordura poliinsaturada (PUFA) os preveniria. Deste modo, o objetivo da presente tese foi avaliar esses possíveis efeitos nestas alterações metabólicas. Para isso, a presente tese foi dividida em dois estudos. O primeiro teve como objetivo avaliar os efeitos da lipectomia visceral retirada cirúrgica do tecido adiposo - em ratos submetidos a diferentes dietas hiperlipídicas. No início do experimento, ratos wistar foram divididos em três grupos, conforme a dieta: rica em SAT, rica em PUFA e controle $(\mathrm{CON})$. Oito semanas depois, foram subdivididos entre grupo lipectomia $(\mathrm{L})$ ou falso operado $(\mathrm{FO})$ e submetidos à cirurgia. Após três semanas foram eutanasiados. As análises de perfil glicídico (testes de tolerância à glicose e à insulina), lipídico (colesterol total e frações) e adiposidade (total e dos diferentes depósitos) foram feitas antes da lipectomia e ao término do experimento. As concentrações de insulina e citocinas inflamatórias foram realizadas apenas no término do estudo. Como resultado, verificamos que a $\mathrm{L}$ ocasionou no grupo SAT um crescimento compensatório significativo do depósito retroperitoneal e da concentração de TNF- $\alpha$ e IL-6, o que ocasionou a piora da sensibilidade à insulina, das concentrações de colesterol total e aumento do conteúdo hepático de gordura. No entanto, a L não ocasionou estes mesmos efeitos deletérios quando associada à dieta PUFA. Este resultado se deve ao aumento do tecido adiposo marrom e a um melhor perfil inflamatório. No segundo estudo visamos avaliar os efeitos dessas mesmas dietas em camundongos com retrocolite ulcerativa induzida por DSS (dextrano sulfato de sódio). Foram aferidos diariamente o consumo calórico, peso corporal, escores inflamatórios (consistência e presença de sangue nas fezes, e o índice de atividade da doença - IAD). A atividade da mieloperoxidase (MPO), corte histológico e a avaliação da expressão gênica de citocinas foram realizadas apenas ao final do estudo, cinco dias após o término da indução da doença. Como principal desfecho observamos que o grupo PUFA apresentou piora de todos os escores inflamatórios - isolados e do IAD -, e aumento no escore de lesão tecidual. Estes efeitos resultaram em uma taxa de óbito de $43 \%$ neste grupo. Já o grupo SAT apresentou maior atividade da MPO e aumento significativo na expressão gênica de citocinas pró-inflamatórias (TNF- $\alpha$, IL- $1 \beta$ e INF- $\gamma$ ). No entanto, as análises histológicas demonstraram que estes resultados pró-inflamatórios ocasionaram melhor resposta deste grupo à doença, nos levando a concluir que a inflamação é necessária para a regeneração deste tecido. Deste modo, os dois estudos demonstram que mais importante que o conteúdo total de lipídios na dieta é seu tipo. Torna-se essencial uma verificação cuidadosa da quantidade de cada um deles a ser administrada em função do perfil metabólico e o objetivo da dieta.

Palavras-chave: Dieta hiperlipídica. Ácidos graxos poli-insaturados. Adiposidade. Retrocolite ulcerativa. 


\begin{abstract}
Coelho DF. The role of different dietary fatty acids on lipectomy and inflammatory bowel diseases. [Ph. D. thesis (Sciences)]. São Paulo: Instituto de Ciências Biomédicas, Universidade de São Paulo; 2013.
\end{abstract}

A high-fat diet consumption has been associated with several disease states including obesity and inflammatory bowel disease. The main hypothesis of this body of work is that different fatty acids will result in different effects on these states: a high-saturated fat (SAT) diet would have deleterious effects, while a high-polyunsaturated fat diet (PUFA) would have beneficial effects. The present thesis is divided into two studies. The aim of the first study was to investigate the effects of visceral (epididymal) lipectomy (surgical adipose tissue removal) in rats submitted to different high-fat diets. The rats were allocated into three groups; a high-saturated fat diet (SAT), a high-polyunsaturated fat diet (PUFA) and a control diet $(\mathrm{CON})$. Following eight weeks, rats in each group were allocated to lipectomy (L) or a sham operation (S); animals were euthanized three weeks after surgery. Glucose and insulin tolerance tests, lipid profile and adiposity were measured prior to and three weeks following surgery. Cytokines and insulin levels were measured only at the end of the experiment. We showed that when L was performed following a SAT diet there was a compensatory growth of the retroperitoneal fat depot and increased TNF- $\alpha$ levels which resulted in decreased insulin sensitivity, increased cholesterol levels and an increased fatty liver. However, when L was performed following a PUFA diet these deleterious effects were not shown likely due to increased brown adipose depot and an improved inflammatory response compared to the SAT diet. The second study aimed to evaluate the effects of the SAT and PUFA diets in mice with ulcerative colitis induced by DSS (dextran sodium sulfate). The disease was induced during a five day period, after which the mice recovered for a further five days prior to being euthanized. Food intake, body mass, inflammatory scores (stool consistency, blood presence in the stool and disease activity index - IAD) were recorded every day. Myeloperoxidase activity (MPO), histological analyses and mRNA expression were determined following euthanasia. The main outcome was that the PUFA diet resulted in increased inflammatory scores and increased tissue lesions as determined by histological analyses, resulting in death to $43 \%$ of the rats. The SAT diet resulted in an increased MPO activity and cytokine mRNA expression (TNF- $\alpha$, IL-1 $\beta$ e INF- $\gamma$ ), indicating that they had increased inflammation. However, the histological analyses showed an improved tissue response suggesting that inflammation is necessary for tissue regeneration. Therefore, it can be concluded that the type of fat is more important than the total amount ingested, and it is necessary to individualize fat requirements according to the disease state.

Keywords: High-fat diet. Polyunsaturated fatty acids. Adiposity. Ulcerative colitis. 


\section{SUMÁRIO}

CAPítulo 1 - O AUMENTO do CONSUMO de gorduras NA DIETA E SUA ASSOCIAÇÃO COM ALTERAÇŌES METABÓLICAS ..................................11

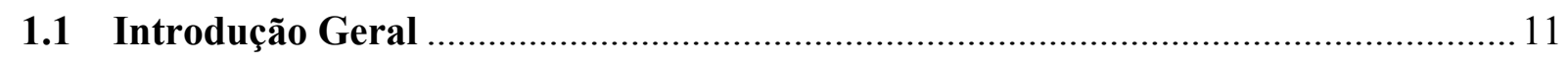

CAPÍtUlO 2 - ESTUdo 1: EFEITO DA RETIRAdA CIRÚRgICA DE PARTE do TECIDO ADIPOSO VISCERAL NA ADIPOSIDADE, INTOLERÂNCIA À GLICOSE, PERFIL LIPÍDICO E INFLAMATÓRIO DE RATOS SUBMETIDOS A DIFERENTES

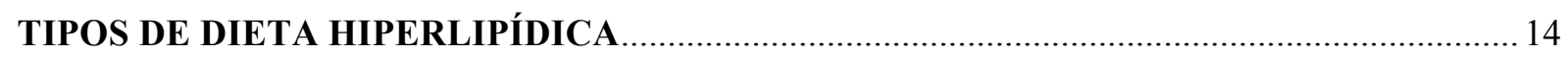

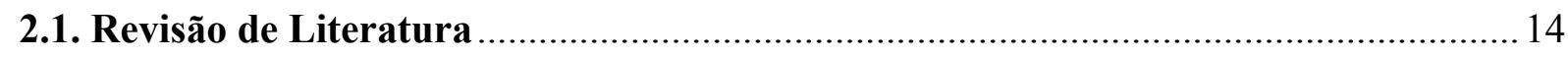

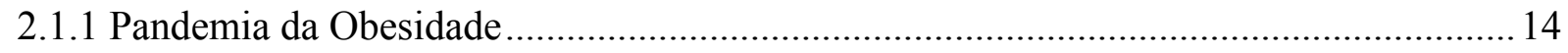

2.1.2 Tecido Adiposo Visceral e Alterações Metabólicas......................................................... 14

2.1.3 Adiposidade, Ácidos Graxos Dietéticos e Perfil Metabólico …………………………..... 17

2.1.4 Lipectomia e Regulação da Adiposidade .......................................................................2 20

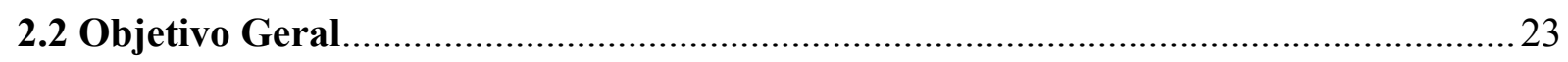

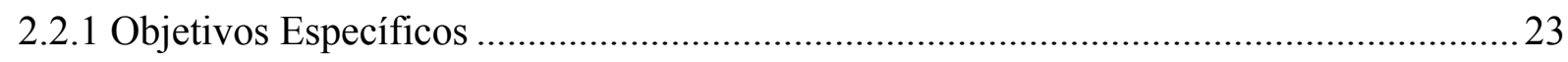

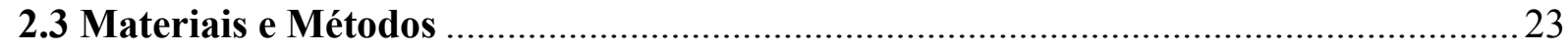

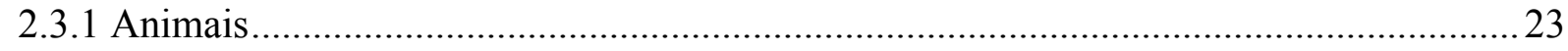

2.3.2 Protocolo Experimental e Dietas ……………………………………………….....2

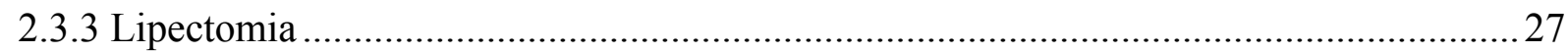

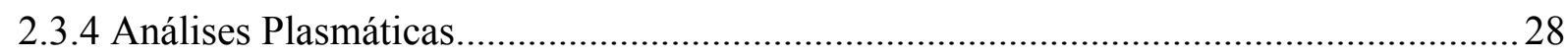

2.3.4.1 Análises de Glicose, Insulina, Perfil Lipídico e Inflamatório ......................................28

2.3.4.2 Índice HOMA (Homeostatic Model Assessment) ........................................................... 28

2.3.4.3 Teste Oral de Tolerância à Glicose (OGTT) e Teste Intraperitoneal de tolerância à

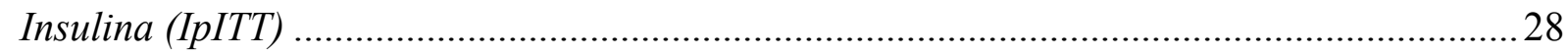

2.3.5 Composição Corporal e Peso dos Tecidos ..................................................................2 29

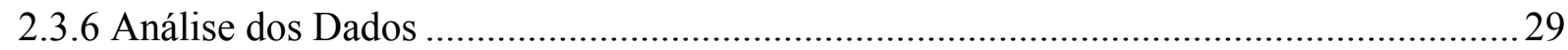

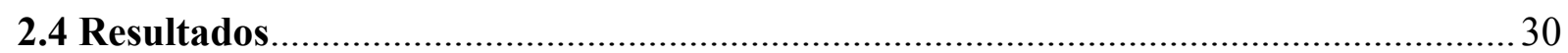

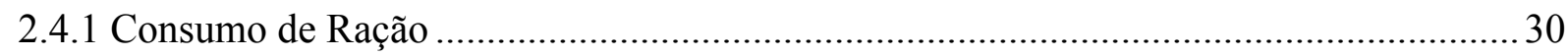

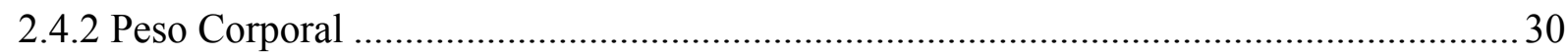

2.4.3 Análises de Gordura ................................................................................................ 31

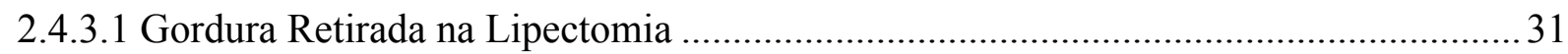

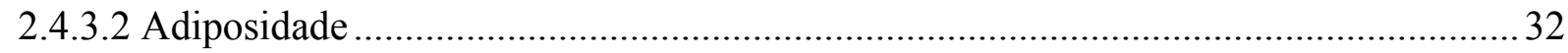

2.4.3.3 Contribuição dos Diferentes Depósitos de Gordura ………………………………….....33 
2.4.4 Glicemia, Insulinemia, Teste Oral de Tolerância à Glicose (OGTT) e Teste

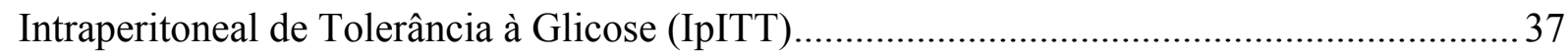

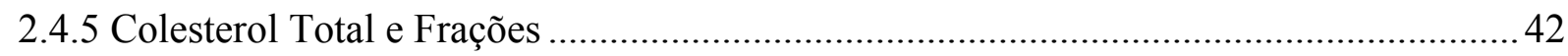

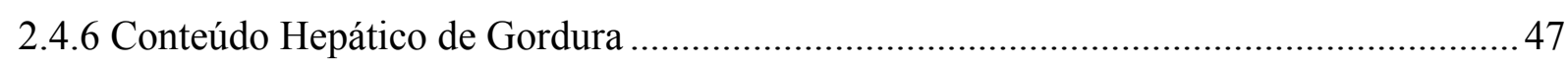

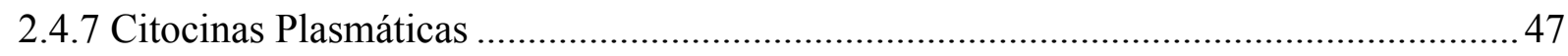

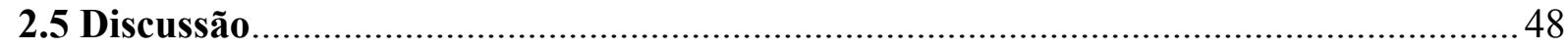

CAPÍTULO 3 - ESTUDO 2: O EFEITO DE DIFERENTES DIETAS HIPERLIPÍDICAS NA

COLITE ULCERATIVA INDUZIDA POR DEXTRANO SULFATO DE SÓDIO...................... 62

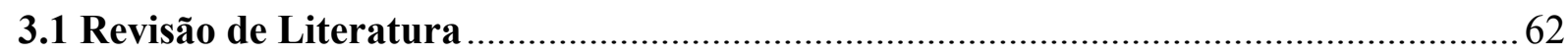

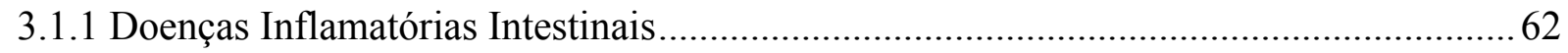

3.1.2 Ácidos Graxos Poli-insaturados e Retrocolite Ulcerativa ............................................63

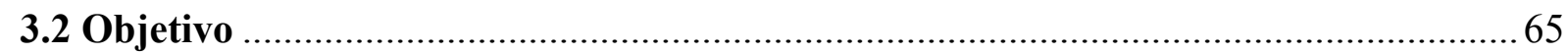

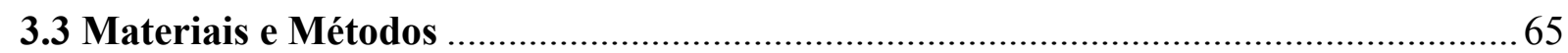

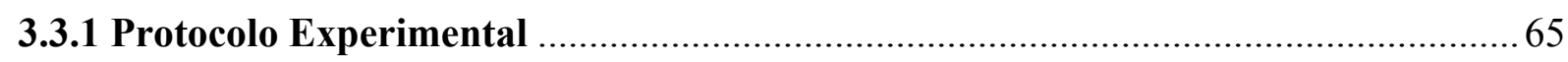

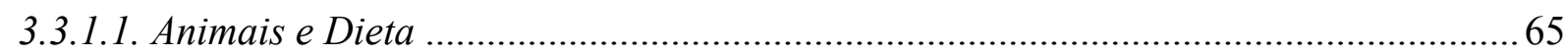

3.3.2 Indução da Retrocolite por meio de Dextrano Sulfato de Sódio (DSS) ..........................66

3.3.3 Escores Inflamatórios e Índice de Atividade da Doença (IAD) .....................................66

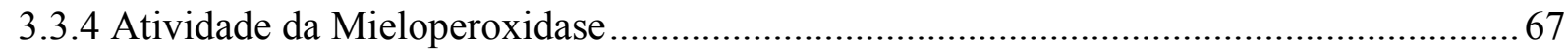

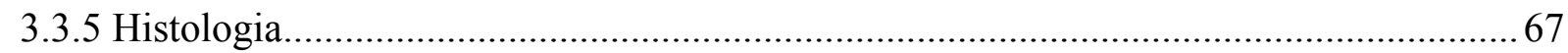

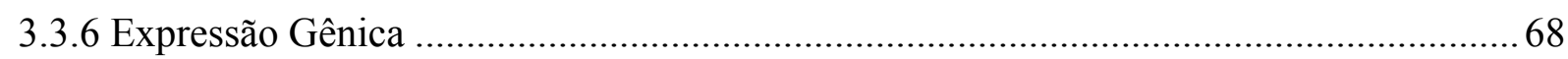

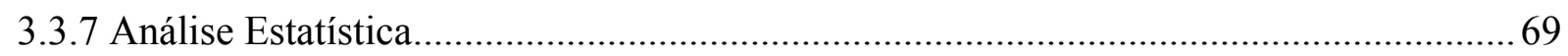

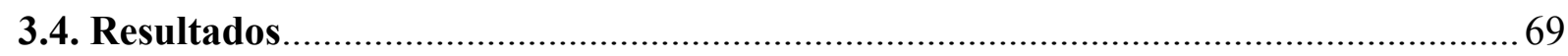

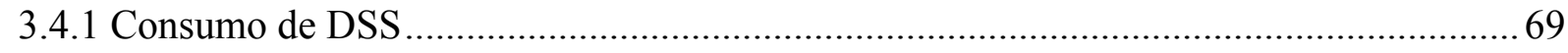

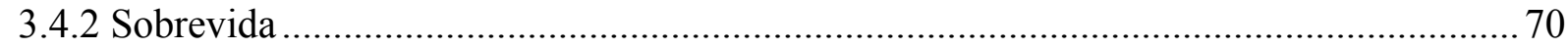

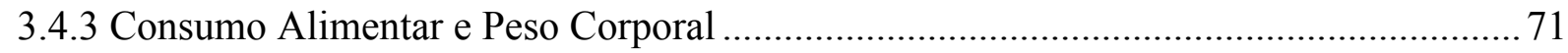

3.4.4 Escores Inflamatórios e Índice de Atividade da Doença .............................................. 73

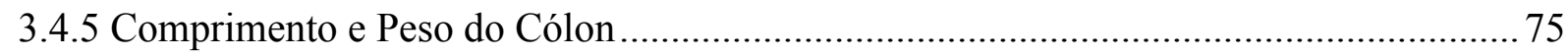

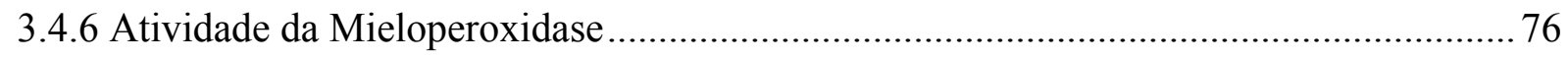

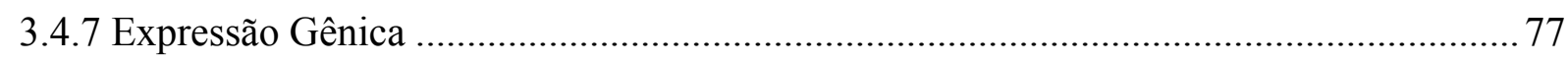

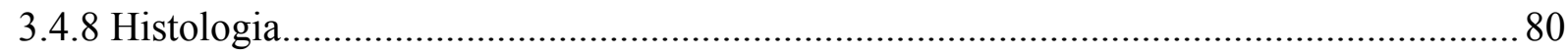

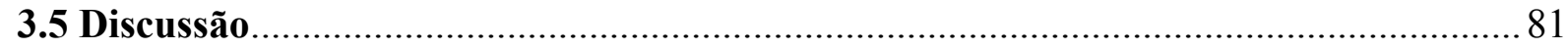

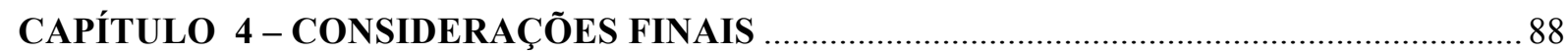

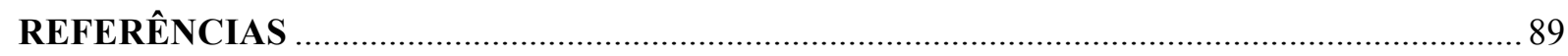


APÊNDICE - Artigo "Review of the association between meat consumption and risk of

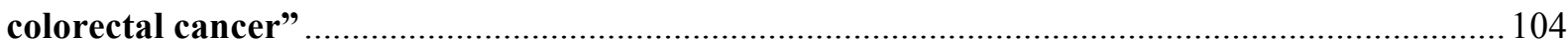

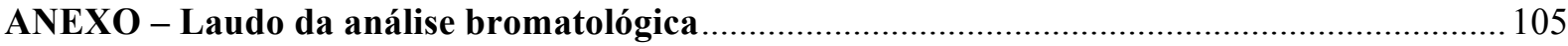




\section{CAPÍTULO 1 - O AUMENTO DO CONSUMO DE GORDURAS NA DIETA E SUA ASSOCIAÇÃO COM ALTERAÇŌES METABÓLICAS}

\subsection{Introdução Geral}

A transição nutricional é caracterizada por uma alteração do padrão alimentar, na qual há uma diminuição do consumo de cereais e fibras acompanhada pelo aumento do consumo de gorduras, açúcares de adição e carnes. Além disso, está geralmente associada à diminuição da prática de atividades físicas (Vedana et al., 2008). Este desbalanço tem sido apontado como fator desencadeante de diversas doenças como obesidade, doenças cardiovasculares, resistência à insulina e outras (Popkin, 2001).

A mudança da alimentação, em especial, tem sido destacada como fator crucial nestas alterações metabólicas (Jeffery et al. 2007). Essa inadequação fica mais evidente em países nos quais a transição nutricional é ainda recente (Popkin, 2001). No Brasil, a diminuição no consumo de cereais e leguminosas, como arroz e feijão, bem como o aumento do consumo de alimentos ricos em gorduras e açúcares (Levy-Costa et al., 2005) têm sido associados ao rápido aumento na prevalência de sobrepeso e obesidade (Monteiro et al., 2007; Vedana et al., 2008). Esse dado é verificável não apenas no Brasil, mas também em outros países (Popkin, 2001).

Dados da população americana demonstram que o consumo calórico diário aumentou em cerca de $200 \mathrm{kcal}$ nos últimos 30 anos. Importante ressaltar que se esse consumo fosse acompanhado de aumento da atividade física, esse quadro poderia ser revertido. No entanto, as pessoas estão cada vez mais sedentárias. Se considerarmos o excesso energético advindo apenas da alimentação, isso somaria um consumo de $73000 \mathrm{kcal} / \mathrm{ano}$, o que considerando-se que aproximadamente $85 \%$ do tecido adiposo é, de fato, gordura (Drewnowski, 2007; Trayhurn, Beattie, 2001), este excedente resultaria em quase $10 \mathrm{~kg}$ de gordura a mais por ano.

Esse excedente calórico advém especialmente do aumento da produção e consumo de alimentos com alta densidade energética, ricos em açúcares e gorduras, que possuem forte apelo junto à população americana por serem baratos, de amplo acesso, saborosos e práticos (Drewnowski, 2007). De fato, esses dois nutrientes têm sido estudados, juntou ou isolados, na tentativa de compreender os diferentes efeitos destes no corpo. Hoje em dia, o consumo de lipídios na dieta é responsável por cerca de 30\% do valor energético total da dieta, o que poderia ser considerado excessivo para os atuais padrões de gasto calórico e poderia ser fator determinando para o aumento da adiposidade. Um dos possíveis mecanismos pelo qual o 
consumo de dietas hiperlipídicas acarretaria um acúmulo de gordura seria através de um prejuízo na sinalização gastrointestinal de saciedade, levando a um consumo calórico aumentado e propiciando o estoque de energia na forma de gordura no tecido adiposo (Duca et al., 2013).

Além de sua relação com a adiposidade, o aumento no consumo de gorduras tem sido associado a um aumento na incidência de diabetes tipo 2 (Lieberman, 2003). Em outros países onde essa transição nutricional ocorreu recentemente, a mudança alimentar e, em especial, o aumento de $52 \%$ no consumo de gorduras, foi diretamente associado a uma alta prevalência da síndrome metabólica em idosos (Liu et al., 2013). Além disso, a cronicidade desse padrão alimentar aumenta o risco de desenvolvimento da síndrome metabólica, diabetes, doenças cardíacas (Jeffery et al., 2007), alguns tipos de câncer e doenças inflamatórias intestinais (Yamamoto, 2013).

Com relação às Doenças Inflamatórias Intestinais (DII), diversos estudos têm demonstrado a relação entre a dieta e o aumento de sua incidência (Asakura et al., 2008; Jowett et al., 2004; Wong et al., 2013). Reif et al. (1997), analisaram o recordatório alimentar habitual e prévio ao aparecimento da doença e verificaram relação positiva entre o aumentado consumo de gorduras e o desenvolvimento de retrocolite ulcerativa (RU), um tipo de DII. Assim como a obesidade, o aumento na incidência dessas doenças tem sido amplamente associado à alteração no padrão alimentar relacionada à transição nutricional (Wong et al., 2013).

No entanto tem sido sugerido, tanto nas DII quanto no acúmulo de gordura, que mais importante que o conteúdo total de gordura na dieta, seria seu tipo. Com relação à adiposidade, tem sido sugerido que dietas ricas em gordura saturada estariam diretamente associadas ao seu aumento e ao surgimento das co-morbidades associadas à ele, enquanto dietas ricas em gordura poli-insaturada, especialmente ricas em ácidos graxos ômega-3 (N3), poderiam prevenir algumas dessas alterações (Lu et al., 2011; Wang et al., 2002). Já nas DII os efeitos seriam similares: enquanto dietas ricas em gorduras saturadas e/ou ricas em ômega-6, mais especificamente ricas em ácido araquidônico, poderiam acelerar o desenvolvimento e piorar o quadro das DII, uma dieta rica em n-3 exerceria um papel protetor (Nielsen et al., 2005; Punyanganie et al., 2010).

Deste modo, o foco central do presente estudo deste doutoramento foi investigar o efeito desses diferentes lipídios na adiposidade, em parâmetros metabólicos e inflamatórios. Para tanto foram conduzidos dois estudos em diferentes condições: no primeiro estudo investigamos o efeito da retirada cirúrgica de parte do tecido adiposo visceral (Capítulo 2) 
em animais com diferentes padrões alimentares e, no segundo estudo, avaliamos o efeito destas dietas em ratos com doença inflamatória intestinal, colite ulcerativa, induzida por DSS (Capítulo 3). 


\section{CAPÍTULO 2 - ESTUDO 1: EFEITO DA RETIRADA CIRÚRGICA DE PARTE DO \\ TECIDO ADIPOSO VISCERAL NA ADIPOSIDADE, INTOLERÂNCIA À GLICOSE, PERFIL LIPÍDICO E INFLAMATÓRIO DE RATOS SUBMETIDOS A DIFERENTES TIPOS DE DIETA HIPERLIPÍDICA}

\subsection{Revisão de Literatura}

\subsubsection{Pandemia da Obesidade}

A pandemia da obesidade e de suas co-morbidades têm sido alvo de grande pesquisa e preocupação por todo o mundo. Uma das principais funções do tecido adiposo é servir de reserva de energia, liberando ácidos graxos (AG) que serão utilizados em momento de privação energética (Trayhurn, Beattie, 2001). No entanto, nas últimas décadas tem ocorrido um excesso do acúmulo deste tecido devido a um balanço energético positivo resultante do aumento do consumo energético em detrimento de um reduzido gasto de energia (Suastika, 2006). Associado a esse acúmulo, diversas alterações metabólicas estão se desenvolvendo como hipertensão, diabetes tipo 2 e doenças cardiovasculares (Bjørndal et al., 2011).

Cada vez mais tem sido relatado que a localização do acúmulo de gordura seria tão importante quanto a quantidade total de gordura corporal. Quando localizado na região visceral, esse acúmulo está diretamente associado a diversas alterações metabólicas, como dislipidemias, aumento da pressão arterial (Pelletier-Beaumont et al., 2012), intolerância à glicose (Wajchenberg, 2000) e esteatose hepática (Item, Konrad, 2012).

Além disso, esse efeito nocivo pode ainda ser exacerbado pelo padrão alimentar e, mais especificamente, pelo consumo de dietas ricas em gorduras (Bray, Popkin, 1998) que, além de palatáveis, possuem alta eficiência de armazenamento (Prentice, 1998) e está também diretamente relacionado com o desenvolvimento de diversas co-morbidades associadas à obesidade e ao tecido adiposo visceral (Einstein et al., 2005; McDonald et al. 2011; Todoric et al., 2006).

\subsubsection{Tecido Adiposo Visceral e Alterações Metabólicas}

Em humanos, o tecido adiposo branco pode ser dividido principalmente em: tecido adiposo subcutâneo (TAS) e tecido adiposo visceral (TAV), sendo que este último pode ainda ser subdividido em omental, mesentérico, retroperitoneal (e perirenal), gonadal e 
pericardial. Em ratos, o TAV pode ainda ser subdividido em tecido epididimal e inguinal (Bjørndal et al., 2011).

Diversos fatores, como genética, idade, sexo e padrão alimentar, são determinantes do local de acúmulo, que varia de pessoa para pessoa (Wajchenberg, 2000). Além da diferença de localização, os depósitos parecem exercer efeitos metabólicos completamente diferentes. Há evidências de que o fator desencadeante das alterações metabólicas supracitadas esteja associado não apenas ao aumento da adiposidade total, mas seja dependente do local desse acúmulo (Einstein et al., 2005; Goodpaster et al., 2000; Lebovitz et al., 2005).

Com o objetivo de verificar se essas alterações estariam relacionadas com a localização anatômica do depósito ou com suas características, Tran et al. (2008) realizaram interessante estudo com utilização da técnica de transplantes de depósito de gordura visceral (epididimal) e subcutânea (região dos flancos): parte destes depósitos era retirada de um animal doador e transplantada em um animal receptor. O procedimento podia ser executado no mesmo local da retirada ou em outro. O achado mais interessante do estudo foi que os animais que receberam transplante de TAS em seu TAV (epidídimo) apresentaram diminuído ganho de peso, menor adiposidade e menores concentrações de glicose e insulina. Esse estudo demonstra que as alterações metabólicas observadas com o acúmulo excessivo de TA estaria, pelo menos em parte, relacionada com características intrínsecas dos diferentes depósitos de gordura.

Em condições normais, os diferentes depósitos corporais de tecido adiposo possuem uma boa capacidade de acumular gordura. No entanto o depósito subcutâneo apresentaria uma capacidade limitada quando comparado aos depósitos viscerais. Deste modo, a continuidade dos estímulos para estoque de gordura ocasionaria o acúmulo nos depósitos viscerais (Bjørndal et al., 2011). Sabe-se, atualmente, que o TAV difere do tecido adiposo TAS sob diversos aspectos: ele possui células maiores (hipertrofiadas), mais responsivas às enzimas lipolíticas e, em parte, resistentes à insulina (Fruhbeck et al., 2001; Giusti et al., 2004; Nielsen et al., 2004; Rosa et al., 2005; Trayhurn, Beattie, 2001) e está diretamente relacionado com uma maior incidência das alterações metabólicas citadas (Einstein et al., 2005). Os mecanismos exatos envolvidos nesse processo ainda não estão plenamente estabelecidos, mas diferentes hipóteses têm sido propostas, dentre as quais podemos destacar:

- Hipótese Endócrina: o acúmulo de gordura dentro da célula adiposa ocasionaria o aumento do tamanho (hipertrofia) desta célula ocasionando uma alteração na função secretora do adipócito (Wajchenberg, 2000). Esse desbalanço na secreção de algumas 
adipocinas produzidas pelo próprio tecido, seria um dos responsáveis pela relação entre a adiposidade visceral e a resistência à insulina (Michel et al., 1999). Foi demonstrado, por exemplo, que adipócitos mais hipertrofiados possuem maior secreção de resistina, adipocina relacionada diretamente com a resistência à ação da insulina (Rondinone, 2006). O tecido adiposo secreta também a adiponectina, uma proteína caracterizada por suas propriedades anti-inflamatórias e antitrombóticas (Matsubara et al., 2003) relacionada com aumento da sensibilidade à insulina, mas que apresenta suas concentrações diminuídas na obesidade (Karki et al., 2011). Consequentemente, adipócitos hipertrofiados secretam mais resistina e menos adiponectina - o que pode resultar num quadro de inflamação e resistência à insulina característico da obesidade (Matsubara et al., 2003).

- Hipótese Inflamatória: a mesma hipertrofia que altera a função endócrina ocasionaria também um aumento da produção de citocinas pró-inflamatórias produzidas pelo próprio tecido adiposo ou pelos macrófagos ali infiltrados (Tilg et al., 2008). O TAV, de modo mais específico, secreta grandes quantidades de mediadores inflamatórios, como a interleucina-6 (IL-6), IL-10, IL-1 $\beta$, proteína que atrai macrófagos 1 (MCP-1) - fator de necrose tumoral $\alpha$ (TNF- $\alpha$ ), entre outros (Fain et al., 2004; Fonseca-Alaniz et al., 2007). Foi demonstrado que indivíduos com obesidade visceral possuem maiores concentrações de marcadores próinflamatórios sistêmicos, se comparados a indivíduos com obesidade subcutânea (JugeAubry, 2005). De fato, a contribuição deste depósito para a inflamação subclínica observada em alguns indivíduos obesos pode ser uma das causas dadas alterações metabólicas observadas (Weiss et al., 2007);

- Hipótese Portal: devido à lipólise aumentada no depósito visceral, ocorreria o aumento do fluxo de ácidos graxos livres ao fígado através da circulação portal, ocasionando acúmulo ectópico de gordura em alguns tecidos, como o fígado, alterando sua atividade (Bjørndal et al., 2011).

Apesar das distintas hipóteses, há evidências de que todos os mecanismos supracitados podem estar, em maior ou menor grau, relacionados ao desenvolvimento das alterações metabólicas. Se levarmos em consideração que indivíduos com obesidade habitualmente apresentam dieta rica em lipídios, esses efeitos podem ser ainda mais exacerbados com esse padrão alimentar. 


\subsubsection{Adiposidade, Ácidos Graxos Dietéticos e Perfil Metabólico}

Conforme discutido anteriormente, o aumento da utilização de dietas ricas em lipídios parece ser um fator muito importante na etiologia da obesidade e suas co-morbidades (Jorgensen et al., 2006). De fato, estudos apontam a dieta hiperlipídica como uma das principais causas do excesso de gordura corporal tanto em animais (Martin et al., 2006) quanto em humanos (Mobbs et al., 2007).

$\mathrm{O}$ acúmulo de gordura seria derivado de suas propriedades organolépticas, tais como alta palatabilidade, textura (Rolls et al., 1992), eficiência em seu armazenamento e baixo poder de saciação quando comparada aos carboidratos (Prentice, 1998). Além disso, a composição da gordura ingerida associada ao teor energético da dieta seria fator determinante no desenvolvimento da obesidade (Bray, Popkin, 1998).

Os AG são os principais componentes das moléculas lipídicas. Eles são compostos por uma cadeia linear de carbono e hidrogênio e uma terminação carboxílica, com tamanhos variados, e podem ser classificados como saturados (SAT) e insaturados. Dentre os ácidos graxos insaturados existem duas subdivisões: monoinsaturados (MUFA) e poli-insaturados (PUFA), sendo que estes últimos se subdividem em três classes principais - ômega-9 (n-9), ômega-6 (n-6) e ômega-3 (n-3) - dependendo da posição da primeira dupla ligação em relação ao grupo metil terminal (Rioux et al., 2007; Schmitz et al., 2008;). Os ácidos graxos (AG) da família n-6 (linoléico) e n-3 (linolênico) são considerados essenciais, visto que não podem ser sintetizados por mamíferos e devem ser obtidos através da dieta.

Os AG dietéticos possuem atividade metabólica distinta, devido suas diferenças estruturais como tamanho da cadeia carbônica, grau de insaturação e posição das duplas ligações. De um modo geral, o tamanho da cadeia carbônica determina uma correlação negativa com a taxa de oxidação: AG insaturados são oxidados mais rapidamente que os saturados (Sagher et al., 1991; Thomson et al., 1987). Sendo assim, dependendo da característica da dieta, o excesso no consumo de um tipo específico de AG pode levar a alterações diferentes no peso e composição corporal (DeLany et al., 2000; Madsen et al., 2005).

Deste modo, tem sido sugerido que mais importante que o conteúdo total de lipídios na dieta, seria seu tipo. Esse dado ainda necessita de muitos estudos e discussões, mas alguns trabalhos sugerem que dietas ricas em SAT estariam diretamente associadas a um aumento da adiposidade e alterações metabólicas, enquanto dietas ricas em PUFA, 
especialmente ricas em ômega-3 (N-3), poderiam prevenir algumas dessas alterações (Lu et al., 2011; Rokling-Andersen et al., 2009; Wang et al., 2002).

Além disso, Nakamura et al. (2004) demonstraram que os diferentes AG podem estimular de maneira distinta a atividade lipogênica. Enquanto os PUFAs parecem regular negativamente essa atividade, os SAT exerceriam um efeito positivo. No entanto, ainda há controvérsias sobre o efeito dos diferentes tipos de gordura dietética e o desenvolvimento da obesidade. Estudos apontam que uma dieta rica em óleo de peixe - PUFAs - é capaz de promover a perda de peso em animais (Flachs et al., 2005) e em humanos (Krebs et al., 2006); porém, a alteração de peso corporal decorrente deste padrão dietético nem sempre é verificada (Awad et al., 1990). Enquanto alguns estudos, apontam correlação positiva entre consumo dos diferentes tipos de lipídios na dieta e a obesidade (Brunner et al., 2001; Gonzalez et al., 2000), outros não apontam essa relação (Sanchez-Villegas et al., 2006; Sundstrom et al., 2001).

Estudo de Gaiva et al. (2001), analisou alterações no metabolismo do tecido adiposo e na composição corporal de ratos Wistar submetidos, durante cinquenta e seis dias, a dieta enriquecida com óleo de peixe, rica em PUFA, em comparação a dieta enriquecida com óleo de soja, rica em SAT. Dentre os resultados destaca-se que o grupo suplementado com óleo de peixe apresentou aumento de peso corporal e de massa magra, sem significativas alterações no consumo alimentar e nas taxas de adipogênese. Já Todoric et al., 2006) utilizaram em seus estudos ratos não diabéticos e ratos geneticamente modificados para diabetes, administrando por um período de seis semanas uma dieta hiperlipídica, rica em ácido eicosapentaenóico (EPA - 20:5, n-3) e ácido docosahexaenóico (DHA - 22:6, n-3), ácidos graxos n-3, versus grupo controle. Observou-se que, nos animais diabéticos, a suplementação com EPA e DHA promoveu aumento de peso corporal. O estudo, no entanto, não avaliou a composição corporal dos animais - o que não permite elucidar se este aumento de peso corporal foi decorrente de alterações na deposição de gordura nos mesmos depósitos corporais em ambos os grupos. Essa diferenciação na composição corporal é de extrema importância, porém pouco aprofundado nos estudos. Conforme já demonstrado, sabe-se que mais importante do que peso corporal é analisar a composição corporal e, principalmente, o local de deposição da gordura, uma vez que é sabido que os diferentes estoques de gordura possuem diferentes ações metabólicas (Bjørndal et al., 2010).

No estudo de Takahashi et al. (2000) foram avaliadas, dentre outros fatores, alterações na adiposidade de ratos submetidos a manipulação dietética. Os animais foram distribuídos em quatro grupos experimentais e submetidos, durante vinte e um dias, a diferentes dietas: 
baixo teor de lipídeos - grupo controle - 20g óleo cártamo/kg de ração (PUFA n-6); ou hiperlipídicas contendo sempre $200 \mathrm{~g}$ de óleos/ $\mathrm{kg}$ de ração, sendo os diferentes óleos ou óleo de cártamo, ou "perilla" (rica em ácido $\alpha$-linolênico - ALA - tipo de n-3), ou óleo de peixe (rico em EPA e DHA - n-3). Os animais suplementados com dieta hiperlipídica rica em óleo de cártamo apresentaram maior adiposidade visceral (depósitos epididimal e perirenal) quando comparados ao grupo controle. Já os animais suplementados com óleo de peixe não apresentaram aumento de adiposidade corporal quando comparados ao grupo controle. A partir desses dados, um possível efeito "anti-obesogênico" atribuído aos PUFA, particularmente ao EPA e DHA, tem sido objeto de discussões.

Além do aumento do peso e adiposidade corporal, a dieta hiperlipídica também ocasiona distúrbios no metabolismo dos carboidratos. Já em 1979, Lavau et al. relataram que a habilidade da insulina em estimular o metabolismo da glicose mostra-se seriamente comprometida no tecido adiposo de ratos submetidos a dieta hiperlipídica. Além disso, ratos submetidos a oito semanas de dieta com $45 \%$ de gordura apresentaram aumento do peso corporal, aumento de 171\% nas concentrações triacilglicerol (TAG) circulante, além de hiperinsulinemia e intolerância à glicose (Raubenheimer et al., 2006).

Os diferentes tipos AG parecem também exercer efeitos distintos nas concentrações de colesterol total e frações. Tur et al. (2012) revisaram os efeitos de diferentes fontes de ômega-3 (peixes, plantas e algas) e verificaram que as algas, ricas em EPA e DHA, possuem efeito benéfico na diminuição do triacilglicerol (TG) e do VLDL-colesterol (very low density lipoprotein), além de aumentar as concentrações de HDL-colesterol (high density liprotein) e de LDL-colesterol (low density lipoprotein). Outra boa fonte de EPA e DHA é o krill (crustáceo semelhante ao camarão). Estudos têm demonstrado que, assim como as algas, ele também possui a capacidade de aumentar as concentrações circulantes de HDL e de diminuir as de TG e LDL (Bunea et al., 2004). Outro estudo com ratos ob/ob (modelo modificado geneticamente com obesidade e alterações metabólicas) apresentou redução no colesterol quando consumindo dieta rica em PUFA (Gonzáles-Périz et al., 2009). Portanto, estes dois ácidos graxos - EPA e DHA - têm demonstrado ser fundamentais para os efeitos benéficos do n-3 no perfil lipídico.

Os dados presentes na literatura de fato parecem demonstrar efeitos benéficos originados do consumo de PUFAs. No entanto, os possíveis mecanismos pelos quais esse tipo de dieta exerceria seus efeitos ainda não são completamente compreendidos. Alguns estudos indicam que podem ser derivados de um aumento do gasto energético através da ativação de proteínas desacopladoras mitocondriais (UCPs); menor captação de ácidos 
graxos pelos adipócitos devido à supressão da atividade da lipoproteína lipase; aumento do catabolismo lipídico ( $\beta$-oxidação); diminuição da síntese de triacilglicerol via inibição de enzimas como o ácido graxo sintetase (FAS) (Enerback, 2010). Todos esses efeitos parecem ser mediados pela capacidade deste $\mathrm{AG}$ em alterar a expressão gênica e proteica de fatores transcricionais e de genes envolvidos na regulação do metabolismo lipídico, como nas famílias dos "receptores ativados da proliferação de peroxissomos" (PPARs), bem como de seu importante efeito anti-inflamatório quando comparado à dieta rica em SAT (Murumalla et al., 2012).

Podemos, assim, constatar que os ácidos graxos dietéticos exercem diferentes efeitos metabólicos que ainda precisam ser melhor investigados. Logo, uma diferenciação entre eles nos estudos, é necessária

\subsubsection{Lipectomia e Regulação da Adiposidade}

Lipectomia é a retirada cirúrgica de parte do tecido adiposo (Faust et al., 1977). Elegemos a utilização desse procedimento em nossos estudos, por proporcionar oportunidade única de verificar o efeito de diferentes depósitos de gordura, sua relação com algumas co-morbidades associadas à obesidade (Klein, 2004), bem como as alterações ocasionadas em virtude de sua diminuição.

Kim et al. (1999) realizaram a retirada do tecido adiposo visceral e subcutâneo de ratos com obesidade induzida por glutamato monossódico. Esses animais apresentavam elevadas concentrações de ácidos graxos livres, insulina e aumentada produção hepática de glicose. No grupo em que foi feita a retirada do tecido adiposo visceral, os valores de produção hepática de glicose diminuíram aos valores normais. Porém não houve diferença significativa na sensibilidade à insulina e nas concentrações de insulina de jejum. Bueno et al. (2005) também estudaram ratos com obesidade induzida por glutamato monossódico e observaram redução nas concentrações de insulina de jejum sete dias após a lipectomia dos depósitos viscerais - retroperitoneal e epididimal - , mas as diferenças não se mantiverem trinta dias após a cirurgia. Um dos motivos para isso pode ser derivado de um crescimento compensatório dos demais depósitos de gorduras em resposta à lipectomia (Hausman et al., 2004; Mauer et al., 2001, Shi, Bartness, 2005), tendo sido demonstrado, inclusive, que a gordura corporal tende a ser recomposta em até quatro semanas (Michel et al., 1999).

No estudo de Mauer et al. (1997), foi realizada a retirada de tecido adiposo inguinal e epididimal de hamsters siberianos, apenas do lado direito ou esquerdo, com o objetivo de 
analisar se ocorreria um crescimento compensatório. A retirada de parte do tecido adiposo epididimal não resultou em reposição, no entanto a retirada do tecido adiposo inguinal foi compensada pelo crescimento do tecido adiposo epididimal. Os autores ainda observaram que, em alguns depósitos, quanto maior a quantidade de tecido retirada, maior era a compensação e que esta, provavelmente, seria regulada por algum mecanismo que reconhece e sinaliza o local em que foi feita a retirada e, consequentemente, onde deve ser feita a reposição. Um dos possíveis mediadores deste efeito seria a leptina, uma adipocina secretada principalmente pelo tecido adiposo branco (Van Harmelen et al., 1998). Ela age através de receptores expressos central e perifericamente, sendo que uma de suas principais funções é ser um sinal aferente para o sistema nervoso central (SNC), atuando em um feedback negativo, regulando a quantidade de tecido adiposo (Negrao et al., 2000).

Já Hausman et al. (2004) na tentativa de compreender os mecanismos responsáveis por esse crescimento compensatório após a lipectomia, realizaram a retirada bilateral do tecido adiposo epididimal, de ratos Wistar e verificaram in vitro que os adipócitos dos animais lipectomizados apresentava maior proliferação de pré-adipócitos que o grupo controle. Estudo do nosso grupo realizou a lipectomia epididimal em ratos com dieta rica em SAT e verificou que o grupo lipectomizado apresentou consumo calórico significativamente maior quando comparado ao controle nos dias subsequentes à lipectomia (Coelho et al., 2009), o que pode ter colocaborado com o crescimento compensatório observado.

Além do crescimento compensatório, estudos experimentais têm demonstrado que a retirada cirúrgica de parte do TAV resulta em melhora da tolerância à glicose (Shi et al., 2007; Foster et al., 2011), diminuição da concentração de triglicerídeos (Foster et al., 2011), melhora da sensibilidade hepática e periférica à insulina (Gabriely et al., 2002) e diminuição da expressão gênica de citocinas pró-inflamatórias como o TNF- $\alpha$ (Barzilai et al., 1999).

Esses resultados corroboram o efeito supracitado da relação direta entre o TAV e as desordens metabólicas. No entanto, a maioria dos estudos citados utilizou dieta controle (padrão). Levando-se em conta que essas alterações estão normalmente associadas a um padrão alimentar inadequado, geralmente relacionado a um excesso no consumo de lipídios e açúcares, alguns estudos passaram a utilizar animais que eram submetidos ao consumo de dieta hiperlipídica e, nesse caso, os resultados encontrados não foram positivos. Foi observado também que a lipectomia induz crescimento compensatório de gordura, o que pode, parcialmente, ser responsável pelos prejuízos metabólicos observados. Além disso, o consumo de dietas ricas em gordura, principalmente de fonte saturada, pode superar possíveis efeitos benéficos que a lipectomia visceral poderia induzir. 
A escolha do depósito de TAV a ser retirado é extremamente importante, pois os diferentes depósitos parecem ter mecanismos distintos regulação em reposta à dieta e à lipectomia. Sato et al. (2012) realizaram a extração de gordura dos tecidos adiposos viscerais epididimal e mesentérico em ratos submetidos a dieta hiperlipídica e verificaram que o tecido adiposo epididimal apresentou maiores concentrações de diversos ácidos graxos, dentre eles, o ácido araquidônico e DHA, quando comparados ao tecido subcutâneo e mesentérico. Os autores sugerem que os diferentes depósitos possuem capacidades diferentes de absorção dos nutrientes.

Coelho et al. (2009) estudaram os efeitos da lipectomia de parte do tecido adiposo epididimal associada a uma dieta rica em gordura (41,6\% do valor calórico total de gordura), tendo como principal fonte a banha de porco, rica em ácidos graxos saturados. Duas semanas após a lipectomia foi observada pior tolerância à glicose. Já Bueno et al. (2011) utilizaram dieta enriquecida com $24 \%$ do conteúdo total de gordura, e, após lipectomia visceral, não observaram alterações nas concentrações de insulina. Trinta dias após a lipectomia foi observado aumento nas concentrações de triacilgliceróis e corticosterona.

Com isso, podemos verificar que os resultados acerca dos efeitos da lipectomia visceral em alguns marcadores de risco cardiovascular ainda não estão bem elucidados, especialmente quando associados ao consumo de dietas hiperlipídicas.

Conforme exposto, através da remoção de parte do tecido adiposo visceral, uma série de adaptações fisiológicas e morfológicas benéficas ocorrem no organismo, adaptações essas que têm sido estudadas em animais consumindo dietas padrão. No entanto, a associação da lipectomia a dietas hiperlipídicas, os resultados sinalizam a supressão do efeito benéfico, porém são poucos os estudos existentes acerca desse tema. Além disso, considerando-se os diferentes efeitos metabólicos dos diferentes lipídios alimentares, podemos supor que estas respostas devem ser ainda mais diferentes. Por isso, se levarmos em consideração que:

- a realização da lipectomia é uma estratégia válida quando há um acúmulo dos estoques e do conteúdo de gordura;

- o acúmulo de gordura ocorre em função de um balanço energético positivo; e que

- os nutrientes atuam de distintas maneiras na regulação da adiposidade.

O estudo com associação da lipectomia associada à manipulação dos tipos de lipídios da dieta se torna extremamente interessante 


\subsection{Objetivo Geral}

Verificar os efeitos da lipectomia na adiposidade, no perfil glicídico, lipídico e inflamatório de ratos submetidos à diferentes tipos de dieta hiperlipídica.

\subsubsection{Objetivos Específicos}

Determinar os efeitos da lipectomia em ratos que consumiam diferentes tipos de gordura na dieta sobre:

a) Adiposidade corporal e nos diferentes depósitos de gordura;

b) Perfil Glicídico: tolerância à glicose e sensibilidade à insulina;

c) Perfil Lipídico: colesterol total e frações e conteúdo de gordura hepática;

d) Perfil Inflamatório após a lipectomia: concentração de citocinas pró- e antiinflamatórias.

\subsection{Materiais e Métodos}

\subsubsection{Animais}

A amostra foi composta por ratos machos da linhagem Wistar, adquiridos no biotério da Faculdade de Medicina da Universidade de São Paulo. Todos os procedimentos realizados neste estudo foram aprovados pela Comissão de Ética do Instituto de Ciências Biomédicas da Universidade de São Paulo (Anexo 1). Os animais foram mantidos no biotério do Laboratório de Nutrição e Metabolismo Aplicado à Atividade Motora da Escola de Educação Física e Esporte da Universidade de São Paulo, local onde foi realizada a maioria das análises descritas a seguir.

\subsubsection{Protocolo Experimental e Dietas}

Os animais permaneceram durante todo o experimento em gaiolas individuais, em ciclo claro escuro invertido, com livre acesso à água e à ração. Cada experimento teve duração de onze semanas e teve início quando os animais atingiram o peso mínimo de $250 \mathrm{~g}$. Após isso, os animais foram distribuídos conforme o peso corporal em três grupos experimentais, que diferiam quanto ao tipo de ração: dieta controle $(\mathrm{CON})$, rica em gordura saturada (SAT) ou rica em gordura poli-insaturada (PUFA). 
O grupo controle recebeu ração comercial convencional (Labina, Ralston Purina do Brasil, São Paulo/SP) e as rações hiperlipídicas foram feitas no próprio laboratório, através da adição de 20,4 gramas de diferentes tipos de gordura ao pó da ração convencional, sendo a ração hiperlipídica saturada produzida através da adição de banha de porco - 20,4 gramas de banha de porco (Sadia ${ }^{\circledR}$, BrasilFoods, Brasil) para cada 100 gramas da ração-controle. Já a ração hiperlipídica poli-insaturada rica em ácidos graxos ômega-3 utilizada foi obtida através da mistura de óleo de salmão (Campestre Ind. E Com. De Óleos Vegetais LTDA, São Paulo, Brasil, -17,3 g SAT; 21,8g MUFA; 33,8 g PUFA; 13 g EPA; 18,2 g DHA; 1,6 g ômega- $\left.6_{\text {total }} / 100 \mathrm{~g}\right)$, azeite de oliva $\left(\right.$ Cocinero $^{\circledR}$, Bunge Alimentos, Brasil - 13,45 g SAT; 73,9g MUFA; 10 g PUFA; 0 g EPA; 0 g DHA; 10 g ômega- $6_{\text {total }} / 100$ g) e óleo de girassol $\left(\right.$ Liza $^{\circledR}$, Cargill Foods, Brasil - 9,76 g SAT; 24,43 g MUFA; 64,2 g PUFA; 0 g EPA; 0 g DHA; $63,71 \mathrm{~g}$ ômega- $6_{\text {total }} / 100 \mathrm{~g}$ ). A mistura foi composta de $45 \%$ de óleo de salmão, $45 \%$ de azeite de oliva e $10 \%$ de óleo de girassol, obtendo-se assim um óleo misto que foi adicionado ao pó da ração convencional. Assim como na ração saturada, para cada 100 gramas da ração controle foram adicionadas 20,4 gramas dessa mistura de óleos.

A composição de macronutrientes das dietas utilizadas está descrita na Tabela 1 e a análise bromatológica das mesmas, com o conteúdo qualitativo lipídico, está descrita na Tabela 2 (Anexo 2).

Tabela 1 - Composição de macronutrientes das dietas utilizadas

\begin{tabular}{|c|c|c|c|c|c|c|}
\hline & \multicolumn{2}{|c|}{ Ração Comercial } & \multicolumn{2}{|c|}{ Ração Saturada } & \multicolumn{2}{|c|}{ Ração Poli-insaturada } \\
\hline & gramas & $\% \mathrm{VCT}^{*}$ & gramas & $\% \mathrm{VCT}^{*}$ & gramas & $\% \mathrm{VCT}^{*}$ \\
\hline Carboidratos e fibras & 55,16 & $63,00 \%$ & 45,8 & $40,20 \%$ & 45,8 & $39,40 \%$ \\
\hline Proteínas & 22,72 & $25,90 \%$ & 18,8 & $16,50 \%$ & 18,8 & $16,20 \%$ \\
\hline Lipídios totais & 4,3 & $11,10 \%$ & 21,9 & $43,30 \%$ & 22,9 & $44,40 \%$ \\
\hline Total calórico em $100 \mathrm{~g}$ & \multicolumn{2}{|c|}{350,22 kcal } & \multicolumn{2}{|c|}{$455,5 \mathrm{kcal}$} & \multicolumn{2}{|c|}{$464,5 \mathrm{kcal}$} \\
\hline
\end{tabular}

* VCT $=$ valor calórico total

A qualidade de lipídios entre as dietas também variou. Vale ressaltar que a dieta do grupo CON e do grupo SAT possuíam quantidades insignificantes de ômega-3, a saber: CON - 0,17 g/100 g de ração, SAT 0,34 g/100g de ração do PUFA 1,67 g/100 g de ração. Sendo assim, a dieta PUFA possuía uma quantidade de ômega-3 dez vezes maior que o grupo CON e cinco vezes maior que o grupo SAT. Como razão final da quantidade ômega6:ômega3, temos - 12:1; 13:1 e 3:1 para os grupos CON, SAT e PUFA, respectivamente. 
Tabela 2 - Composição lipídica das dietas utilizadas

\begin{tabular}{|c|c|c|c|c|c|c|c|}
\hline Fórmula & Nome & Controle & Saturada & Poli-insaturada & Controle & Saturada & Poli-insaturada \\
\hline & & \multicolumn{3}{|c|}{$\mathrm{g} / \mathbf{1 0 0} \mathrm{g}$ de ração } & \multicolumn{3}{|l|}{$\%$ Ac graxos } \\
\hline 12:00 & Láurico & - & - & - & - & - & - \\
\hline 14:00 & Mirístico & $0,01 \pm 0,00$ & $0,22 \pm 0,01$ & $0,25 \pm 0,01$ & $0,14 \pm 0,00$ & $1,14 \pm 0,03$ & $1,25 \pm 0,01$ \\
\hline 15:00 & Pentadecanóico & - & - & $0,02 \pm 0,00$ & - & - & $0,08 \pm 0,00$ \\
\hline 16:00 & Palmítico & $0,51 \pm 0,01$ & $4,38 \pm 0,24$ & $2,50 \pm 0,08$ & $13,29 \pm 0,06$ & $21,89 \pm 0,24$ & $11,93 \pm 0,04$ \\
\hline 16:01 & Hexadecenóico & - & $0,34 \pm 0,02$ & $0,44 \pm 0,02$ & $0,11 \pm 0,01$ & $1,71 \pm 0,03$ & $2,10 \pm 0,01$ \\
\hline 17:00 & Margárico & $0,01 \pm 0,00$ & $0,08 \pm 0,00$ & $0,03 \pm 0,00$ & $0,11 \pm 0,01$ & $0,39 \pm 0,01$ & $0,13 \pm 0,00$ \\
\hline 17:01 & Heptadecenóico & - & $0,06 \pm 0,00$ & $0,02 \pm 0,00$ & - & $0,28 \pm 0,01$ & $0,10 \pm 0,00$ \\
\hline 18:00 & Esteárico & $0,15 \pm 0,00$ & $2,25 \pm 0,14$ & $0,74 \pm 0,02$ & $3,88 \pm 0,01$ & $10,97 \pm 0,21$ & $3,45 \pm 0,01$ \\
\hline $18: 1$ t (n-9) & Elaídico & - & - & - & - & - & - \\
\hline $18: 1(n-9)$ & Oleico & $0,87 \pm 0,02$ & $7,89 \pm 0,42$ & $9,86 \pm 0,44$ & $21,92 \pm 0,29$ & $38,22 \pm 0,41$ & $45,66 \pm 0,46$ \\
\hline $18: 1(n-11)$ & Vacênico & $0,05 \pm 0,01$ & $0,47 \pm 0,02$ & $0,40 \pm 0,02$ & $1,33 \pm 0,25$ & $2,26 \pm 0,04$ & $1,86 \pm 0,06$ \\
\hline $18: 2 \mathrm{t}$ & Linolelaídico & - & - & - & $0,11 \pm 0,01$ & - & - \\
\hline $18: 2(n-6)$ & Linoleico & $2,15 \pm 0,04$ & $4,46 \pm 0,09$ & $5,30 \pm 0,08$ & $53,91 \pm 0,09$ & $21,49 \pm 0,63$ & $24,40 \pm 0,48$ \\
\hline 20:00 & Eicosanóico & $0,01 \pm 0,00$ & - & $0,06 \pm 0,00$ & $0,33 \pm 0,01$ & - & $0,29 \pm 0,00$ \\
\hline $18: 3 \mathrm{~g}$ & g Linolênico & - & - & - & $0,12 \pm 0,01$ & - & - \\
\hline $20: 1(n-9)$ & Eicosenóico & - & - & $0,19 \pm 0,01$ & - & - & $0,88 \pm 0,00$ \\
\hline $18: 3(n-3)$ & Linolênico & $0,17 \pm 0,00$ & $0,34 \pm 0,03$ & $0,44 \pm 0,02$ & $4,19 \pm 0,04$ & $1,63 \pm 0,24$ & $2,00 \pm 0,03$ \\
\hline 20:02 & Eicosadienóico & - & - & - & - & - & - \\
\hline $18: 4(n-3)$ & Octadecatetraenóico & - & - & $0,10 \pm 0,01$ & - & - & $0,47 \pm 0,01$ \\
\hline 22:00 & Docosanóico & $0,01 \pm 0,00$ & - & $0,04 \pm 0,00$ & $0,31 \pm 0,00$ & - & $0,17 \pm 0,01$ \\
\hline $20: 3(n-6)$ & Eicosatrienóico & - & - & $0,02 \pm 0,00$ & - & - & $0,09 \pm 0,00$ \\
\hline 22:01 & Docosenóico & - & - & - & - & - & - \\
\hline $20: 3(n-3)$ & Eicosatrienóico & - & - & - & - & - & $0,09 \pm 0,00$ \\
\hline $20: 4(n-6)$ & Araquidônico & - & - & $0,03 \pm 0,00$ & - & - & $0,14 \pm 0,01$ \\
\hline $20: 4(n-3)$ & Eicosatetraenóico & - & - & $0,05 \pm 0,00$ & - & - & $0,22 \pm 0,00$ \\
\hline 24:00:00 & Lignocérico & $0,01 \pm 0,00$ & - & - & $0,25 \pm 0,00$ & - & - \\
\hline $20: 5(n-3)$ & Eicosapentaenóico & - & - & $0,48 \pm 0,02$ & - & - & $2,04 \pm 0,02$ \\
\hline $22: 5(n-6)$ & Docosapentaenóico & - & - & $0,03 \pm 0,00$ & - & - & $0,11 \pm 0,00$ \\
\hline $22: 5(n-3)$ & Docosapentaenóico & - & - & $0,20 \pm 0,01$ & - & - & $0,89 \pm 0,01$ \\
\hline $22: 6(n-3)$ & Docosahexaenóico & - & - & $0,40 \pm 0,02$ & - & - & $1,74 \pm 0,01$ \\
\hline Total n-6 & & 2,15 & 4,46 & 5,38 & & & \\
\hline Total n-3 & & 0,17 & 0,34 & 1,67 & & & \\
\hline$n-6 / n-3$ & & 12:1 & $13: 1$ & $3: 1$ & & & \\
\hline \multirow{4}{*}{ Totais } & Saturados & $0,71 \pm 0,01$ & $6,93 \pm 0,39$ & $3,64 \pm 0,12$ & $18,31 \pm 0,09$ & $34,39 \pm 0,48$ & $17,30 \pm 0,04$ \\
\hline & Monoinsaturados & $0,93 \pm 0,02$ & $8,67 \pm 0,47$ & $10,92 \pm 0,48$ & $23,36 \pm 0,06$ & $42,46 \pm 0,43$ & $50,60 \pm 0,48$ \\
\hline & Poli-insaturados & $2,32 \pm 0,04$ & $4,80 \pm 0,07$ & $7,05 \pm 0,15$ & $58,22 \pm 0,06$ & $23,12 \pm 0,86$ & $32,10 \pm 0,45$ \\
\hline & Trans & - & - & - & $0,11 \pm 0,01$ & - & - \\
\hline$\%$ gordura & & $4,2 \pm 0,05$ & $21,9 \pm 0,96$ & $22,96 \pm 0,79$ & & & \\
\hline
\end{tabular}


Nas oito primeiras semanas, os animais permaneceram apenas recebendo a ração específica de cada grupo e água à vontade. Este período, denominado Fase 1, teve como objetivo verificar o efeito do consumo crônico dos diferentes tipos de gordura. Passadas as oito semanas de dieta, os animais foram submetidos às análises pré-cirurgia: teste oral de tolerância à glicose (OGTT), teste intraperitoneal de tolerância à insulina (IpITT), colesterol total e frações. Além disso, em um experimento extra foi realizado e os animais eutanasiados antes da lipectomia para aferição da adiposidade e do perfil de distribuição da gordura corporal. Nos outros, experimento, dois dias após o último teste, foi realizada uma nova divisão intragrupos, separando-se os animais que seria submetidos à lipectomia dos falsooperados (tabela 3). Deu-se, então, início à Fase 2, com o objetivo verificar o efeito da lipectomia nesses animais. O procedimento cirúrgico está descrito no ítem 2.3.3.

Tabela 3 - Grupos experimentais

\begin{tabular}{ll}
\hline \hline Grupos & Estratégia \\
\hline SAT-L & Hiperlipídica Saturada Lipectomia \\
SAT-FO & Hiperlipídica Saturada Falso Operado \\
PUFA-L & Hiperlipídica Poli-insaturada Lipectomia \\
PUFA-FO & Hiperlipídica Poli-insaturada Falso Operado \\
CON-L & Controle e Lipectomia \\
CON-FO & Controle e Falso Operado \\
\hline \hline
\end{tabular}

Três semanas após a cirurgia, foi realizada a eutanásia dos animais, após 12 horas de jejum, por decapitação. Foram coletados sangue, fígado, tecido adiposo epididimal, retroperitoneal e marrom para análise dos parâmetros descritos a seguir. A Figura 1 ilustra o desenho experimental. 
Figura 1 - Desenho Experimental

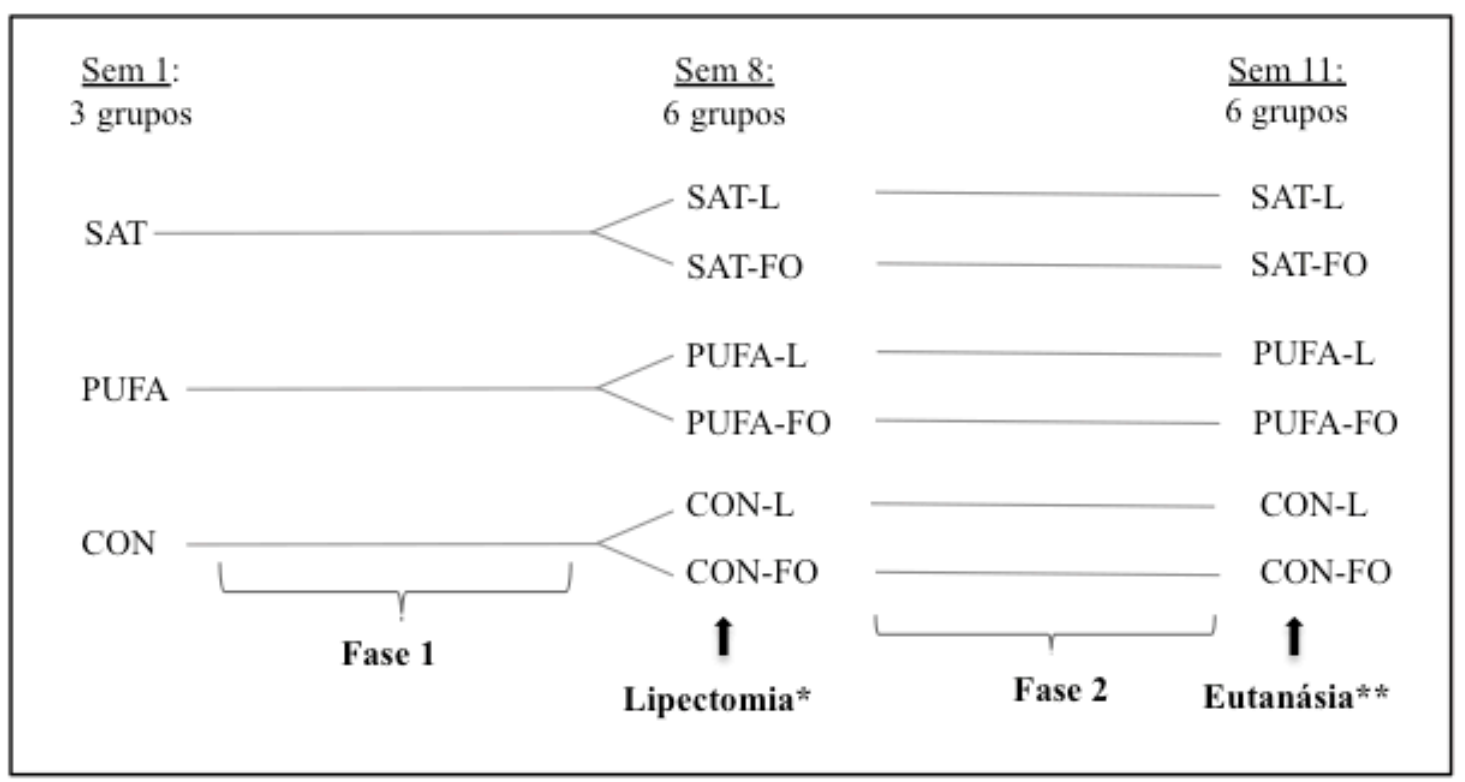

*Análises pré-lipectomia: OGTT, IpITT, insulinemia e perfil Lipídico; análises pós-lipectomia: adiposidade. **Análises pré-eutanásia: OGTT, IpITT, insulinemia, perfil lipídico. Análises pós-eutanásia: adiposidade e citocinas inflamatórias.

Durante todo o experimento houve acompanhamento semanal do crescimento ponderal dos animais. As quantidades de ração consumidas per capita foram aferidas três vezes por semana, a fim de obter o consumo alimentar médio diário de cada grupo.

\subsubsection{Lipectomia}

A cirurgia foi realizada nos animais sob anestesia geral, intraperitoneal $(66,6 \mathrm{mg} / \mathrm{kg}$ peso de ketamina e $33,3 \mathrm{mg} / \mathrm{kg}$ de peso de xilazina), a partir de incisão na região central, para a retirada bilateral do máximo possível de tecido adiposo epididimal (Barzilai et al., 1999; Gabriely et al., 2002; Michel et al., 1999). Os ratos do grupo falso operado sofreram a mesma intervenção cirúrgica, até mesmo a manipulação dos intestinos, porém sem remoção de gordura. Ao final da cirurgia foi realizada sutura na incisão e durante todo o procedimento foi utilizado material cirúrgico esterilizado. 


\subsubsection{Análises Plasmáticas}

Para a análise da glicemia durante o teste oral de tolerância à glicose (OGTT), o sangue foi coletado da cauda dos animais vivos. Nas demais análises foi utilizado o sangue obtido no dia da eutanásia. Para todas as coletas o sangue foi centrifugado a $4000 \mathrm{rpm}$, para extração do plasma e armazenado a $-80^{\circ} \mathrm{C}$, para posterior dosagem.

\subsubsection{Análises de Glicose, Insulina, Perfil Lipídico e Inflamatório}

A glicemia de jejum pré-lipectomia foi analisada no dia do OGTT pré-lipectomia e novamente no dia da eutanásia através do método enzimático com auxílio do Kit da marca Celm ${ }^{\circledR}$ (São Paulo, Brasil). Todos os demais resultados foram obtidos a partir de análises realizadas no dia da eutanásia. Colesterol total, lipoproteína de alta densidade (HDL), lipoproteína de baixa densidade (LDL) e triglicerídeos (TG) também foram analisados por kit enzimático da mesma marca. A análise de insulina foi realizada por kit de radioimunoensaio e as análises plasmáticas de TNF- $\alpha$, IL-10, IL-1 $\beta$ e IL-6 foram analisadas através da tecnologia Luminex ${ }^{\circledR}$ da Millipore (Merck KGaA, Darmstadt, Germany).

\subsubsection{2 Índice HOMA (Homeostatic Model Assessment)}

Este índice possibilitou a estimativa da sensibilidade à insulina e foi calculado através dos valores de glicemia (mmol/l) e insulinemia (mU/l) de jejum da décima primeira semana (Mojiminiyi et al., 2010), conforme metodologia descrita por Wallace et al. (2004).

\subsubsection{Teste Oral de Tolerância à Glicose (OGTT) e Teste Intraperitoneal de tolerância à Insulina (IpITT)}

O OGTT foi realizado em dois momentos do estudo, na semana anterior à lipectomia e, na semana da eutanásia, após 12 horas de jejum. Para isso foi dada, via gavagem, uma dose de $2 \mathrm{~g} / \mathrm{kg}$ peso corporal de uma solução de dextrose. Para análise das concentrações de glicose foi coletado sangue da veia caudal dos animais no momento 0 (jejum) e aos, 30, 60, 90 e 120 minutos após o início do procedimento, para a análise das concentrações circulantes de glicose.

Para o testes de IpITT foi realizado jejum de 6 horas e, após esse período, foi feita infusão intraperitoneal de uma dose de $0.75 \mathrm{mU} / \mathrm{g}$ peso corporal de insulina. Para os dois 
testes foi coletado sangue da veia caudal dos animais no momento 0 (jejum) e aos 30, 60, 90 e 120 minutos após o início do procedimento, para a análise das concentrações circulantes de glicose.

Após a obtenção da concentração de glicose nos diferentes momentos do teste foi realizado o cálculo da Área Abaixo da Curva (AUC), conforme trabalho de Matthews et al. (1990).

\subsubsection{Composição Corporal e Peso dos Tecidos}

Para determinar o peso dos tecidos, os diferentes depósitos de gordura e o fígado foram pesados separadamente no dia da eutanásia. Para a análise de adiposidade corporal, o corpo dos animais foi acrescido de água destilada em quantidade equivalente ao seu peso e autoclavado por 40 minutos. Em seguida foram homogeneizados e uma amostra do homogenato produzido foi utilizada para determinar o conteúdo total de lipídios procedimentos realizados segundo a metodologia previamente descrita Stansbie et al. (1976). Essa mesma metodologia foi utilizada com amostras do fígado para análise do conteúdo hepático de gordura.

\subsubsection{Análise dos Dados}

Os dados foram organizados com o objetivo de se diferençar os efeitos das suas intervenções: dieta e lipectomia. Sendo assim, até a semana 8 os dados foram analisados respeitando os três grupos experimentais. A partir dessa semana, os grupos foram divididos e os dados analisados organizados dentro de cada um dos 6 grupos experimentais.

Objetivando testar a significância das diferenças entre os grupos foram utilizadas as seguintes análises:

- Análise de variância (ANOVA) one way - para a análise de gordura retirada na lipectomia e dos diferentes depósitos de gordura;

- Mixed Models para medidas repetidas (2 fatores - dieta e cirurgia), seguido por teste post hoc de Tukey quando necessário - peso corporal e consumo de ração.

Os dados foram expressos na forma de média \pm erro padrão (SEM) e os resultados foram considerados significantes quando $p \leq 0,05$. As análises foram realizados com o auxílio do software SAS 9.1. 


\subsection{Resultados}

\subsubsection{Consumo de Ração}

O consumo calórico dos animais foi calculado através do consumo em gramas de ração dividido pelo peso corporal médio. Desse modo obtivemos o consumo relativo - em g de ração/g peso corporal/dia. Para o cálculo do consumo calórico foram então utilizados os dados da análise bromatológica feita (Tabela 1), obtendo-se, assim, as calorias consumidas por grama de peso corporal por dia.

Foi observado consumo calórico aumentado de modo significativo apenas na primeira semana nos dois grupos que consumiram dieta rica em gordura saturada e poli-insaturada, quando comparados ao grupo controle ( $<<0,05$, Figura 2). Após a lipectomia não foi observada qualquer alteração no consumo alimentar entre os grupos.

Figura 2 - Efeito da dieta hiperlipídica e da lipectomia no consumo de ração de ratos em $\mathrm{kcal} / \mathrm{g}$ peso corporal.

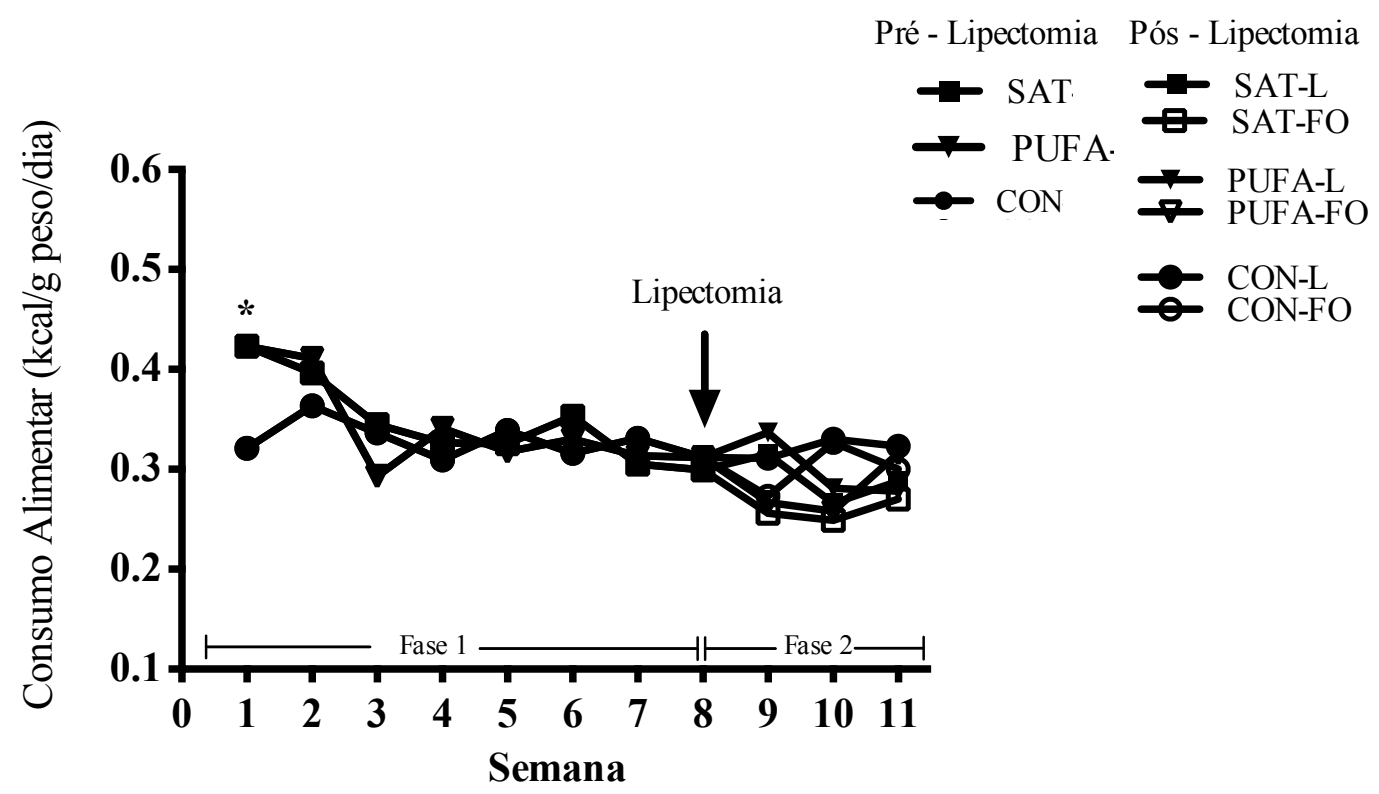

*p $<0.05$ SAT e PUFA versus CON na Fase 1 (SAT n=21, PUFA n=22, CON n=21). Dados apresentados na forma de média \pm SEM (SAT-L n=11, SAT-FO n=10, PUFA-L n=12, PUFA-FO n=10, CON-L n=11 e CONFO $n=10$ ).

\subsubsection{Peso Corporal}

Não foi observada diferença significante de peso corporal $(p \geq 0,99)$ entre os grupos durante todo o experimento (Figura 3). 
Figura 3 - Efeito da dieta hiperlipídica e da lipectomia sobre o crescimento ponderal de ratos.

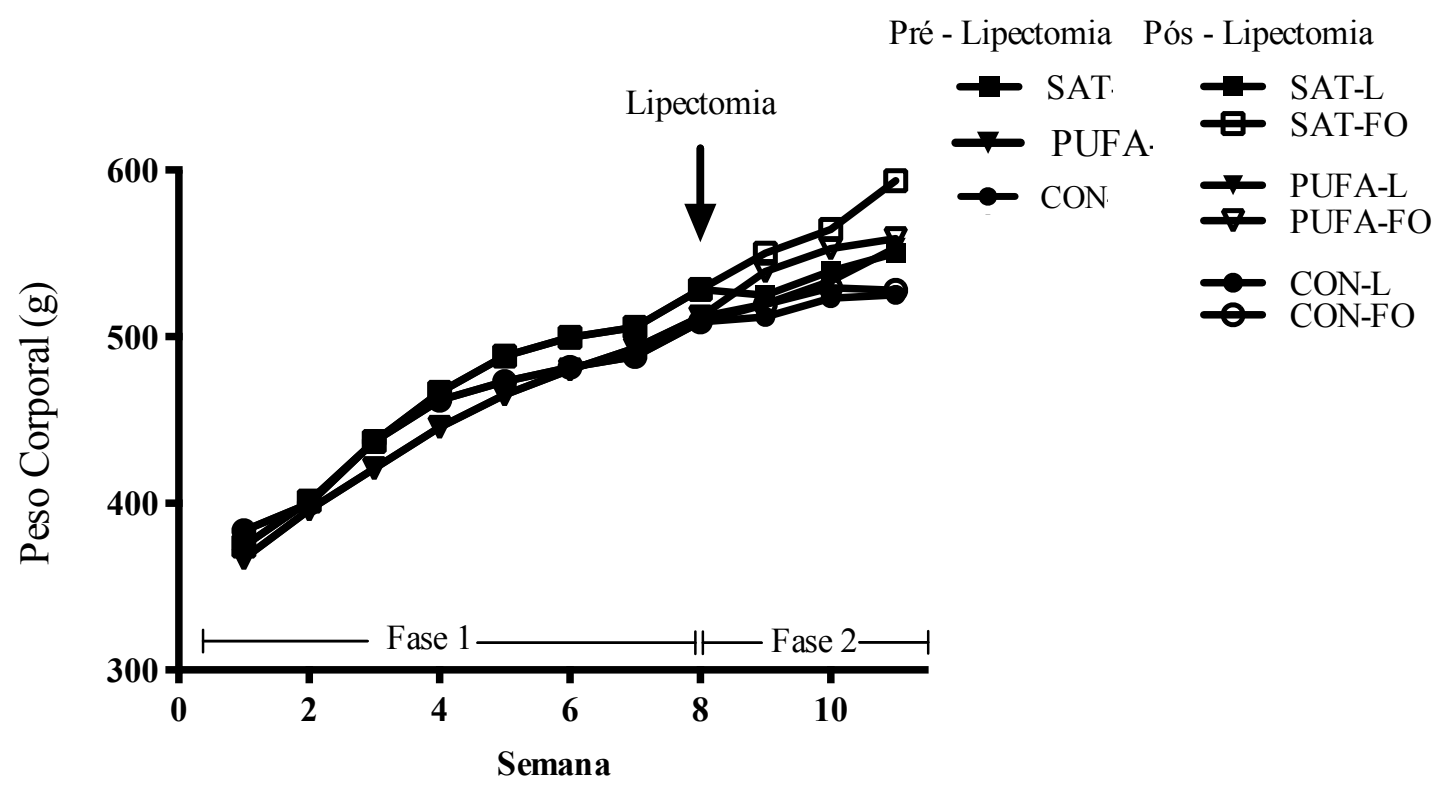

Sem diferença significativa. Dados apresentados na forma de média \pm SEM (Fase $1-$ SAT $n=21$, PUFA $\mathrm{n}=22, \mathrm{CON} n=21$; Fase 2 - Grupo SAT-L n=11, SAT-FO n=10, PUFA-L n=12, PUFA-FO n=10, CON-L n=11 e CON-FO $n=10$ ).

\subsubsection{Análises de Gordura}

\subsubsection{Gordura Retirada na Lipectomia}

A quantidade de gordura retirada na lipectomia não foi diferente entre os grupos ( $\mathrm{p}>0,2$ ), tendo sido retiradas, em média, SAT-L 8,1 $\pm 6,2 \mathrm{~g}$, PUFA-L 6,9 $\pm 2,9$ g, e CON-L $5,2 \pm 1,8$ g. No gráfico 4 os valores estão expressos na forma de porcentagem do peso corporal $1,45 \pm 0,86 \%$ para o SAT-L, $1,29 \pm 0,44 \%$ para o grupo PUFA-L e $1,06 \pm 0,38 \%$ para o grupo CON-L (Figura 4). 
Figura 4 - Quantidade de gordura relativa ao peso corporal retirada na lipectomia.

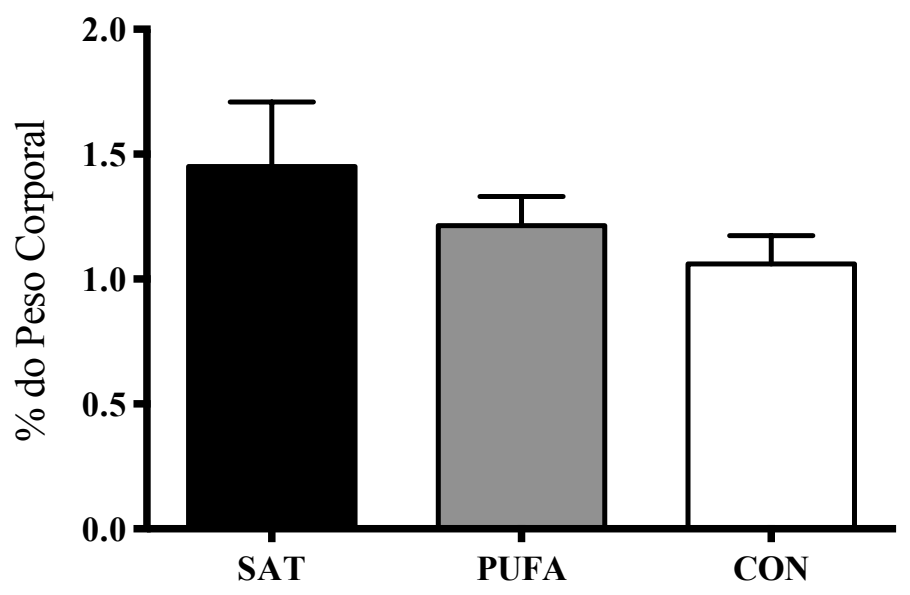

Sem diferença significativa entre os grupos. Dados apresentados na forma de média \pm SEM (SAT $n=21$, PUFA $n=22$, CON $n=21$ ).

\subsubsection{Adiposidade}

Conforme análise de extração de gordura realizada, observamos que a adiposidade na Fase 1 (efeito da dieta) dos grupos SAT e PUFA foi significativamente maior quando comparada ao grupo $\mathrm{CON}(\mathrm{p}<0,05$, Figura 5), ou seja a dieta hiperlipídica ocasionou aumentada adiposidade em comparação à dieta controle. Três semanas após a lipectomia, os grupos SAT-FO e PUFA-FO apresentaram conteúdo significativamente maior de gordura quando comparados aos demais grupos $(\mathrm{p}<0,05$, Figura 5 - Fase 2). Este resultado demonstra que a gordura retirada na lipectomia resultou em queda significativa na quantidade de gordura corporal nos grupos que consumiram dieta hiperlipídica. 
Figura 5 - Efeito da dieta hiperlipídica e da lipectomia sobre a adiposidade de ratos.

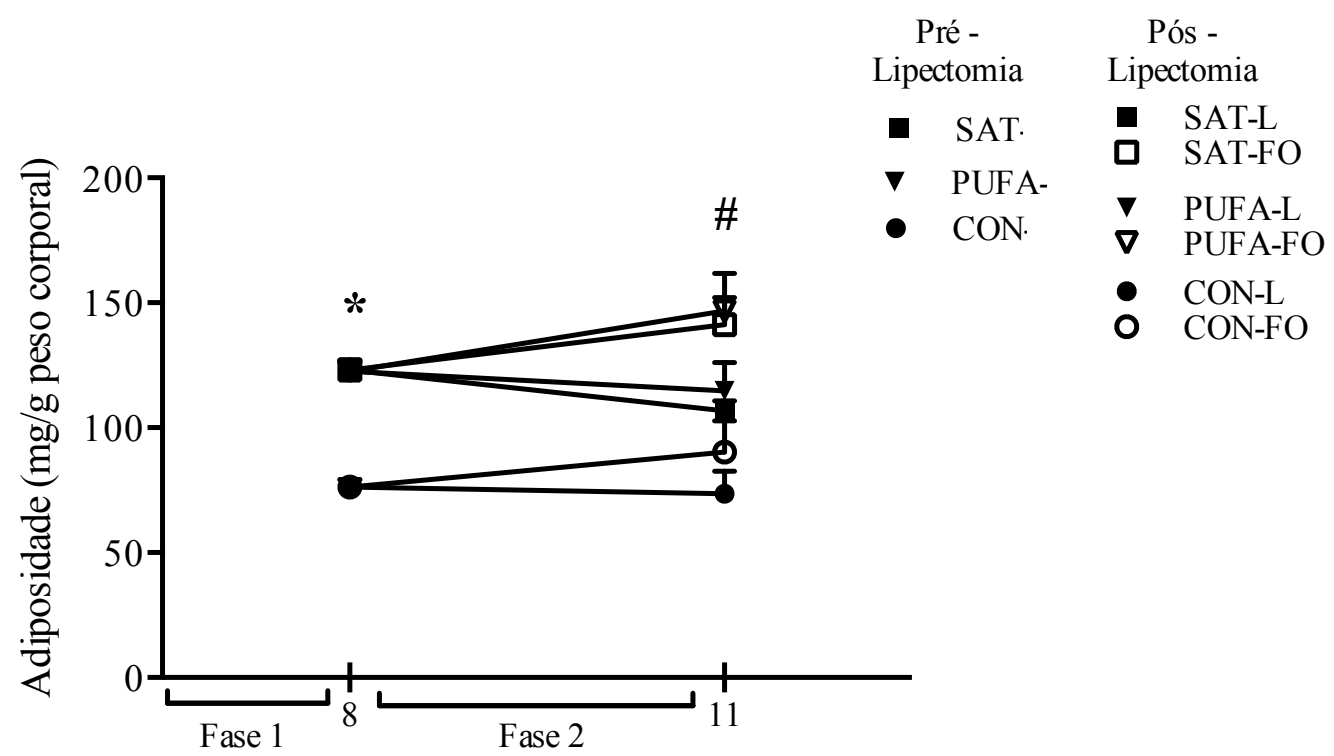

Fase $1-^{*} \mathrm{p}<0,05$ SAT e PUFA versus CON (SAT $\mathrm{n}=8$, PUFA $\mathrm{n}=8, \mathrm{CON} \mathrm{n}=8$ ); Fase 2 - \#p $<0,05$ SAT-FO e PUFA-FO versus demais grupos (SAT-L $\mathrm{n}=10$, SAT-FO $\mathrm{n}=10$, PUFA-L $\mathrm{n}=10$, PUFA-FO $\mathrm{n}=9$, CON-L $\mathrm{n}=11$ e CON-FO $n=9$ ). Dados apresentados na forma de média \pm SEM.

\subsubsection{Contribuição dos Diferentes Depósitos de Gordura}

a) Tecido Adiposo Epididimal

A dieta hiperlipídica rica em gordura saturada ocasionou acúmulo aumentado significativo do tecido adiposo epididimal, quando comparado ao grupo $\mathrm{CON}(\mathrm{p}=0,03$; Fase 1 - Figura 6). Nos resultados da Fase 2 podemos observar que a lipectomia foi efetiva em diminuir este depósito no grupos operados: os grupos SAT-FO e PUFA-FO apresentaram conteúdo significativamente maior deste depósito quando comparados aos demais grupos $(\mathrm{p}=0,03$; Fase $2-$ Figura 6$)$. 
Figura 6 - Efeito da dieta hiperlipídica e da lipectomia no depósito de gordura epididimal de ratos.

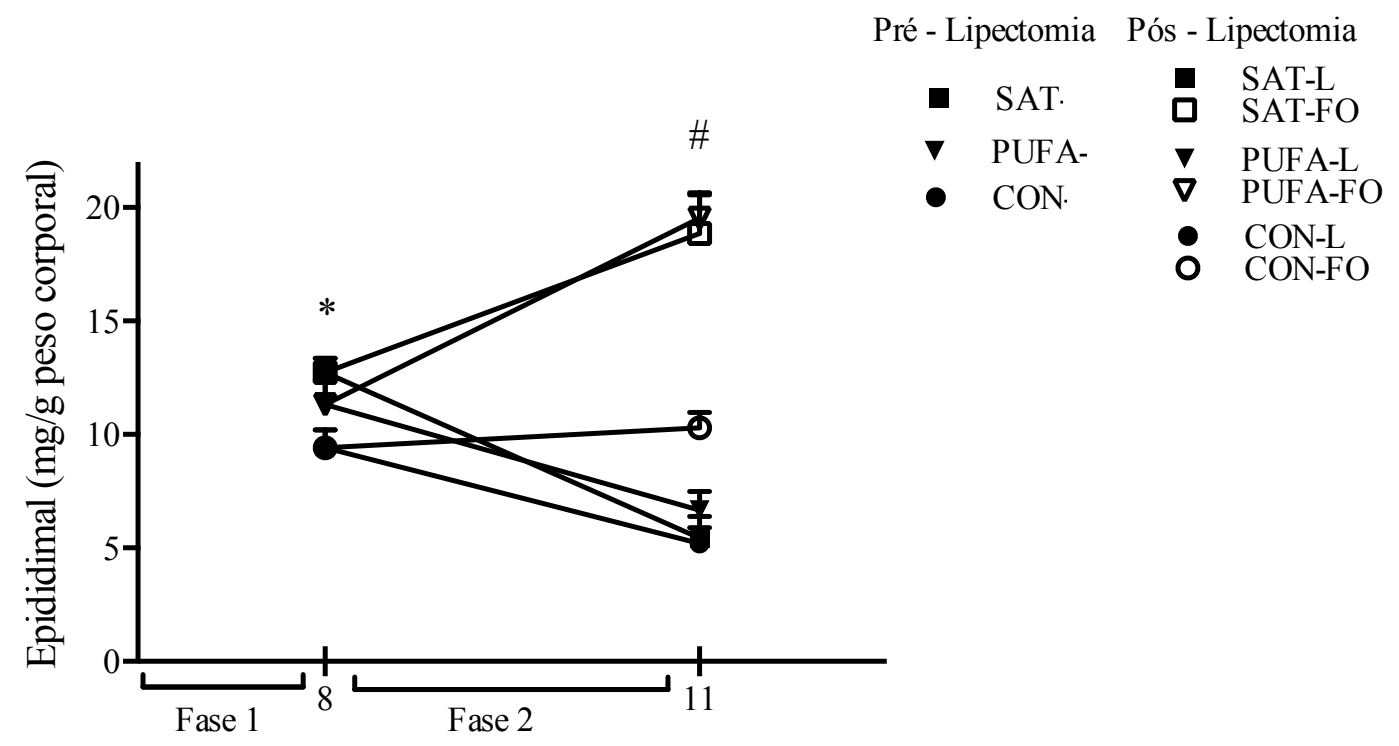

Fase $1-* \mathrm{p}=0.03$ SAT versus CON (SAT $\mathrm{n}=8$, PUFA $\mathrm{n}=8$, CON $\mathrm{n}=8$ ); Fase $2-\# \mathrm{p}<0.01$ para SAT-FO e PUFA-FO versus demais grupos (SAT-L $n=11$, SAT-FO $n=10$, PUFA-L $n=12$, PUFA-FO $n=10$, CON-L $n=11$ e CON-FO n=10). Dados apresentados na forma de média \pm SEM.

b) Tecido Adiposo Retroperitoneal

As dietas hiperlipídicas, SAT e PUFA, ocasionaram acúmulo significativo de tecido adiposo retroperitoneal quando os dois grupos foram comparados ao grupo $\operatorname{CON}(p<0,0001$; Fase 1 - Figura 7). A lipectomia resultou em aumento compensatório deste depósito quando associada a dieta rica em gordura saturada, SAT-L versus demais grupos $(\mathrm{p}<0,03$; Fase 2 Figura 7). Os demais grupos que receberam dieta hiperlipídica mantiveram um conteúdo aumentado quando comparados ao grupo com dieta controle, tanto lipectomizado quanto falso operado $(\mathrm{p}<0,01 ;$ Fase 2 - Figura 7$)$. 
Figura 7 - Efeito da dieta hiperlipídica e da lipectomia no depósito de gordura retroperitoneal de ratos.

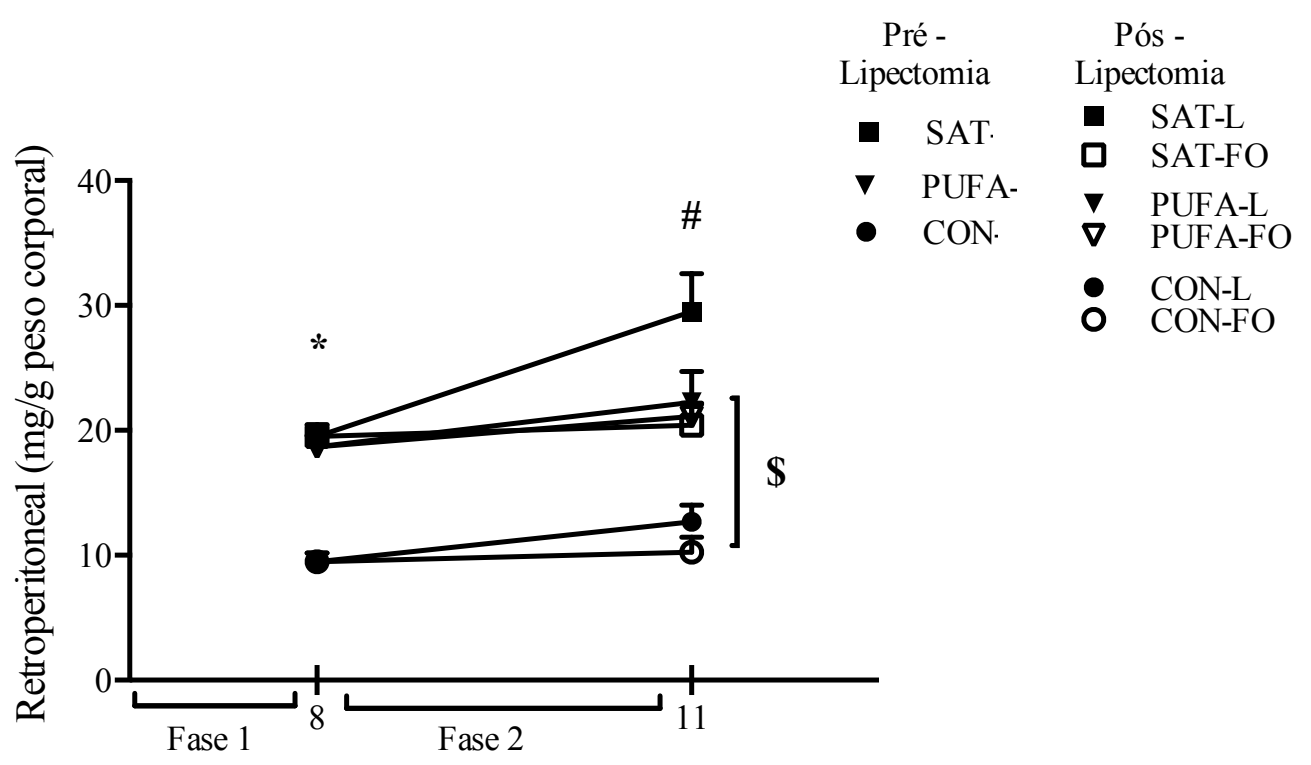

Fase 1 - ${ }^{*} \mathrm{p}<0.0001$ SAT e PUFA versus CON (Fase $1-\operatorname{SAT} \mathrm{n}=8$, PUFA $\mathrm{n}=8, \operatorname{CON} \mathrm{n}=8$ ); Fase 2 - $\# \mathrm{p}<0.03$ para SAT-L versus demais grupos, $\$ \mathrm{p}<0,01$ para SAT-FO, PUFA-L, PUFA-FO versus CON-L e CON-FO (SAT-L $n=11$, SAT-FO $n=10$, PUFA-L $n=12$, PUFA-FO $n=10$, CON-L $n=11$ e CON-FO $n=10$ ). Dados apresentados na forma de média $\pm \mathrm{SEM}$.

c) Tecido Adiposo Marrom

A dieta rica em gordura poli-insaturada fez com que esse grupo acumulasse significativamente mais gordura no tecido adiposo marrom interescapular, quando em comparação aos grupos com dieta rica em gordura saturada e dieta controle $(p<0,001$, Fase 1- Figura 8). A lipectomia manteve a diferença entre os grupos dieta rica em gordura PUFA, PUFA-L e PUFA-FO, quando comparados aos grupos com dieta controle, CON-L e CONFO $(\mathrm{p}<0,0001 ;$ Fase 2 - Figura 8$)$. 
Figura 8 - Efeito da dieta hiperlipídica e da lipectomia no depósito de gordura marrom interescapular de ratos.
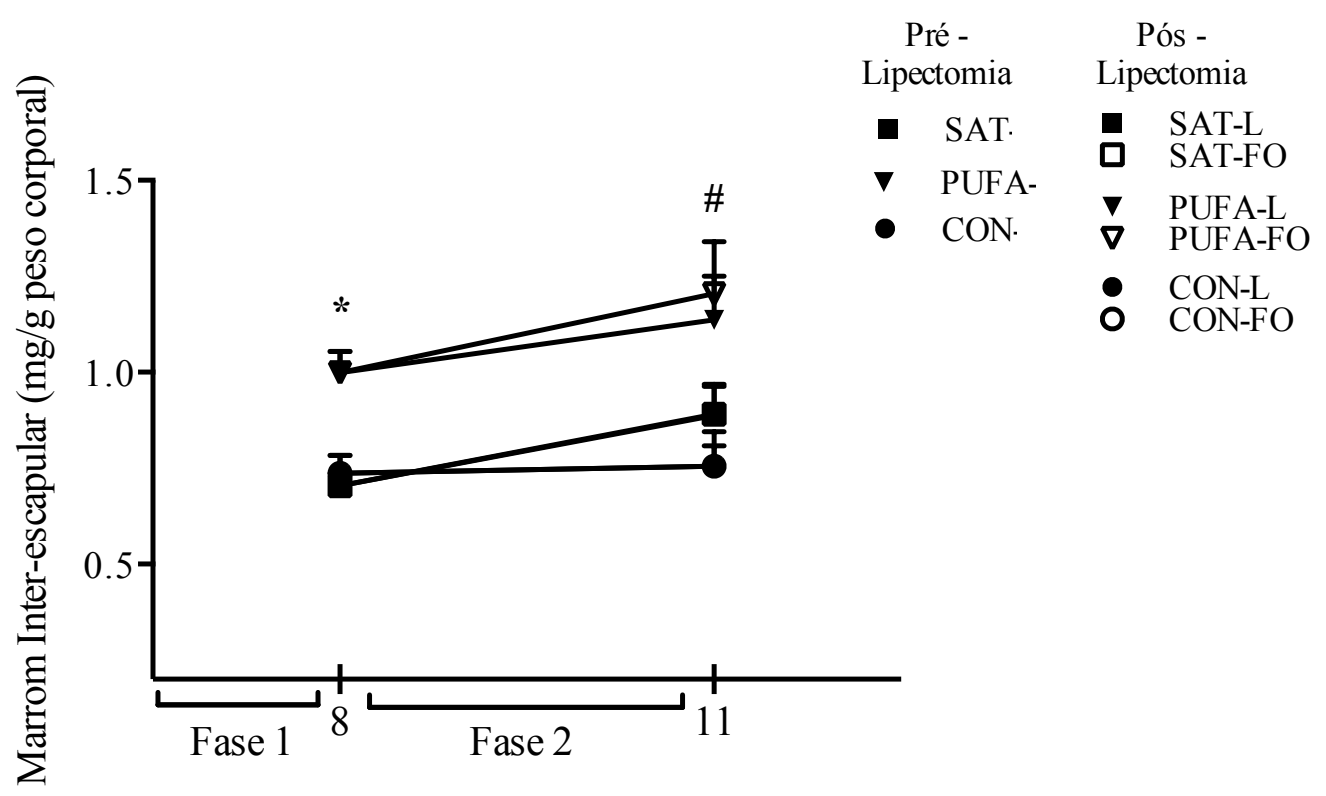

Fase $1-* p<0.001$ PUFA versus SAT e CON (SAT $n=8$, PUFA $n=8, \operatorname{CON} n=8$ ); Fase 2 - $\# p<0.0001$ PUFA-L e PUFA-FO versus CON-L e CON-FO (SAT-L $n=11$, SAT-FO $n=10$, PUFA-L $n=12$, PUFA-FO $n=10$, CON$\mathrm{L} n=11$ e CON-FO $\mathrm{n}=10$ ). Dados apresentados na forma de média \pm SEM. 
Tabela 4 - Adiposidade total e nos diferentes depósitos. Dados apresentados em mg de gordura/g de peso corporal (média $\pm \mathrm{SEM}$ ).

\begin{tabular}{|c|c|c|c|c|c|c|c|}
\hline \multirow{2}{*}{ Adiposidade } & \multirow{2}{*}{$\begin{array}{l}\text { Sem } 8 \\
\text { Sem } 11\end{array}$} & \multicolumn{2}{|c|}{$\begin{array}{c}\text { SAT } \\
123,1 \pm 3,9\end{array}$} & \multicolumn{2}{|c|}{$\begin{array}{c}\text { PUFA } \\
122,6 \pm 3,57\end{array}$} & \multicolumn{2}{|c|}{$\begin{array}{c}\text { CON } \\
76,17 \pm 2,9\end{array}$} \\
\hline & & $\begin{array}{c}\text { SAT-L } \\
106,83 \pm \\
3,9 \\
\end{array}$ & $\begin{array}{c}\text { SAT-FO } \\
141,3 \pm 10,7 \\
\end{array}$ & $\begin{array}{c}\text { PUFA-L } \\
114,81 \pm 11,3 \\
\end{array}$ & $\begin{array}{l}\text { PUFA-FO } \\
146,8 \pm 15,0 \\
\end{array}$ & $\begin{array}{c}\text { CON-L } \\
73,64 \pm 8,8 \\
\end{array}$ & $\begin{array}{l}\text { CON-FO } \\
90,28 \pm 12,4 \\
\end{array}$ \\
\hline \multirow[b]{2}{*}{ Retroperitoneal } & Sem 8 & \multicolumn{2}{|c|}{$\begin{array}{c}\text { SAT } \\
12,74 \pm 0,62 \\
\end{array}$} & \multicolumn{2}{|c|}{$\begin{array}{c}\text { PUFA } \\
11,32 \pm 1,09 \\
\end{array}$} & \multicolumn{2}{|c|}{$\begin{array}{c}\mathbf{C O N} \\
9,41 \pm 0,77 \\
\end{array}$} \\
\hline & Sem 11 & $\begin{array}{c}\text { SAT-L } \\
5,43 \pm 0 \\
95 \\
\end{array}$ & $\begin{array}{c}\text { SAT-FO } \\
18,85 \pm 1,79 \\
\end{array}$ & $\begin{array}{l}\text { PUFA-L } \\
6,66 \pm 0,82 \\
\end{array}$ & $\begin{array}{l}\text { PUFA-FO } \\
19,54 \pm 1,02 \\
\end{array}$ & $\begin{array}{c}\text { CON-L } \\
5,19 \pm 0,68 \\
\end{array}$ & $\begin{array}{l}\text { CON-FO } \\
10,3 \pm 0,67 \\
\end{array}$ \\
\hline \multirow[b]{2}{*}{ Epididimal } & Sem 8 & \multicolumn{2}{|c|}{$\begin{array}{c}\text { SAT } \\
19,50 \pm 0,94\end{array}$} & \multicolumn{2}{|c|}{$\begin{array}{c}\text { PUFA } \\
18,67 \pm 0,91 \\
\end{array}$} & \multicolumn{2}{|c|}{$\begin{array}{c}\text { CON } \\
9,49 \pm 0,69 \\
\end{array}$} \\
\hline & Sem 11 & $\begin{array}{c}\text { SAT-L } \\
29,51 \pm 3 \\
, 04 \\
\end{array}$ & $\begin{array}{c}\text { SAT-FO } \\
20,43 \pm 1,76\end{array}$ & $\begin{array}{c}\text { PUFA-L } \\
22,25 \pm 2,46\end{array}$ & $\begin{array}{l}\text { PUFA-FO } \\
21,11 \pm 0,96 \\
\end{array}$ & $\begin{array}{c}\text { CON-L } \\
12,7 \pm 1,32 \\
\end{array}$ & $\begin{array}{l}\text { CON-FO } \\
10,25 \pm 1,19 \\
\end{array}$ \\
\hline \multirow{2}{*}{$\begin{array}{c}\text { Marrom } \\
\text { Interescapular }\end{array}$} & Sem 8 & \multicolumn{2}{|c|}{$\begin{array}{c}\text { SAT } \\
0,704 \pm 0,03 \\
\end{array}$} & \multicolumn{2}{|c|}{$\begin{array}{c}\text { PUFA } \\
0,998 \pm 0,05\end{array}$} & \multicolumn{2}{|c|}{$\begin{array}{c}\text { CON } \\
0,736 \pm 0,04\end{array}$} \\
\hline & Sem 11 & $\begin{array}{c}\text { SAT-L } \\
0,88 \pm 0 \\
07\end{array}$ & $\begin{array}{l}\text { SAT-FO } \\
0,89 \pm 0,07\end{array}$ & PUFA-L & PUFA-FO & CON-L & CON-FO \\
\hline
\end{tabular}

2.4.4 Glicemia, Insulinemia, Teste Oral de Tolerância à Glicose (OGTT) e Teste Intraperitoneal de Tolerância à Glicose (IpITT)

a) Glicemia

Não foi observada qualquer diferença nos valores de glicemia seja na Fase 1, ou na Fase 2 (Figura 9). 
Figura 9 - Efeito da dieta hiperlipídica e da lipectomia na concentração plasmática de glicose, em ratos.

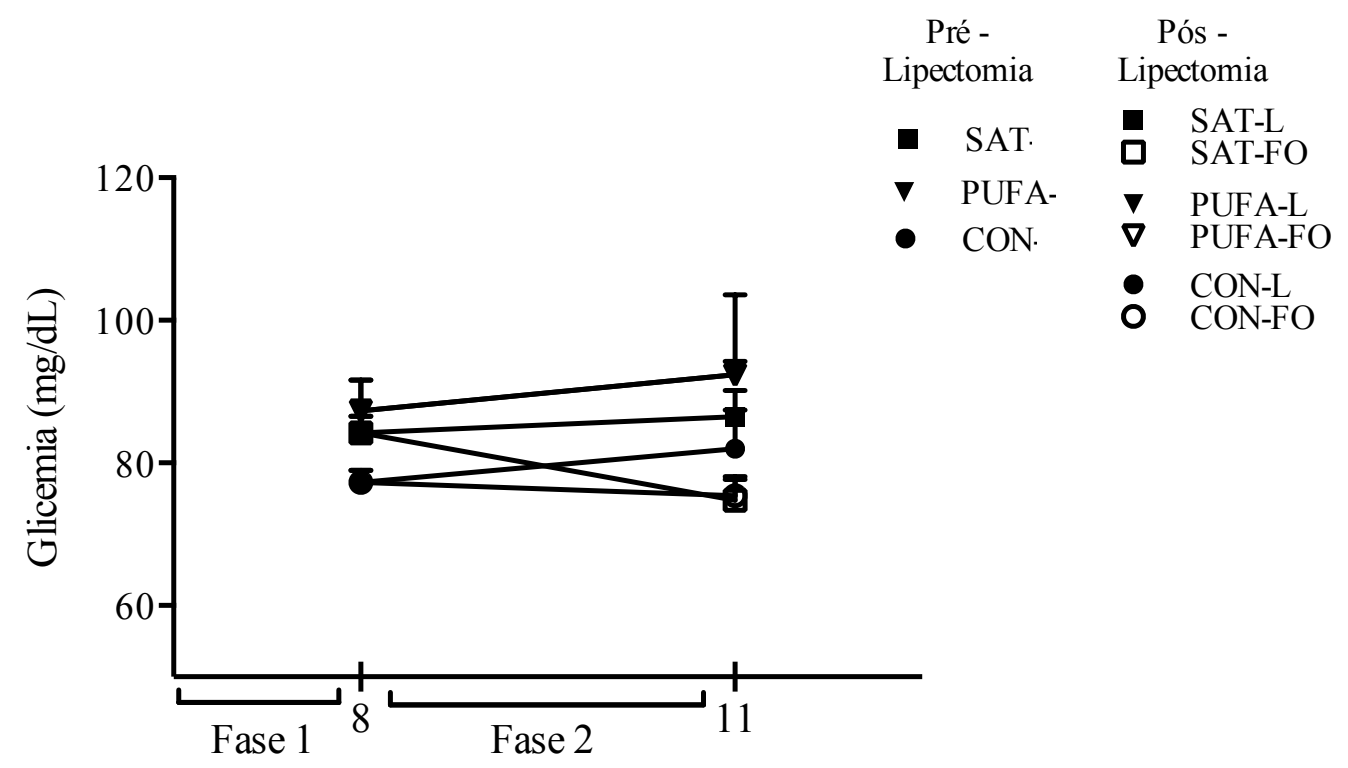

Sem diferença significativa. Dados apresentados na forma de média \pm SEM (Grupo SAT-L $n=9$, SAT-FO $n=9$, PUFA-L $n=11$, PUFA-FO n=7, CON-L n=7 e CON-FO $n=7$ ).

b) Teste Oral de Tolerância à Glicose (OGTT)

A dieta rica em gordura saturada ocasionou piora significativa da tolerância à glicose nos animais deste grupo, quando comparados ao grupo controle $(\mathrm{p}<0,05$, Fase 1 - Figura 10). No entanto essa diferença não se manteve após a lipectomia (Fase 2 - Figura 10). 
Figura 10 - Efeito da dieta hiperlipídica e da lipectomia na tolerância à glicose de ratos aferida pelo teste oral de tolerância à glicose.

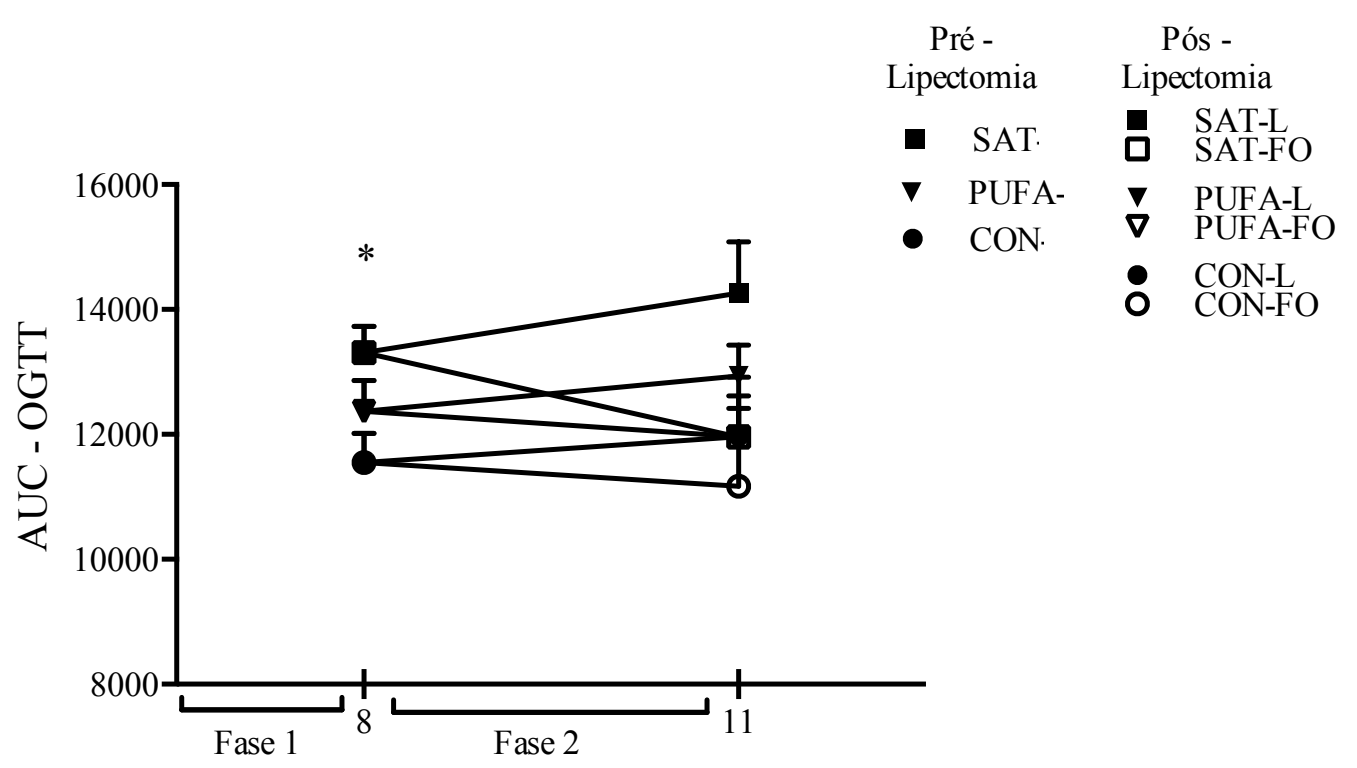

Fase $1-{ }^{*} p<0.05$ SAT versus CON (SAT $n=21$, PUFA $n=22$, CON $n=21$ ); Fase $2-$ Sem diferença significante (Grupo SAT-L n=11, SAT-FO n=10, PUFA-L n=12, PUFA-FO $n=10$, CON-L n=11 e CON-FO n=10). Dados apresentados na forma de média \pm SEM.

c) Teste Intraperitoneal de Tolerância à Glicose (IpITT)

Não foi observada alteração na sensibilidade à insulina entre os grupos na Fase 1. No entanto, na Fase 2, o grupo SAT-L apresentou diminuída sensibilidade quando comparado aos demais grupos que consumiram outras dietas ricas em gordura poli-insaturada e a dieta controle - PUFA-L, PUFA-FO, CON-L e CON-FO. Já grupo SAT-FO apresentou pior sensibilidade quando comparado ao seu respectivo grupo com dieta controle, CON-FO; ambas diferenças significativas, $\mathrm{p}<0,004$ e $\mathrm{p}=0,03$; respectivamente (Fase 2 - Figura 11). Estes dados denotam um efeito adicional da lipectomia ao tipo de dieta oferecida. 
Figura 11 - Efeito da dieta hiperlipídica e da lipectomia na sensibilidade à insulina de ratos, aferida pelo teste intraperitoneal de tolerância à insulina.

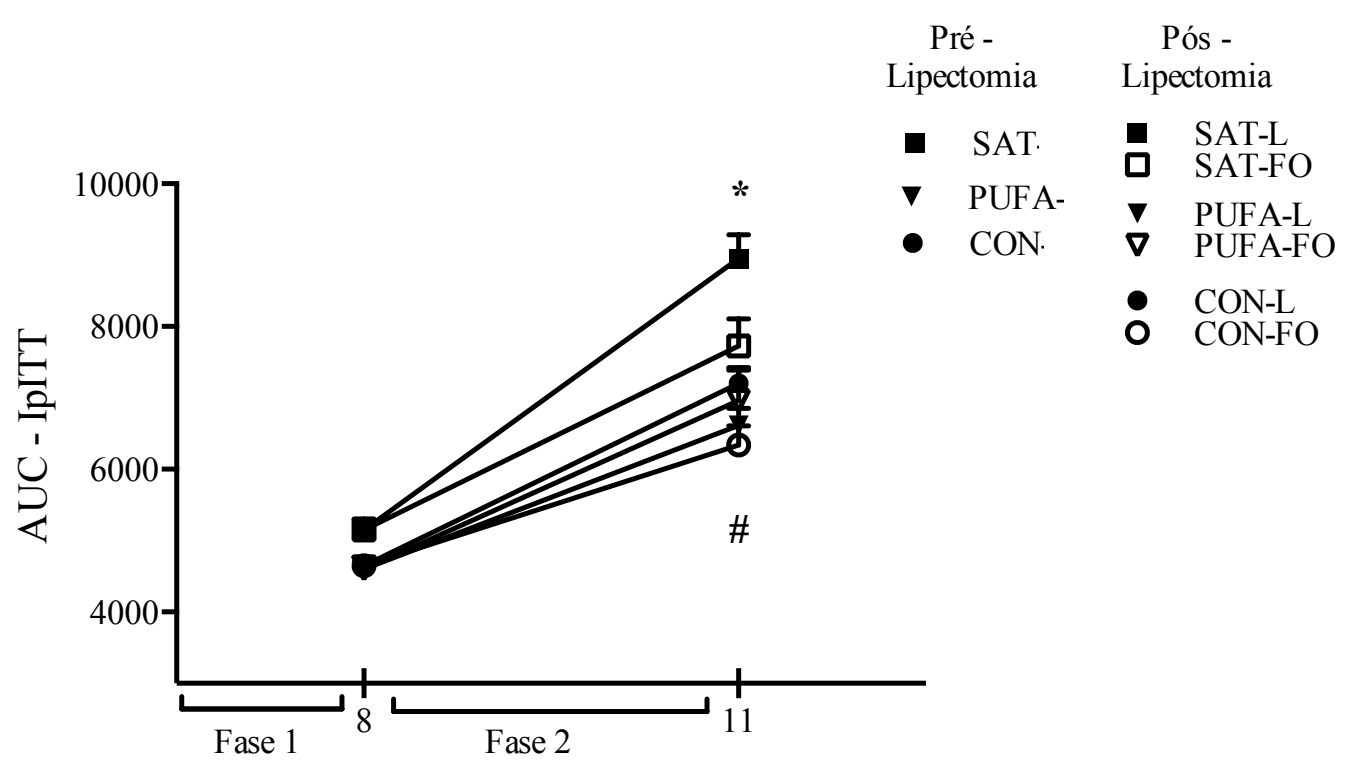

Fase 1 - sem diferença significativa (SAT $\mathrm{n}=21$, PUFA $\mathrm{n}=22, \mathrm{CON} \mathrm{n}=21$ ); Fase $2-{ }^{*} \mathrm{p}<0,004$ SAT-L versus PUFA-L, PUFA-FO, CON-L e CON-FO; \# $\mathrm{p}=0,03$ SAT-FO versus CON-FO (Grupo SAT-L n=11, SAT-FO $n=10$, PUFA-L $n=12$, PUFA-FO $n=10$, CON-L $n=11$ e CON-FO $n=10$ ). Dados apresentados na forma de média \pm SEM.

d) Insulinemia

Na Fase 2 foi realizada a medida da concentração de insulina e não foi observada diferença entre os grupos (Figura 12). 
Figura 12 - Efeito da lipectomia na insulinemia de ratos submetidos a diferentes tipos de dieta hiperlipídica.

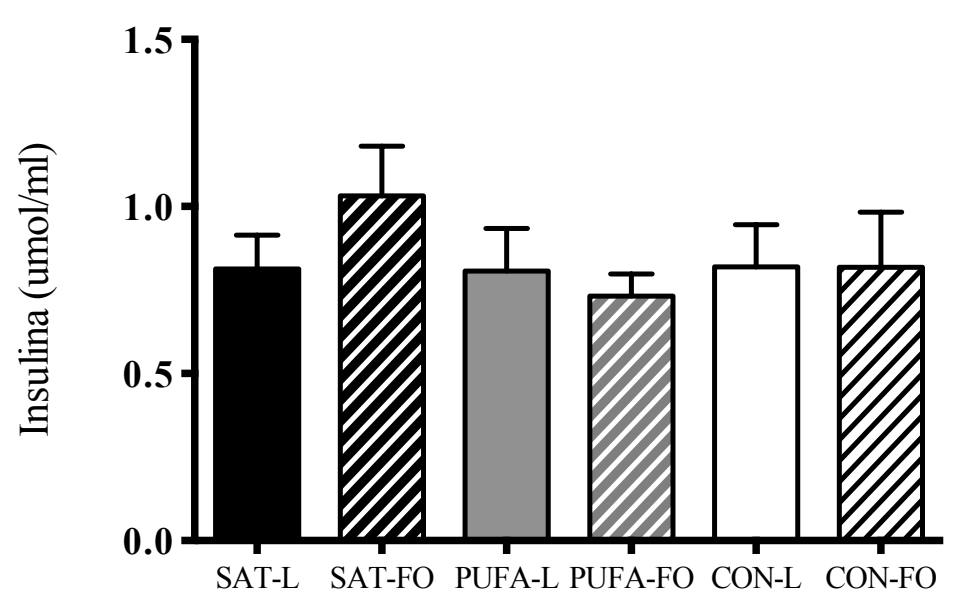

Sem diferença significativa. Dados apresentados na forma de média \pm SEM (Grupo SAT-L n=9, SAT-FO $n=9$, PUFA-L n=11, PUFA-FO n=7, CON-L n=7 e CON-FO n=7).

e) Índice HOMA

O cálculo do índice HOMA demonstrou que os grupos que consumiram dieta rica em gordura saturada, SAT-L e SAT-FO apresentaram pior sensibilidade à insulina. O grupo SAT-L apresentou piora quando comparado aos grupos PUFA-FO, CON-L e CON-FO $(\mathrm{p}<0,004$; Figura 13) e o grupo SAT-FO apresentou aumentada resistência à insulina quando comparado aos grupos PUFA-L, PUFA-FO, CON-L e CON-FO ( $<<0,005$; Figura 13). 
Figura 13 - Efeito da lipectomia na resistência à insulina de ratos submetidos a diferentes tipos de dieta hiperlipídica.

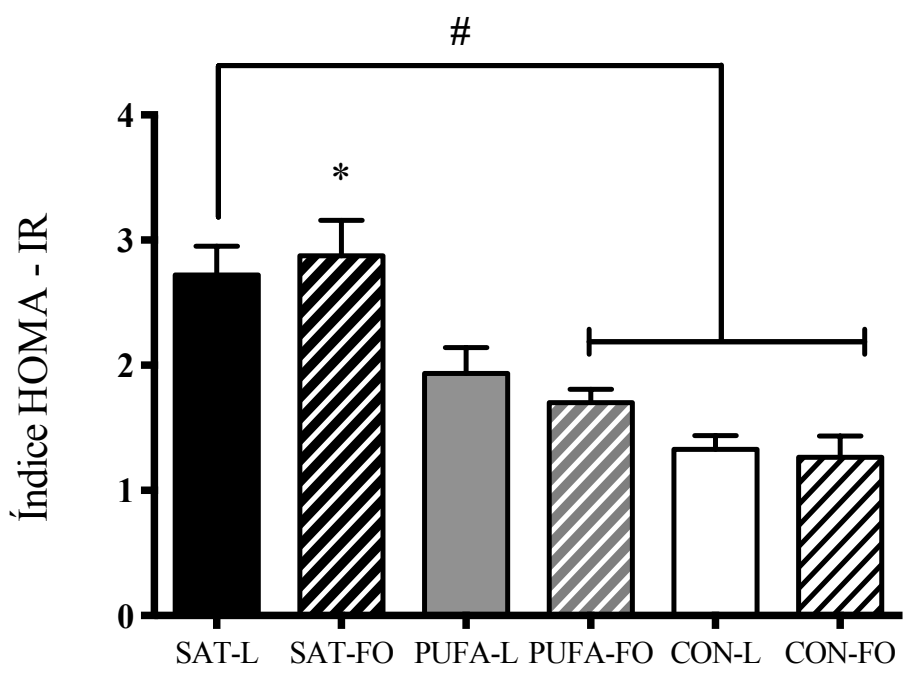

\# $\mathrm{p}<0,004$ para SAT-L versus PUFA-FO, CON-L e CON-FO; * $\mathrm{p}<0,005$ para PUFA-FO versus PUFA-L, PUFA-FO, CON-L e CON-FO (Grupo SAT-L n=9, SAT-FO n=9, PUFA-L n=11, PUFA-FO n=7, CON-L n=7 e CON-FO n=7). Dados apresentados na forma de média \pm SEM.

\subsubsection{Colesterol Total e Frações}

$\mathrm{Na}$ Fase 1, o grupo SAT apresentou aumento significativo das concentrações de colesterol total quando comparado aos demais grupos PUFA e CON ( $<<0,0001$; Fase 1 Figura14). A lipectomia fez com que o grupo SAT-L continuasse com suas concentrações aumentadas quando comparado aos grupos com diferentes dietas - PUFA-L, PUFA-FO CON-L e CON-FO ( $<<0,0003)$. Já o grupo SAT-FO apresentou concentrações aumentadas quando comparado ao seu respectivo grupo controle, CON-FO ( $p=0,03$; Fase 2 - Figura 14). 
Figura 14 - Efeito da dieta hiperlipídica e da lipectomia na concentração de colesterol total de ratos.

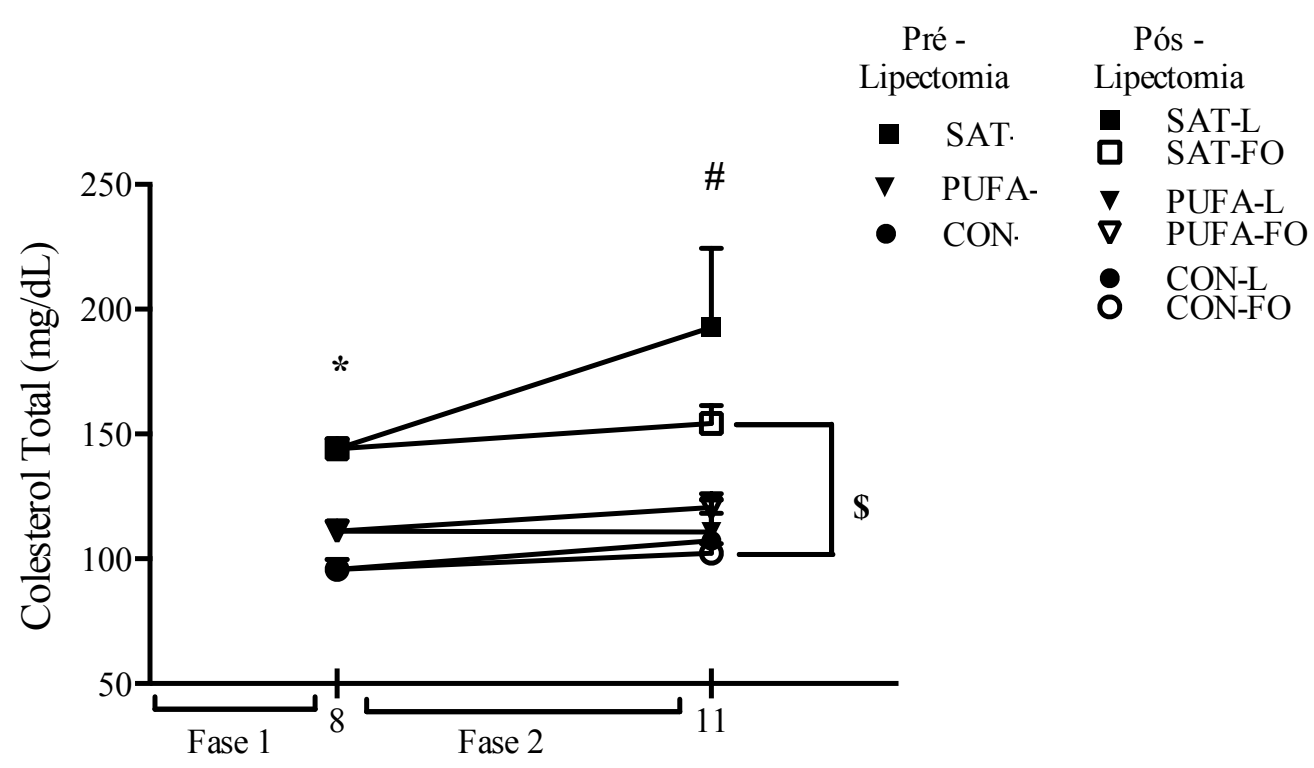

Fase $1-{ }^{*} \mathrm{p}<0,0001$ SAT versus PUFA e CON (SAT $n=21$, PUFA $n=22$, CON n=21); Fase $2-\# p<0,0003$ SAT-L versus PUFA-L, PUFA-FO, CON-L e CON-FO; $\$ \mathrm{p}=0,03$ SAT-FO versus CON-FO (SAT-L $\mathrm{n}=11$, SAT-FO n=10, PUFA-L n=12, PUFA-FO n=10, CON-L n=11 e CON-FO n=10). Dados apresentados na forma de média \pm SEM.

Não foram observadas diferenças significativas nas concentrações das frações do colesterol - TG, HDL, LDL, e VLDL (Painéis A, B, C e D; Figura 15). No entanto quando somamos as frações não-HDL verificamos diferença significativa entre os grupos. Na Fase 1, SAT apresentou concentrações significativamente aumentadas quando comparado aos grupos PUFA e CON ( $<<0,0001$; Fase 1 - Figura 16) e o grupo PUFA também foi significativamente maior que o grupo $\operatorname{CON}(\mathrm{p}<0,003$; Fase $1-$ Figura 16). Na Fase 2 as concentrações do grupo SAT-L foram significativamente maiores quando comparado aos demais grupos ( $<<0,0003$; Fase 2 - Figura 16). 
Figura 15 - Efeito da dieta hiperlipídica e da lipectomia na concentração das frações de colesterol de ratos.

A
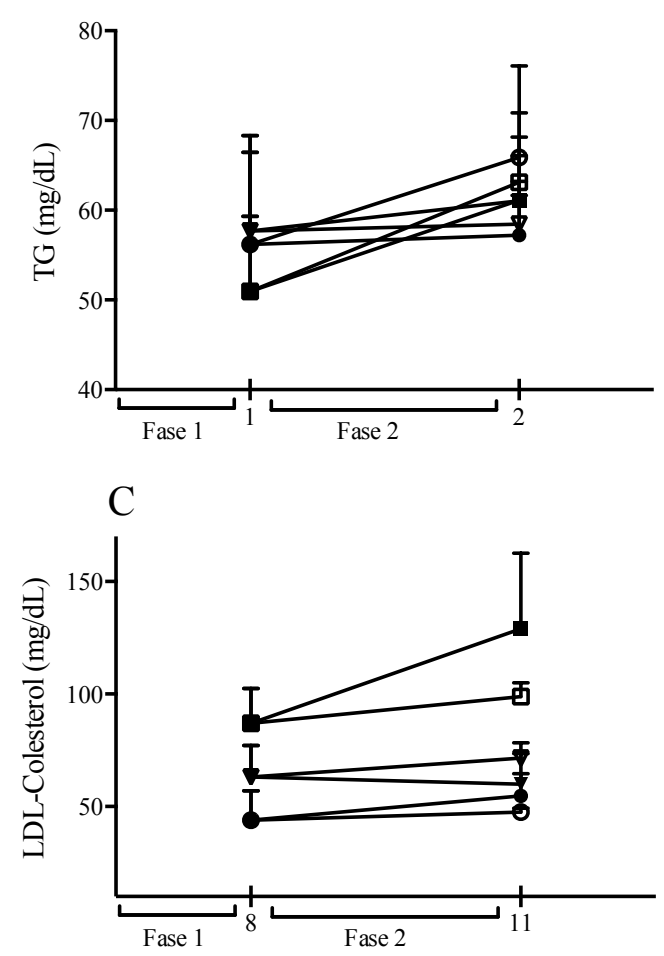

Pré - Pós -

Lipectomia Lipectomia

$\begin{array}{llll}\text { - SAT } & \text { SAT-L } \\ \text { 口AT-FO }\end{array}$

$\nabla$ PUFA- $\nabla$ PUFA-L

- CON. $\boldsymbol{\nabla}$ PUFA-FO
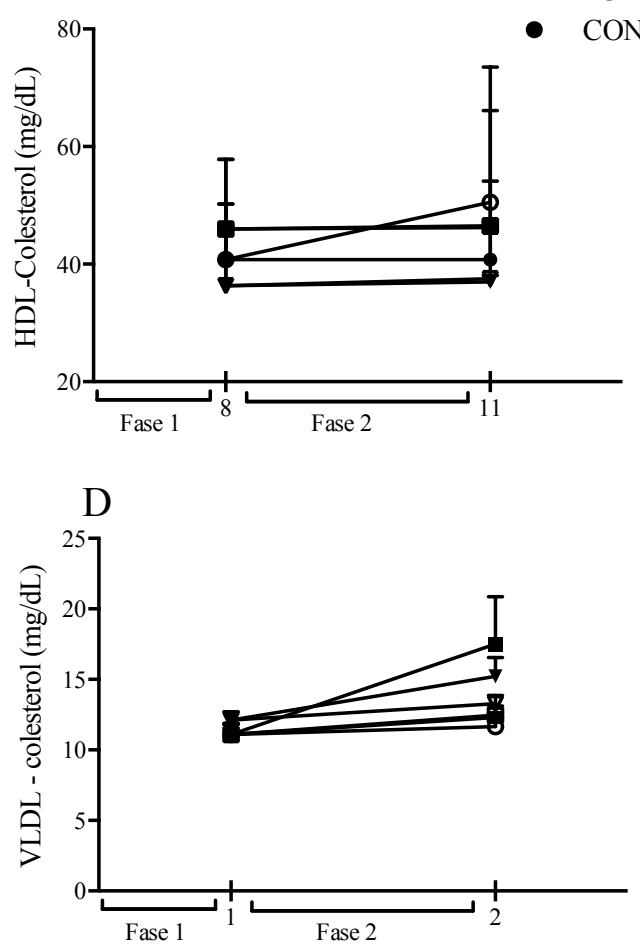

Fase 1 e Fase 2 - sem diferença significativa. Dados apresentados na forma de média \pm SEM (Fase 1 - SAT n= 21, PUFA n=22, CON n=21; Fase 2 - Grupo SAT-L n=11, SAT-FO n=10, PUFA-L n=12, PUFA-FO $n=10$, CON-L n=11 e CON-FO n=10). 
Figura 16 - Efeito da dieta hiperlipídica e da lipectomia na concentração das frações nãoHDL de ratos.

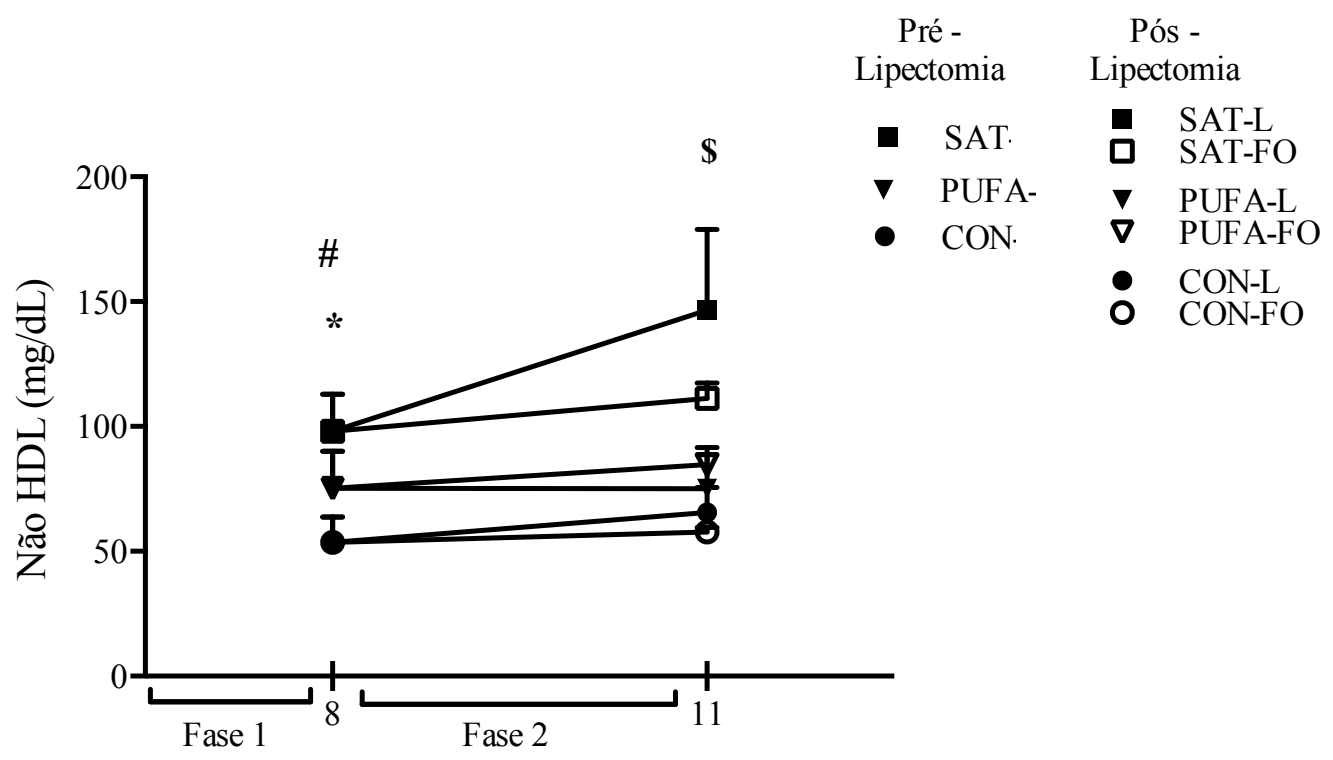

Fase $1-{ }^{*} \mathrm{p}<0,0001$ SAT versus PUFA e CON; $\# \mathrm{p}<0,003$ PUFA versus CON (SAT $\mathrm{n}=21$, PUFA $\mathrm{n}=22$, CON $\mathrm{n}=21$ ); Fase $2-\$ \mathrm{p}<0,0003$ SAT-L versus demais grupos (Grupo SAT-L $\mathrm{n}=11$, SAT-FO $\mathrm{n}=10$, PUFA-L $\mathrm{n}=12$, PUFA-FO n=10, CON-L n=11 e CON-FO n=10). Dados apresentados na forma de média \pm SEM. 
Tabela 5 - Efeitos da dieta hiperlipídica e da lipectomia nas concentrações de colesterol total e frações $\mathrm{mg} / \mathrm{dL}$, em ratos.. Dados apresentados na forma de média \pm SEM.

\begin{tabular}{|c|c|c|c|c|c|}
\hline \multicolumn{6}{|c|}{ Colesterol Total } \\
\hline \multicolumn{2}{|c|}{ SAT } & \multicolumn{2}{|c|}{ PUFA } & \multicolumn{2}{|c|}{$\mathrm{CON}$} \\
\hline \multicolumn{2}{|c|}{$144,1 \pm 4,0$} & \multicolumn{2}{|c|}{$111,6 \pm 4,1$} & \multicolumn{2}{|c|}{$95,8 \pm 4,3$} \\
\hline SAT-L & SAT-FO & PUFA-L & PUFA-FO & CON-L & CON-FO \\
\hline $216,7 \pm 13,2$ & $182,8 \pm 5,6$ & $152,4 \pm 11,2$ & $139,5 \pm 8,9$ & $112,5 \pm 5,8$ & $118,0 \pm 1,1$ \\
\hline \multicolumn{6}{|c|}{ Triglicerídeos (TG) } \\
\hline \multicolumn{2}{|c|}{ SAT } & \multicolumn{2}{|c|}{ PUFA } & \multicolumn{2}{|c|}{$\mathrm{CON}$} \\
\hline \multicolumn{2}{|c|}{$50,9 \pm 2,5$} & \multicolumn{2}{|c|}{$57,6 \pm 3,0$} & \\
\hline SAT-L & SAT-FO & PUFA-L & PUFA-FO & $\mathrm{CON}-\mathrm{L}$ & CON-FO \\
\hline $61,13 \pm 7,0$ & $63,12 \pm 2,9$ & $61,0 \pm 9,8$ & $58,4 \pm 4,7$ & $57,2 \pm 4,4$ & $65,8 \pm 10,1$ \\
\hline \multicolumn{6}{|c|}{ VLDL-colesterol } \\
\hline \multicolumn{2}{|c|}{ SAT } & \multicolumn{2}{|c|}{ PUFA } & \multicolumn{2}{|c|}{$\mathrm{CON}$} \\
\hline \multicolumn{2}{|c|}{$11,1 \pm 0,7$} & \multicolumn{2}{|c|}{$12,1 \pm 0,5$} & \multicolumn{2}{|c|}{$11,0 \pm 0,7$} \\
\hline SAT-L & SAT-FO & PUFA-L & PUFA-FO & $\mathrm{CON}-\mathrm{L}$ & CON-FO \\
\hline $17,5 \pm 3,3$ & $12,4 \pm 0,6$ & $15,2 \pm 1,3$ & $13,2 \pm 0,5$ & $12,3 \pm 0,3$ & $11,6 \pm 0,6$ \\
\hline \multicolumn{6}{|c|}{ LDL-colesterol } \\
\hline \multicolumn{2}{|c|}{ SAT } & \multirow{2}{*}{\multicolumn{2}{|c|}{$\begin{array}{c}\text { PUFA } \\
63,18 \pm 4,0\end{array}$}} & \multirow{2}{*}{\multicolumn{2}{|c|}{$\begin{array}{c}\mathrm{CON} \\
43,93 \pm 4,9\end{array}$}} \\
\hline \multicolumn{2}{|c|}{$87,0 \pm 4,6$} & & & & \\
\hline SAT-L & SAT-FO & PUFA-L & PUFA-FO & CON-L & CON-FO \\
\hline $129,0 \pm 33,5$ & $98,8 \pm 6,1$ & $59,8 \pm 13,7$ & $71,5 \pm 6,8$ & $54,7 \pm 9,8$ & $47,4 \pm 1,7$ \\
\hline \multicolumn{6}{|c|}{ HDL-colesterol } \\
\hline \multicolumn{2}{|c|}{ SAT } & \multicolumn{2}{|c|}{ PUFA } & \multicolumn{2}{|c|}{$\mathrm{CON}$} \\
\hline \multicolumn{2}{|c|}{$45,9 \pm 3,5$} & 36,3 & 2,9 & 40,7 & \\
\hline SAT-L & SAT-FO & PUFA-L & PUFA-FO & $\mathrm{CON}-\mathrm{L}$ & CON-FO \\
\hline $46,2 \pm 7,9$ & $46,5 \pm 19,6$ & $36,9 \pm 8,5$ & $37,5 \pm 0,5$ & $40,7 \pm 6,3$ & $50,54 \pm 2,3$ \\
\hline & & Porção $\mathrm{N}$ & O-HDL & & \\
\hline $\mathrm{S} A$ & & & & & \\
\hline 98,1 & 4,4 & 75,3 & 3,9 & 53,6 & $=3,8$ \\
\hline SAT-L & SAT-FO & PUFA-L & PUFA-FO & $\mathrm{CON}-\mathrm{L}$ & CON-FO \\
\hline $146,5 \pm 32,3$ & $111,2 \pm 6,2$ & $75,0 \pm 13,7$ & $84,8 \pm 6,7$ & $65,6 \pm 9,8$ & $57,7 \pm 1,8$ \\
\hline
\end{tabular}


2.4.6 Conteúdo Hepático de Gordura

Após a lipectomia foi verificado aumento significativo no conteúdo de gordura hepática dos grupos SAT-L versus SAT-FO e PUFA-L ( $<<0,003$; Figura 17). O grupo CON-L apresentou aumento significativo quando comparado ao CFP ( $\mathrm{p}<0,05$; Figura 17).

Figura 17 - Efeito da lipectomia no conteúdo de gordura no fígado em ratos submetidos a diferentes tipos de dieta hiperlipídica.

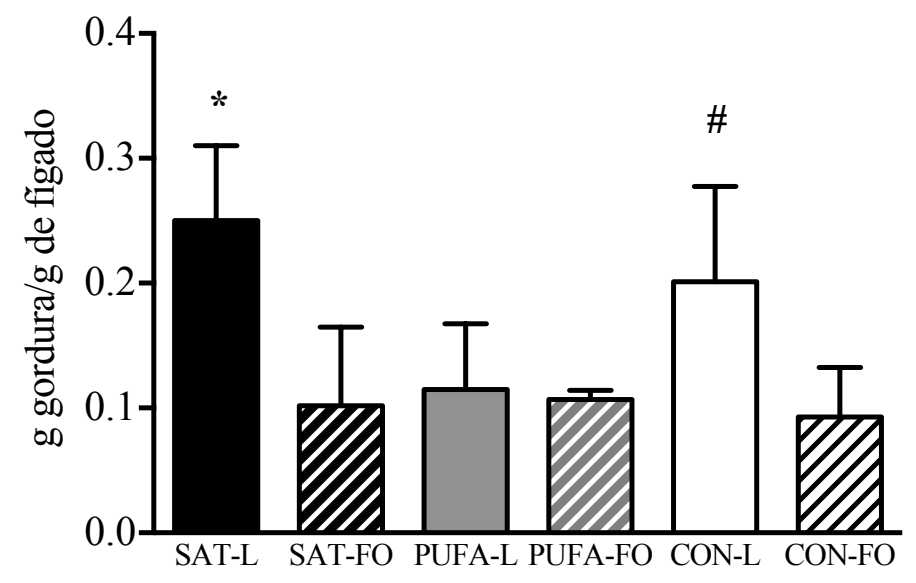

*p $<0,004$ SAT-L versus SAT-FO, PUFA-L, PUFA-FO e CON-FO; \#p=0,03 CON-L versus CON-FO (SAT-L $\mathrm{n}=10$, SAT-FO n=10, PUFA-L n=9, PUFA-FO n=9, CON-L n=11 e CON-FO n=10). Dados apresentados na forma de média \pm SEM.

\subsubsection{Citocinas Plasmáticas}

Na Figura 18, ao analisar as os níveis de citocinas plasmáticas não foi verificada diferença nas concentrações da citocina pró-inflamatória IL-10 (Painel A) e nem nas concentrações da citocina anti-inflamatória IL-10 (Painel B). No entanto houve um aumento significativo nas concentrações de IL-6 n grupo SAT-L quando comparado aos demais grupos ( $<<0,05$; Figura 18 - Painel C). 
Figura 18 - Efeito da dieta hiperlipídica e da lipectomia nas concentrações plasmáticas de citocinas de ratos

A

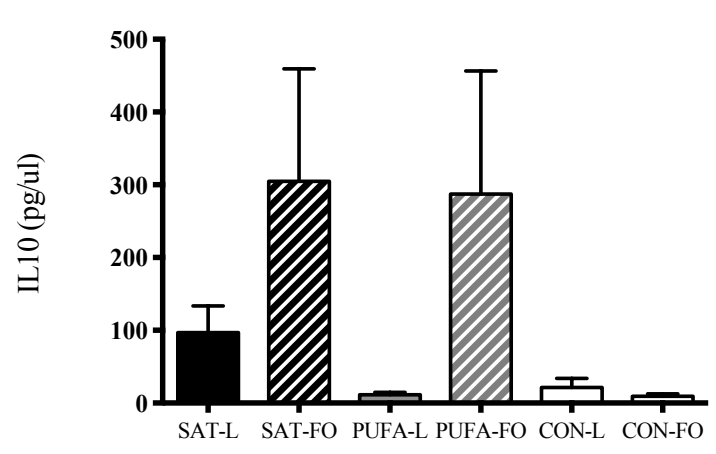

$\mathrm{C}$

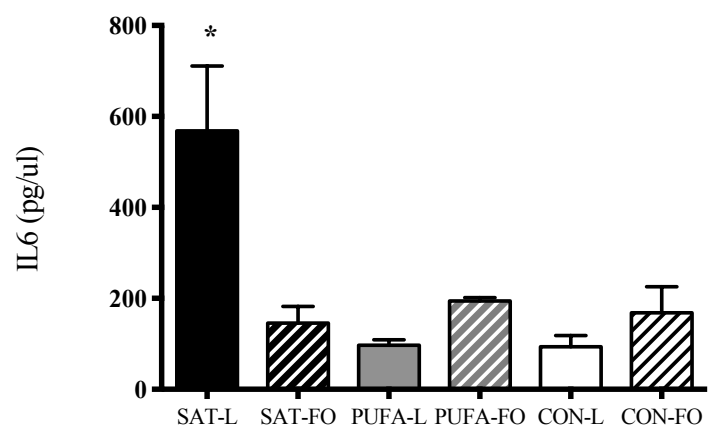

$\mathrm{B}$

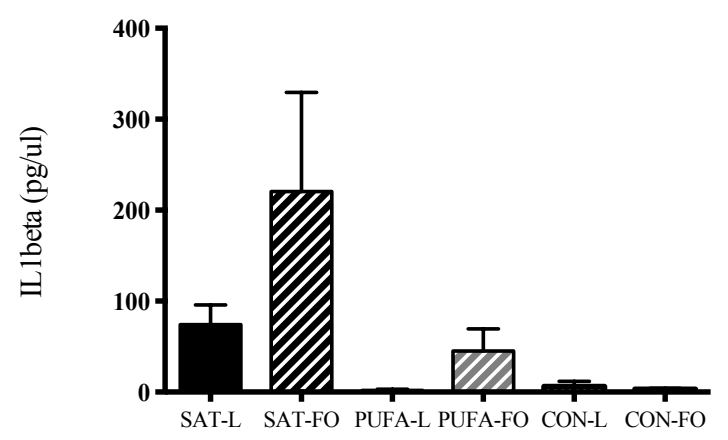

$\mathrm{D}$

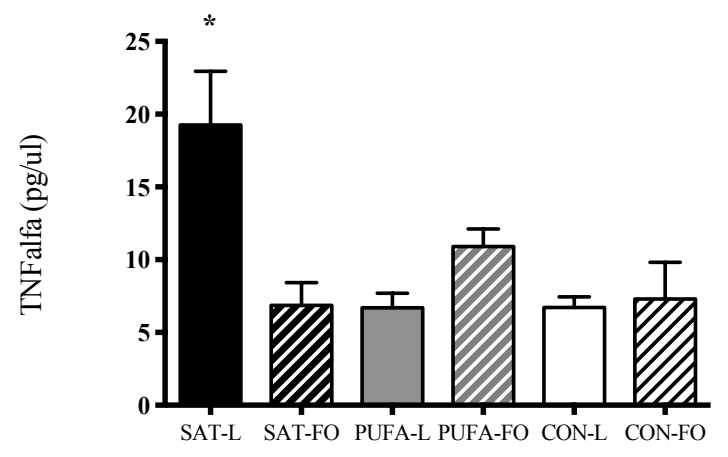

Painel A- Il-10, sem diferença significativa. Painel B - IL-1 $\beta$, sem diferença significativa; Painel C - Il-6, * $\mathrm{p}<0,05$ SAT-L versus demais grupos. Painel D - TNF $\alpha,{ }^{*} \mathrm{p}<0,05$ SAT-L versus SAT-FO, PUFA-L, CON-L e CON-FO. (Grupo SAT-L n=6, SAT-FO $n=6$, PUFA-L $n=6$, PUFA-FO $n=6$, CON-L $n=5$ e CON-FO $n=5$ ). Dados apresentados na forma de média \pm SEM.

\subsection{Discussão}

O presente estudo teve como objetivo avaliar o efeito da lipectomia em ratos submetidos a diferentes tipos de dieta hiperlipídica. Para isso, o mesmo foi dividido em duas Fases. Na Fase 1 o objetivo foi verificar os efeitos de diferentes dietas hiperlipídicas na adiposidade e, na Fase 2, verificar os efeitos da lipectomia nos animais com esse padrão alimentar.

O principal desfecho observado do presente estudo foi que a lipectomia, quando associada a dieta rica em gordura saturada, ocasionou uma pior resistência à insulina e pior 
perfil inflamatório quando comparada aos demais grupos. Estes efeitos parecem estar relacionados ao crescimento compensatório no depósito retroperitoneal observado nesse grupo. Além disso, o consumo de uma dieta rica em gordura poli-insaturada preveniu tais efeitos.

O consumo de dietas hiperlipídicas tem aumentado no mundo todo e tem sido diretamente relacionada com diversas alterações metabólicas (Popkin, 2010; West et al., 1998). Quando associada a um padrão de inatividade física, esse consumo pode ocasionar um balanço energético positivo que leva ao acúmulo de gordura na forma de triacilglicerol no tecido adiposo (Queiroz et al., 2009). Esse acúmulo, quando exacerbado, leva à hipertrofia das células adiposas, alterando sua função autócrina, parácrina e endócrina, agravando ainda mais esse quadro.

a) Fase 1 - Efeitos das diferentes dietas

Antes do início do experimento os animais consumiam dieta padrão/controle e, ao passarem para a dieta hiperlipídica, esses grupos apresentaram um aumento transitório no consumo calórico, o que caracteriza uma hiperfagia, ou seja, um consumo exagerado, comumente ocasionada por esse tipo de dieta. De fato, Savastano et al. (2005) relataram que a ingestão de uma dieta hiperlipídica leva, em curto-prazo, a um consumo calórico excessivo. Na tentativa de entender os mecanismos relacionados a essa alteração, foi demonstrado que este padrão alimentar ocasiona prejuízo na sinalização de alguns hormônios que regulam a fome e a saciedade. Ocorre, por exemplo, diminuição nas concentrações do hormônio CCK (colecistoquinina) (Duca et al., 2013). Além deste efeito, parece ocorrr também um comprometimento no sistema das melanocortinas, um dos responsáveis pela regulação do consumo energético (van den Heuvel et al.; van den Heuvel et al., 2011). Interessante notar que após a primeira semana os animais readequaram seu consumo calórico para o mesmo dos animais que consumiam dieta controle. Esse dado encontrado é consistente com outros estudos que verificaram que, quando oferecida ad libitum, o consumo calórico de ração tende a permanecer semelhante entre animais alimentados com dieta hiperlipídica ou controle (Coelho et al., 2009; Rokling-Andersen et al., 2009).

Após essa primeira semana, o consumo calórico permaneceu semelhante até o final. Associado a esse resultado, não foi observada qualquer diferença nos valores de peso corporal dos animais durante todo o experimento. Esse dado é corroborado por estudos anteriores, tanto do nosso quanto de outros grupos, que não verificaram tal diferença no peso corporal com o consumo de dietas hiperlipídicas em ratos (Coelho et al., 2009; Rokling- 
Andersen et al., 2009; Matsuo et al., 2002) e aves (Newman et al., 2002). No entanto, um dado interessante encontrado no presente estudo foi que, apesar dos grupos apresentarem, de um modo geral, consumo calórico e peso corporal semelhantes, os animais que receberam dieta hiperlipídica rica tanto em SAT quanto em PUFA, apresentaram maior adiposidade quando comparados ao grupo controle.

Analisando o efeito da dieta hiperlipídica na adiposidade, o estudo de Shiraev et al. (2009) utilizou dieta palatável, rica em gordura, que exacerba os efeitos da hiperfagia, oferecida de duas maneiras: ad libitum ou pair feeding, pareando com o consumo calórico do grupo que recebeu dieta controle (14\%VCT provenientes da gordura). Após 14 semanas de experimento, os autores verificaram que o grupo ad libitum apresentou maior consumo calórico, peso corporal e adiposidade que os demais grupos. No entanto, os animais que consumiram a dieta hiperlipídica, mas isocalórica ao grupo controle, apresentaram adiposidade significativamente maior em detrimento do mesmo peso corporal. Este último resultado é ratificado em nosso estudo, no qual, mesmo com peso corporal semelhante, os grupos que consumiram dieta hiperlipídica apresentaram maior adiposidade corporal comparados, ao final do estudo, ao grupo controle. Furnes et al. (2009) avaliaram como ocorreria esse consumo alimentar dos animais. Os autores utilizaram dois grupos experimentais, que se diferenciavam quanto ao teor de gordura (hiperlipídica versus hipolipídica) e, durante 43 semanas, avaliaram dentre outros fatores o consumo calórico, número de refeições e consumo calórico por refeições. Ao final do estudo verificaram que os animais que receberam dieta hiperlipídica, apesar de apresentarem consumo calórico diário semelhante, realizaram menos refeições por dia, porém consumiram o dobro de calorias por refeição. Esses resultados demonstram que além do peso corporal não ser um indicador adequado que padrão de consumo alimentar também exerce um papel importante quando se estuda o efeito de diferentes dietas.

$\mathrm{Na}$ tentativa de entender o aumento de adiposidade observado nos grupos com dietas hiperlipídicas, analisamos os possíveis efeitos da hiperfagia verificada na primeira semana de experimentos com esses animais. Os grupos com dieta hiperlipídica (SAT e PUFA) apresentaram, em média, cerca de $47 \mathrm{mg}$ de gordura/ g peso corporal a mais que o grupo controle (CON). Considerando-se que o peso médio dos animais era em média de $500 \mathrm{~g}$ nessa semana, isso significa cerca de 23,5 g a mais de gordura corporal. Calculando-se o excedente calórico da primeira semana, temos que o grupo controle consumiu uma média de $80 \mathrm{kcal} / \mathrm{dia}$, enquanto os grupos com dieta hiperlipídica apresentaram um consumo de aproximadamente $105 \mathrm{kcal} / \mathrm{dia}$, ou seja, $25 \mathrm{kcal}$ a mais por dia ( 24\% a mais). Se 
considerarmos os sete dias da semana, isso significa que esses grupos consumiram aproximadamente $175 \mathrm{kcal}$ a mais que o grupo controle. Se, somente para fins de cálculo, resolvêssemos extrapolar e considerássemos uma eficiência de $100 \%$ no estoque desse excedente calórico, isso resultaria em uma síntese de 19,4 g de gordura. Considerando ainda que o tecido adiposo não é composto apenas de adipócitos, mas também de água, células vasculares endoteliais, fibroblastos e macrófagos, poderíamos inferir que essa adiposidade aumentada ter-se-ia originado do excesso calórico apresentado no início do estudo. Deste modo, os animais que consumiram proporcionalmente mais gordura foram capazes de acumular mais gordura corporal, independentemente do peso corporal, devido ao maior consumo calórico ocasionado por uma hiperfagia transitória.

Interessante notar que, ao contrário do verificado em alguns estudos, o grupo PUFA, assim como SAT, também apresentou adiposidade aumentada. Este resultado ainda é alvo de muita discussão, uma vez que ao passo que diversos estudos verificam um efeito protetor dos PUFAs na adiposidade (Costa et al., 2012; Rokling-Andersen et al., 2009), outros não verificam este mesmo efeito (Awad et al., 1990). Além disso, cada vez mais os estudos demonstram que, mais importante do que a adiposidade total, é o local de seu acúmulo (Foster et al., 2011a; Prunet-Marcassus et al., 2006; Wajchenberg, 2000) e o tipo de adipócito presente (Smorlesi et al., 2012; Veyrat-Durebex et al., 2011).

De fato, apesar de os grupos apresentarem mesma adiposidade, houve diferença no padrão de aumento nos diferentes depósitos. Ambos os grupos, PUFA e SAT, apresentaram maior acúmulo de gordura no depósito retroperitoneal quando comparados ao grupo controle. Já com relação ao depósito epididimal, o grupo SAT apresentou maior acúmulo quando comparado ao grupo controle. Tal diferença não foi observada no grupo PUFA. Importante destacar que ambos os depósitos, epididimal e retroperitoneal, são considerados como viscerais e diretamente relacionados com as alterações metabólicas associadas à obesidade (Tchernof et al., 2013). Assim como em nosso estudo, So et al., 2011 verificaram que o consumo de dieta hiperlipídica (mistura de banha de porco e óleo de soja) por oito semanas ocasionou aumento da adiposidade e do estoque de gordura visceral em ratos wistar - resultado também observado por McDonald et al., 2011).

Porém, ao contrário do observado em nosso estudo, Newman et al. (2002), estudaram o efeitos de quatro dietas na adiposidade: dieta rica em gordura saturada, rica em ômega-3, rica em ômega-6 e dieta controle. Após cinco semanas, os autores observaram que os animais submetidos às duas dietas ricas em gordura poli-insaturada apresentaram menor adiposidade total e menor estoque de gordura visceral quando comparados ao grupo que 
consumiu gordura saturada - dado esse corroborado pelo trabalho de Nuernberg et al. (2011).

Fickova et al. (1998) verificaram que animais que receberam a dieta rica em ômega-3 apresentaram menor conteúdo de tecido epididimal quando comparados aos com dieta rica em ômega-6. De modo semelhante, Rokling-Andersen et al. (2009) verificaram menor acúmulo dos depósitos viscerais de gordura (mesentérico, perirenal e epididimal) nos ratos submetidos à dieta rica em ômega-3 quando comparados ao grupo que consumiu banha de porco. Costa et al. (2012) obtiveram resultado semelhante e observaram, ainda, que o consumo aumentado de ômega-3 preveniu o aumento de tecido adiposo visceral e ocasionou menor hipertrofia dos adipócitos. Conforme discutido anteriormente, o aumento no estoque de triacilglicerol faz com que o adipócito aumente de tamanho, e prejudique significativamente sua atividade.

Rustan et al. (1998), estudaram o efeito de uma dieta rica em gordura saturada versus uma dieta rica em ômega-3. Após sete semanas, o grupo de animais que consumiu dieta rica em ômega-3 apresentou adipócitos três vezes mais hipertrofiados, contra cinco vezes do grupo que recebeu dieta saturada. Neste estudo foi demonstrado que além da dieta saturada ter ocasionado uma maior hipertrofia do adipócito, este apresentou resposta lipolítica aumentada com relação ao grupo ômega-3 - características que estão relacionadas ao desenvolvimento de parte das alterações metabólicas como dislipidemias, pior tolerância à glicose e esteatose hepática (Item et al., 2012). Isso ocorre porque uma resposta lipolítica aumentada neste depósito ocasiona incremento do influxo de ácidos graxos no fígado, que podem ficar estocados. Além disso, adipócitos hipertrofiados possuem maior infiltração de macrófagos e, como consequência, maior produção de citocinas pró-inflamatórias (Wajchenberg, 2000; McDonald et al., 2011).

Um importante resultado encontrado no presente estudo foi que, apesar do PUFA não ter prevenido o ganho de gordura em alguns depósitos viscerais, o grupo submetido a essa dieta apresentou quantidade aumentada de tecido adiposo marrom quando comparado aos demais grupos. Isto se torna interessante uma vez que este tecido tem sido relacionado como protetor metabólico. Enquanto o adipócito branco teria como função primordial o estoque de energia, o adipócito marrom teria seria o responsável por sua queima (Moreno-Aliaga et al., 2010). Isto se deve principalmente a sua função termogênica, derivada da atividade da UCP1 (uncoupling protein 1 - proteína desacopladora), localizada na membrana interna da mitocôndria, cuja principal função é dissipar o excesso de energia na forma de calor. 
Outros estudos também verificaram acúmulo significativamente maior de tecido adiposo marrom em ratos submetidos à dieta hiperlipídica quando comparados ao grupo controle (Shiraev et al., 2009; So et al., 2011; Takahashi et al., 2000). Uma possível explicação deste efeito deriva de um estudo de Locke, em 1982, no qual foi demonstrado que a UCP-1 parece ter sua atividade regulada pela concentração aumentada de ácidos graxos livres. Estes nutrientes atuariam como ativadores dessa proteína, para serem oxidados por ela. Deste modo, esse depósito conseguiria proteger o organismo do acúmulo excessivo de gordura ectópica e, desse modo, conseguiria até mesmo prevenir alterações metabólicas como a resistência à insulina e dislipidemias (Kozak et al., 2010).

Vale ressaltar que nos estudos supracitados, o aumento de depósito marrom foi verificado em animais que consumiam dietas hiperlipídicas com conteúdo equilibrado de gorduras. Já no presente estudo, esse resultado foi observado apenas no grupo que consumiu dieta rica em gordura poli-insaturada.

De fato, os resultados dos diferentes ácidos graxos nesse depósito são divergentes. Ludwig et al. (2013) estudaram por doze semanas os efeitos de diferentes dietas hiperlipídicas, sendo uma padrão e outra rica em ômega-3. Ao final do estudo, verificaram que os animais do grupo n-3 apresentaram conteúdo diminuído de tecido adiposo marrom interescapular quando comparado ao grupo que recebeu a dieta hiperlipídica padrão. No entanto o grupo n-3 apresentava maior expressão gênica de UCP-1. Sadurskis et al. (1995) estudaram o efeito de dietas normolipídicas mas com conteúdo aumentado de ácidos graxos poli-insaturados e verificaram consequente aumento do conteúdo de UCP-1. Oudart et al. (1997) analisaram o efeitos dos diferentes tipos de ômega-3, EPA, DHA, a mistura entre eles e uma dieta hiperlipídica padrão. Após 4 semanas verificaram que apesar das dietas apresentarem conteúdo similar desse depósito, a dieta rica em ômega-3 resultou em aumentada atividade termogênica mitocondrial em comparação à dieta hiperlipídica padrão. Mercer et al. (1987) também verificaram positivo efeito da atividade termogênica da dieta rica em PUFA.

Analisando todos esses estudos, seria esperado que o consumo de dietas hiperlipídicas induzissem aumento desse depósito adiposo e, consequentemente, modulassem a atividade dessa proteína. Porém este resultado não foi observado no presente estudo, uma vez que os animais que consumiram dieta rica em gordura saturada não apresentam este aumento. Este dado ainda precisa ser confirmado por futuros estudos.

Além dessa habilidade de dissipação energética, o adipócito marrom parece exercer um importante efeito no metabolismo glicídico. Stanford et al. (2013) realizaram 
interessante estudo no qual transplantaram o depósito marrom interescapular de camundongos doadores no tecido adiposo epididimal de camundongos receptores. Dozes semanas após a cirurgia os animais demonstraram melhora significante da sensibilidade à insulina.

No presente estudo, apesar de não observada diferença na glicemia de jejum, foi observada pior tolerância à glicose nos grupos alimentados com dieta hiperlipídica rica em gordura saturada. Tal resultado também foi verificado por Vessby et al. (2001) em ratos submetidos a dieta hiperlipídica rica em ácidos graxos saturados. Do mesmo modo, Storlien et al. (2000) estudaram animais submetidos a diferentes tipos de dietas hiperlipídicas ricas em gordura saturada, e verificaram severa resistência à insulina deste grupo quando comparado ao grupo com dieta controle e ao grupo que recebeu dieta rica em ômega-3. Em sua revisão, Moreno-Aliaga et al. (2010) discutem os efeitos do ômega-3 na melhora da resistência à insulina e citam o importante efeito anti-inflamatório deste ácido graxo. Ainda relatam efeito adicional na atividade secretora do tecido adiposo alterando a secreção de algumas adipocinas que podem atuar neste mecanismo, destacando os efeitos negativos da visfatina, e melhorando a secreção de adiponectina, que está diretamente relacionada com melhora da sensibilidade à insulina. Outro possível mecanismo é descrito por Liu et al. (2013), que verificaram os efeitos na resistência à insulina de diferentes dietas ricas em gordura PUFA com diferentes razões de ômega3/ômega 6 - 1:1 e 1:4 - versus dieta rica em gordura SAT. Assim como no presente estudo, o grupo que consumiu dieta rica em gordura SAT apresentou pior resistência à insulina quando comparado aos dois grupos PUFA.

Além do prejuízo no metabolismo glicídico, tem sido discutido sobre o consumo crônico de dietas ricas em ácidos graxos saturados e sua capacidade de aumentar as concentrações plasmáticas de colesterol, prejudicando o perfil lipídico (Bi et al., 2013; Kromhout et al., 2011). Já a dieta rica em PUFA não apresentou essa mesma alteração. De fato, estudos anteriores demonstraram que esses ácidos graxos também possuem um efeito positivo sobre fatores de risco cardiovascular (Harris et al., 2008; Poudyal et al., 2013). Karanth et al. (2013) relatam que tal efeito pode ser derivado de uma capacidade deste nutriente em inibir a enzima HMG-CoA redutase (i.e., 3-hidroxi-3-metil-glutaril-Coenzyma $A)$, uma das responsáveis pela biossíntese de colesterol.

Todos esses dados estão de acordo com o presente estudo, no qual foi verificado que a dieta rica em gordura saturada ocasionou pior tolerância à glicose - efeito não observado no grupo PUFA. Considerando que os demais parâmetros analisados entre os dois grupos eram similares, supomos que tal prejuízo pode ter sido evitado neste grupo em função da 
capacidade deste ácido graxo em ocasionar maior acúmulo do depósito marrom, conforme analisado. No entanto podemos especular que, no presente estudo, a dieta PUFA pode ter exercido um efeito metabólico protetor.

Através dos dados obtidos, podemos verificar que apesar de peso corporal semelhante, as dietas ricas em gordura ocasionaram aumentado acúmulo de gordura corporal. Este aumento foi resultado da hiperfagia ocasionada por este padrão alimentar. O qual verificamos na primeira semana sem que houvesse redução compensatória da ingestão nas semanas seguintes. Além disso, a dieta rica em gordura saturada resultou em pior tolerância à glicose e aumento das concentrações de colesterol total, ao passo que a dieta rica em gordura poli-insaturada foi capaz de prevenir tais alterações.

\section{Fase 2 - Efeitos da Lipectomia}

Tendo em vista a ampla gama de evidências acerca dos efeitos maléficos do tecido adiposo visceral para a saúde, tem sido proposto que a realização de lipectomia - retirada cirúrgica de parte do tecido adiposo - com consequente diminuição deste estoque, ocasionaria uma melhora do perfil metabólico corporal.

Grande parte dos estudos que utilizaram a lipectomia como estratégia para analisar a regulação de diferentes depósitos de gordura e seus efeitos no perfil metabólico utilizaram animais que consumiam uma dieta padrão, controle. No entanto, sabendo-se que o perfil alimentar de muitos países, entre eles o Brasil, tem mudado nos últimos anos e que o aumento do consumo de gordura desencadeou um grande impacto na regulação metabólica corporal (Monteiro et al., 2007; Queiroz et al., 2009), tornava-se ainda mais relevante estudar a regulação destes depósitos com esse tipo de alimentação.

A quantidade de tecido adiposo epididimal retirado na cirurgia não foi diferente entre os grupos sendo, em média, $1,26 \pm 0,56 \%$ do peso corporal. Essa quantidade está de acordo com a relatada em estudos anteriores, nos quais o percentual retirado na lipectomia variou entre 0,9 a 1,7\% do peso corporal (Barzilai et al., 1999; Hausman et al., 2004; Kim et al., 1999). Apenas o estudo de Gabriely et al. (2002) excedeu essa quantidade, com retirada média de tecido adiposo correspondente a 3,3\% do peso corporal. Esses dados demonstram que o presente estudo realizou retirada média semelhante ao dos demais.

A lipectomia não ocasionou diferenças significativas nem no consumo calórico, nem no peso corporal. Na semana seguinte à cirurgia houve uma queda no consumo calórico dos animais em virtude do trauma cirúrgico, mas essa diminuição não foi diferente entre os grupos. Estudos anteriores verificaram que a lipectomia também pareceu exercer efeito 
mínimo no peso corporal, perceptível apenas nos primeiros dias, mas sendo recuperado ainda na primeira semana (Shi et al., 2007; Shi et al., 2005; Hamilton et al., 1988).

Três semanas após a lipectomia, a adiposidade dos grupos que consumiram dieta hiperlipídica permaneceu menor em comparação aos seus respectivos grupos controle, falso operados. Este resultado nos leva a concluir que este período não foi suficiente para que ocorresse a total reposição do tecido. Poucos estudos utilizaram a lipectomia associada a dietas hiperlipídicas e, os que utilizaram apresentaram resultados semelhantes ao do presente estudo (Bueno et al., 2011; Shi et al., 2004).

Um dado interessante foi que, ao contrário dos grupos que consumiram dieta hiperlipídica, o grupo CON-L apresentou adiposidade final parecida com seu grupo controle, falso operado, CON-FO. É importante destacar que, como a quantidade de gordura retirada na cirurgia foi $31 \%$ menor neste grupo, ele precisaria de um menor crescimento compensatório para igualar seu conteúdo anterior, quando comparado aos demais grupos com dieta hiperlipídica. Levando ainda em consideração que, após a lipectomia, os grupos apresentaram semelhante consumo calórico, podemos ressaltar que a quantidade de tecido adiposo que precisaria ser resposta no grupo CON-L era menor que nos outros grupos lipectomizados, SAT-L e PUFA-L. Este dado está de acordo com o encontrado em outros estudos que demonstram que a gordura é reposta após a lipectomia em animais que consomem dieta padrão (Michel et al., 1999; Shi et al., 2004).

São poucos os estudos de nosso conhecimento que avaliaram o efeito da lipectomia associada a dietas hiperlipídicas: Faust et al. estudaram, em 1977, os efeitos da lipectomia subcutânea de ratos submetidos a dieta hiperlipídica, mesmo procedimento seguido por Foster et al. (2011a). Já no estudo de Bueno et al. (2011), os autores utilizaram dieta hiperlipídica e realizaram lipectomia nos depósitos viscerais, epididimal e retroperitoneal. No entanto, em nenhum desses estudos foi observada a adiposidade total dos animais, apenas os depósitos isolados e, no estudo de Foster, a adiposidade não foi o objeto de estudo.

Ao final da Fase 2, os animais dos grupos lipectomizados apresentaram menor quantidade de tecido adiposo epididimal quando comparados aos respectivos grupos falsooperados. Este resultado demonstrou um efeito duradouro da retirada cirúrgica desse estoque. Demais estudos também verificaram ausência de reposição tecidual e relataram que a lipectomia ocasionou um aumento compensatório na massa do tecido não retirado que resultou na restauração do conteúdo de gordura corporal. 
No presente estudo apenas os animais que consumiram dieta rica em gordura saturada e submetidos a lipectomia (SAT-L) apresentaram crescimento compensatório do depósito retroperitoneal. Ou seja, ocorreu um efeito aditivo da lipectomia associada a esse tipo de dieta.

Este resultado já havia sido observado em estudos anteriores. Mauer et al. (1994) relataram em seu estudo que a retirada de parte do tecido adiposo epididimal de hamsters siberianos resultou em aumento compensatório no tecido adiposo inguinal e retroperitoneal. De fato, essa compensação tem sido bem demonstrada em alguns estudos, mesmo com a utilização de dieta padrão (Foster et al., 2011b; Shi et al., 2004). Apesar do presente estudo não ter observado diferença significativa no aumento deste depósito, uma análise dos dados brutos indica que, antes da lipectomia, este grupo apresentava 9,5mg/g de peso corporal deste depósito. Três semanas após a lipectomia, os valores eram de 12,7 e 10,25 mg/g de peso corporal para os grupos CON-L e CON-FO, respectivamente. Ou seja, um aumento de $3,2 \mathrm{~g}$ para o grupo lipectomizado e de $0,75 \mathrm{~g}$ para o grupo falso operado. Logo, apesar da ausência significativa de diferença na quantidade deste depósito, esses dados nos levam a supor que a adipogênese estava aumentada neste grupo, quando comparado ao seu controle.

Hausman et al. (2004) realizaram retirada bilateral do depósito epididimal em ratos wistar e verificaram crescimento compensatório de diversos depósitos, como retroperitoneal, inguinal e mesentérico. No estudo de Shi et al. (2004), seis semanas após a cirurgia o grupo lipectomizado não apenas recuperou o conteúdo de gordura como, na verdade, apresentou maior adiposidade do que o grupo falso operado. Ou seja, um crescimento compensatório exacerbado. Na tentativa de entender possíveis mecanismos, os autores analisaram o metabolismo energético através do turnover na norepinefrina e concluíram que essa compensação adiposa parece estar relacionada a uma menor termogênese do tecido adiposo marrom interescapular. Levando-se em conta que ambos os estudos utilizaram dieta padrão, podemos supor que uma dieta rica em gordura poderia ter exercido efeitos ainda mais contundentes.

Bueno et al. (2011) estudaram ratos submetidos a dieta hiperlipídica e verificaram que a lipectomia parcial dos depósitos epididimal e retroperitoneal ocasionou aumento da taxa de lipogênese no tecido adiposo marrom quando comparado ao grupo controle. Importante pontuar que, no presente estudo, o grupo que consumiu dieta rica em PUFA apresentou aumento do conteúdo do depósito marrom. Logo podemos supor que este depósito pode ter exercido importante benefício neste grupo. 
Mesmo antes da lipectomia, na primeira fase do estudo, o grupo SAT já apresentava aumento das concentrações de colesterol total. No entanto, a lipectomia parece ter exercido um efeito adicional nos grupos lipectomizados, uma vez que, após a lipectomia, apenas o grupo SAT-L permaneceu com essas concentrações aumentadas. Um possível fator agravante para este resultado provavelmente estaria relacionado ao fato que este mesmo grupo apresentou aumento do conteúdo hepático de lipídios.

Um possível efeito da lipectomia neste parâmetro foi proposto por Bueno et al. (2011). Os autores avaliaram o metabolismo lipídico e verificaram que, mesmo trinta dias após a cirurgia, o grupo lipectomizado apresentava maior atividade da enzima málica. Uma enzima citosólica, responsável pelo fornecimento de NADPH através da conversão de malato em piruvato, que é utilizado na lipogênese. Endo et al. (2007) relatam que outro possível fator responsável pelo aumento de gordura no fígado seria a ação pró-inflamatória do TNF- $\alpha$. Os pesquisadores induziram a produção desta citocina através da injeção de LPS (lipopolissacarídeos) e verificaram o desenvolvimento de esteatose hepático nos animais. Relataram ainda que o TNF- $\alpha$ ocasionou aumento da expressão gênica das enzimas FAS (i.e., fatty acid synthase) e SREBP-1c (i.e., sterol regulatory element binding protein-1c), ambas responsáveis pela lipogênese.

Curiosamente, o grupo que consumiu dieta padrão, CON-L, também apresentou maior conteúdo de lipídios quando comparado ao seu grupo controle, CON-FO. Este resultado nos leva a supor que, assim como no estudo anterior, que utilizou animais que consumiam dieta rica em gordura, talvez a lipectomia também tenha desencadeado um aumento da atividade lipogênica desses animais. No entanto, ao contrário do grupo SAT-L, o grupo CON-L, não apresentou aumento nas concentrações de colesterol. Além disso, outro importante fator que pode ter auxiliado neste quadro foi o aumento compensatório do depósito retroperitoneal. Diversos autores relatam a estreita relação entre o aumentado conteúdo de gordura visceral e o desenvolvimento de esteatose hepática (Bozzetto et al., 2011; Item et al., 2012).

Resultados semelhantes a partir da lipectomia não foram observados nos animais que receberam dieta rica em PUFA. De fato, os resultados obtidos por Jia et al. (2012) demonstraram que o consumo de PUFA possui a capacidade de prevenir a esteatose hepática não alcoólica. Estudo de Nuernberg et al. (2011) verificou que os animais que consumiam dieta rica em ácidos graxos ômega-3 acumulavam gordura preferencialmente no tecido adiposo, em detrimento de outros tecidos, como o fígado. Associando esta característica aos seus efeitos sobre os marcadores inflamatórios, ressaltando seu importante papel anti- 
inflamatório, este ácido graxo tem sido utilizado não apenas na prevenção, mas também no tratamento de alterações metabólicas, como dislipidemias (Rangel-Huerta et al., 2012).

Outra possível explicação seria o fato de que este nutriente teria a capacidade não apenas de diminuir a atividade de enzimas lipogênicas (Teran-Garcia et al., 2007), mas também diminuiria a expressão gênica da SREBP-1c, e estimularia a via lipolítica através do PPAR- $\alpha$ (receptor $\alpha$ ativado por proliferadores de peroxissomas; Clarke, 2001).

Mesmo três semanas após a retirada de gordura não foi observada diferença significativa na glicemia de jejum - resultado este observado também em outros estudos (Coelho et al., 2009; Rokling-Andersen et al., 2009; Shiraev et al., 2009). No entanto, quando verificamos a sensibilidade à insulina, encontramos novamente um efeito aditivo negativo da lipectomia e da dieta rica em gordura saturada que apresentaram pior sensibilidade nos animais desse grupo quando comparados aos dos demais grupos que consumiam diferentes tipos de dieta. Este resultado não havia sido verificado em outros estudos, que apontaram melhora da tolerância à glicose ou da sensibilidade à insulina após a remoção de parte do depósito visceral (Barzilai et al., 1999; Nogalska et al., 2009). Este resultado demonstra novamente a diferente adaptação a esse procedimento em função do tipo de dieta consumido.

Novamente, o crescimento compensatório do depósito visceral pode ter colaborado com este efeito. Conforme já discutido anteriormente, existe uma relação direta entre o acúmulo deste depósito e a resistência à insulina (Chan et al., 2004; Turer et al., 2011). Além disso, como apenas o grupo SAT-L apresentou esse resultado, outra possível explicação pode ser com o importante papel estimulador de respostas pró-inflamatórias deste nutriente, uma vez que ele age como um ativador de TLR4 (toll-like receptor 4), estimulando assim a liberação de citocinas pró-inflamatórias (Liu et al., 2013; Suganami et al., 2009) . Este grupo apresentou concentrações aumentadas tanto de TNF- $\alpha$ quanto de IL-6 que, como será discutido a seguir, estão diretamente relacionadas com as alterações metabólicas verificadas.

De fato, no presente trabalho foi observado que o grupo SAT-L apresentou concentração significativamente aumentadas da citocina pró-inflamatórias TNF- $\alpha$. Este resultado contraria outros dados da literatura, que verificaram que a retirada de parte do tecido adiposo visceral ocasionaria melhora no metabolismo glicolítico (Barzilai et al., 1999; Gabriely et al., 2002; Hausman et al., 2004; Kim et al., 1999). De modo interessante, este grupo apresentou maior expressão gênica do TNF- $\alpha$, citocina pró-inflamatória altamente correlacionada com o aparecimento da resistência à insulina. Ela é expressa em maior 
quantidade no músculo esquelético de homens com resistência à insulina e diabetes, quando comparados a sujeitos sensíveis à insulina Saghizadeh et al. (1996).

Na tentativa de desvendar possíveis mecanismos de ação, Jove et al. (2006) estudaram o efeito in vitro da gordura saturada na expressão do TNF- $\alpha$ e verificaram que houve um aumento de até 2,5 vezes em sua expressão gênica e proteica e que este aumento estaria inversamente correlacionado com as concentrações de GLUT4 e a captação de glicose. Esta diminuição da concentração de TNF- $\alpha$ com concomitante aumento da concentração de GLUT4 já havia sido verificada por Kirwan et al., 2003. Borst et al. (2004) realizaram a administração de um anti-TNF- $\alpha$, que neutraliza o efeito desta citocina, em ratos SpragueDawley e verificaram que a administração deste composto resultou em aumento de mais $60 \%$ na transporte muscular de glicose. Além disso, o TNF- $\alpha$ atuaria também diminuindo a sinalização da insulina. Evidências sugerem que o TNF- $\alpha$ ativa quinases de serina/treonina, que atuam no receptor de insulina e na IRS-1, ocasionando prejuízo na ligação desta proteína com o receptor de insulina e inibindo a propagação do sinal Yu et al. (2005).

Além disso, o TNF- $\alpha$ parece regular a produção de algumas adipocinas, alterando sua secreção. Estudos verificaram que esta citocina possui a capacidade de diminuir a expressão gênica da adiponectina. Esta, por sua vez, relacionada com melhora da sensibilidade à insulina, e de aumentar a expressão das IL-1 e IL-6 (Ruan et al., 2002). De fato, no presente estudo também foi verificada concentração aumentada de IL-6, atuando, mais uma vez, no desenvolvimento do quadro de resistência à insulina.

O aumento na produção dessas citocinas também pode estar relacionado ao aumento da infiltração de macrófagos no tecido adiposo. Estudo realizado em ratos submetidos a dieta hiperlipídica (45\% de gordura) verificou que esta dieta possui a capacidade de aumentar a infiltração de macrófagos em, aproximadamente, 55\% (Weisberg et al., 2003). Este dado se torna relevante devido a evidências que sugerem que a obesidade é um estado inflamatório crônico de intensidade leve (Ito et al., 2007), resultante principalmente da hipertrofia do adipócito e, também, do aumento da atividade de macrófagos residentes no tecido adiposo e de macrófagos infiltrados (Gil et al., 2007). Estudos anteriores já demonstraram que na obesidade o tecido adiposo sofre uma acentuada infiltração de macrófagos (Berg et al., 2005) e que esta infiltração precede ou coincide com o início da resistência à insulina em ratos obesos (Xu et al., 2003).

O mecanismo pelo qual ocorre o recrutamento da infiltração de macrófagos no tecido adiposo ainda não está bem estabelecido, mas a MCP-1 (macrophage chemoattractant protein-1) parece exercer papel fundamental (Yu et al., 2006). Ela é secretada 
principalmente por pré-adipócitos e por adipócitos maduros (Gerhardt et al., 2001) e sua expressão aumenta em animais obesos (Weisberg et al., 2003) e em ratos submetidos a dieta hiperlipídica - aumento este mais severo no tecido adiposo epididimal, em comparação ao inguinal (Chen et al., 2005). Ratos com deficiência de MCP-1 que receberam dieta hiperlipídica apresentaram alterações no metabolismo glicolítico e lipídico e, quando comparados ao grupo controle, também se mostraram menos suscetíveis a desenvolverem obesidade induzida pela dieta (Rull et al., 2007).

Interessante notar que os animais do grupo PUFA novamente não apresentaram as mesmas alterações metabólicas presentes no grupo SAT. Uma possível explicação seria que uma dieta rica em ômega-3 estaria relacionada com menor infiltração de macrófagos no tecido adiposo (Spencer et al., 2013). Este dado é extremamente interessante, uma vez que os macrófagos presentes no tecido adiposo são responsáveis por grande parte da produção das citocinas pró-inflamatórias, como TNF- $\alpha$ e IL-1b, que estão diretamente relacionadas com alterações metabólicas relacionadas ao acúmulo de tecido adiposo visceral. Interessante notar também que os animais do grupo PUFA não apresentaram as mesmas alterações metabólicas presentes no grupo SAT.

Levando em consideração todos esses dados, a dieta hiperlipídica rica em gordura saturada, quando associada a lipectomia, pode ter acarretado hipertrofia dos adipócitos remanescentes e, também, aumento da infiltração de macrófagos que, por sua vez, contribuíram com a maior concentração de citocinas pró-inflamatórias observadas nesse grupo, ocasionando todas as alterações metabólicas verificadas no presente estudo.

Conforme os dados apresentados, podemos concluir que a lipectomia, quando associada a uma dieta rica em gordura saturada, ocasionou efeitos deletérios nos animais testados, como aumento das concentrações de colesterol total, pior sensibilidade à insulina e aumento do conteúdo hepático de gordura. Estes efeitos parecem estar associados ao aumento compensatório do depósito retroperitoneal e ao aumento das concentrações das citocinas pró-inflamatórias TNF- $\alpha$ e IL-6. No entanto, quando a lipectomia foi associada a uma dieta rica em ácidos graxos poli-insaturados, estes efeitos negativos não foram observados. Este resultado nos leva a concluir que este padrão alimentar ocasionou um efeito protetor através do aumento do conteúdo de tecido adiposo marrom e melhor perfil inflamatório. 


\section{CAPÍTULO 3 - ESTUDO 2: O EFEITO DE DIFERENTES DIETAS HIPERLIPÍDICAS NA COLITE ULCERATIVA INDUZIDA POR DEXTRANO SULFATO DE SÓDIO}

\subsection{Revisão de Literatura}

\subsubsection{Doenças Inflamatórias Intestinais}

As doenças inflamatórias intestinais (DII) possuem etiologia desconhecida, mas sabese que suas causas são multifatoriais. Em geral são caracterizadas por uma susceptibilidade genética associada a uma alteração na mucosa intestinal que, por sua vez, ocasiona uma exacerbação da resposta inflamatória (Ordás et al., 2012). Essa alteração da mucosa intestinal pode ser causada por alguns fatores, como padrões alimentares, higiene e medicamentos (Wong et al., 2013).

Até o presente momento não se tem relato de cura para as DII. Elas são caracterizadas pela alternância de episódios de atividade da doença com episódios de remissão e incluem a Retrocolite Ulcerativa (RU) e a Doença de Crohn (DC) (Fiocchi, 2012).

A RU é uma doença inflamatória intestinal crônica que compromete o reto e o cólon e se caracteriza por uma exacerbada resposta inflamatória desregulada que, normalmente, está presente apenas na superfície da mucosa (Ordás et al., 2012). Ela é caracterizada pela infiltração de neutrófilos, acompanhada de uma necrose das células epiteliais e ulceração (Kono et al., 2010). Apesar de sua causa ainda ser desconhecida, sabe-se que existe um importante papel genético e ambiental associados à ela (Ko et al., 2013).

Assim como em outras doenças, o tratamento de primeira escolha é medicamentoso e composto pelo uso de corticoides e do ácido aminosalicílico, que inibem as enzimas fosfolipase A2, ciclooxigenase (COX) e 5-lipoxigenase, suprimindo a síntese de mediadores inflamatórios como prostaglandina E2 e leucotrieno B4. A aspirina também possui papel importante, inibindo a produção de $\mathrm{COX}$ e a síntese de tromboxanos A2, diminuindo a agregação plaquetária. Deste modo, todos esses medicamentos exercem um efeito antiinflamatório (Uchiyama et al., 2013). Tais efeitos são importantes, pois nas DIIs há uma produção exacerbada de eicosanoides pró-inflamatórios, principalmente de prostaglandina E2 e leucotrienos B4. No entanto, é importante notar que ambos são derivados principalmente do metabolismo do ácido araquidônico (ARA), um ácido graxo poli- 
insaturado da família do ômega-6 (C20:4n-6; James et al., 2000).

Muito se tem estudado sobre os efeitos do consumo de ácidos graxos poli-insaturados exacerbando a doença, como no caso do ácido araquidônico, ou protegendo contra ela, no caso do consumo de uma dieta rica em ômega-3 (Ananthakrishnan, 2013). E, de fato, em populações que passaram pela transição nutricional, adotando um perfil alimentar mais ocidentalizado, com aumentado consumo de gorduras mas baixo consumo de ômega-3, houve um aumento concomitante dos casos de DII (Wong et al., 2013).

\subsection{2 Ácidos Graxos Poli-insaturados e Retrocolite Ulcerativa}

Os ácidos graxos podem ser divididos em saturados, monoinsaturados e poliinsaturados. Dentre os ácidos graxos poli-insaturados (PUFA), as duas principais categorias são: ácidos graxos ômega-3 (n-3) e ácidos graxos ômega-6 (n-6).

Enquanto os n-3 são conhecidos por exercer um importante papel anti-inflamatório, o n-6 parece exercer um papel pró-inflamatório. Levando isso em consideração, alguns autores sugerem que um consumo de 3:1 (n-6:n-3) seria o ideal e que um aumento no consumo de n6, característico de dietas ocidentais, ocasionaria um desbalanço que propiciaria o desenvolvimento de um quadro pró-inflamatório (Sharma, 2009).

$\mathrm{Na}$ tentativa de avaliar essa hipótese, Tyagi et al. (2012) estudaram diferentes razões de ômega6:ômega-3 na resposta inflamatória de ratos com RU induzida por DSS. Foi verificado que uma razão de 2:1 seria a ideal, por ocasionar uma redução significativa na concentração de citocinas pró-inflamatórias como o fator de necrose tumoral $\alpha$ (TNF- $\alpha$ ), interleucina-1 $\beta$ (IL-1 $\beta$ ) e melhora dos escores inflamatórios verificados nos cortes histológicos.

Uchiyama et al. (2013) analisaram a taxa de ômega6:ômega 3 dos eritrócitos de pacientes em fase inicial de Doença de Crohn e, de fato, verificaram maior concentração de ômega-6, mais especificamente de ácido araquidônico, quando comparados a indivíduos sadios. Os autores sugerem um papel importante da dieta alterando essa composição de AG das membranas, podendo, desta maneira, retardar a resposta inflamatória alterada desses pacientes.

Tais efeitos benéficos de um aumento no consumo de PUFA estariam relacionados a três fatores (Chapkin et al., 2009):

- Supressão da produção de eicosanoides pelo ácido araquidônico;

- Melhora da permeabilidade da membrana plasmática; 
- Modulação da ativação de receptores nucleares como fator nuclear kappa $\beta$ (NF-k $\beta$ ).

Atuando dessa maneira, os PUFAs poderiam exercer um efeito benéfico, até mesmo acelerando o processo de cicatrização do epitélio intestinal (Calder, 2008). Ruthig et al. (2002), relatam que os AG n-3 parecem atuar diretamente através da estimulação do TGF- $\beta$ (fator de crescimento transformador $-\beta$ ), estimulando a cicatrização epitelial pela modulação da atividade de monócitos e macrófagos e também aumentando a produção de colágeno e a vascularização epitelial.

Dentre todos os ácidos graxos ômega-3, dois tipos merecem destaque: o ácido eicosapentaenóico (EPA) e o ácido docosaexaenóico (DHA), ambos presentes em grandes quantidades no óleo de peixe. De Silva et al. (2012) analisaram a dieta de pacientes com RU e verificaram um aumento no conteúdo de ácido araquidônico e outros tipos de ômega-6 relativo à dieta nos sujeitos com retrocolite ulcerativa, ao passo que indivíduos com aumentado consumo de ômega-3, principalmente de DHA, pareceram sofrer um efeito protetor.

Este efeito benéfico do ômega-3 seria que seus ácidos graxos, principalmente o EPA, seriam preferencialmente incorporados nas membranas celulares, diminuindo, assim, a quantidade de ARA, o que levaria à diminuição da síntese de eicosanoides pró-inflamatórios (Cabre et al., 2012). De fato, diminuir a quantidade ARA na membrana é um efeito benéfico, uma vez que esse ácido graxo estimula a resposta inflamatória nas DIIs, além de aumentar o tempo de cicatrização (Jacobi et al., 2012).

No interessante estudo de Jia et al. (2008), os autores induziram a RU por cinco dias com dextrano sulfato de sódio (DSS) em camundongos transgênicos que expressavam a enzima fat-1 ( $n$-3 fatty acid desaturase). Essa enzima catalisa a conversão de n-6 em n-3 através da adição de uma dupla ligação na cadeia carbônica. Após duas semanas do término da indução, na fase de recuperação, foi observado que apenas o grupo fat-1 apresentou melhora dos parâmetros de perfil inflamatório quando comparado aos camundongos selvagens. Verificaram também o grupo fat-1 apresentava menor número de macrófagos, e o n-3 suprimiu diretamente o desenvolvimento de células do sistema imune $\mathrm{T}$ helper - que estão diretamente ligadas com o início e a progressão da RU (Mudter et al., 2011).

Grimstad et al. (2012) utilizaram ratos wistar com RU induzida por DSS para avaliar os possíveis efeitos preventivos de uma dieta rica em n-3. Sete dias após o término da indução da doença, foi verificado que o grupo que consumiu dieta rica em n-3 apresentava maiores concentrações desse ácido graxo no tecido colônico. Além disso, foi verificado um efeito anti-inflamatório e protetor através de uma redução na concentração de marcadores 
oxidativos e preservação do comprimento do cólon.

Barros et al. (2011) avaliaram o efeito de dietas hiperlipídicas ricas em n-3 (óleo de peixe) e n-6 (óleo de soja) na inflamação colônica induzida por DSS e verificaram que uma mistura desses óleos foi o método mais eficaz para alcançar um melhor perfil inflamatório.

Outro estudo conduzido com dieta enteral rica em n-3 e/ou rica em triglicerídeos de cadeia média verificou que, após duas semanas de intervenção, a mistura de ácidos graxos resultou em uma menor concentração de citocinas pró-inflamatórias como fator de necrose tumoral $\alpha(\mathrm{TNF}-\alpha)$ e interleucina $1 \beta$ (IL-1b) e menor atividade da mieloperoxidase (Kono et al., 2010).

Apesar de alguns resultados positivos, nem todos os trabalhos foram capazes de verificar esse mesmo padrão. Middleton et al. (2002) estudaram os efeitos da suplementação de n-3 por doze meses em pacientes com RU em estágio de remissão e não verificaram qualquer diferença entre o grupo suplementado e o grupo placebo (óleo de girassol). Feagan et al. (2008) também não verificaram efeito benéficos da suplementação de n-3 na remissão de pacientes com Doença de Crohn (doença inflamatória que acomete todo o intestino).

Por isso, devido aos diferentes resultados encontrados, faz-se necessária a realização de estudos adicionais, que verifiquem, de modo aprofundado, a relação entre os lipídios da dieta e retrocolite ulcerativa.

\subsection{Objetivo}

Este estudo teve como objetivo avaliar o efeito do consumo de uma dieta rica em ácidos graxos poli-insaturados, principalmente do tipo ômega-3, no perfil inflamatório e na progressão da retrocolite ulcerativa em camundongos.

\subsection{Materiais e Métodos}

\subsubsection{Protocolo Experimental}

\subsubsection{Animais e Dieta}

Foram utilizados camundongos da linhagem C57B16, com seis semanas de vida. Eles foram mantidos durante todo o procedimento em um biotério isolado no Laboratório "Physiologie de la nutrition et du comportement alimentaire" na AgroParisTech/INRA (Institut National de la Recherche Agronomique) em Paris, França. 
Os animais permaneceram uma semana em período de aclimatação e, após esse período, foram divididos em três grupos experimentais que diferiam conforme o tipo de dieta recebida, conforme exposto nas Tabelas 1 e 2 (Capítulo 2), a saber:

- Dieta controle (CON);

- Dieta hiperlipídica rica em gordura saturada (SAT);

- Dieta hiperlipídica rica em gordura poli-insaturada (PUFA).

O experimento teve duração de 10 dias, sendo cinco de indução da doença (ítem 3.3.2) e cinco de recuperação. Durante esse tempo os animais permaneceram em gaiolas individuais e receberam água e ração, ad libitum, conforme o grupo a que pertenciam, com aferição diária das quantidades consumidas. Após o período experimental os animais foram eutanasiados por deslocamento cervical. O cólon foi retirado e pesado vazio, e seu comprimento foi aferido com o auxílio de uma régua. Após essas análises, foram retiradas alíquotas de sua porção distal, para posteriores análises conforme descrito a seguir.

\subsubsection{Indução da Retrocolite por meio de Dextrano Sulfato de Sódio (DSS)}

A retrocolite ulcerativa foi induzida através de uma solução de DSS oferecida $a d$ libitum por cinco dias consecutivos, com concentração de 3,5\% (Sprong et al., 2010). Durante os dias de indução não foi oferecida água. Após esse período, a solução de DSS foi retirada e, então, feito o acompanhamento dos animais por mais cinco dias, durante o período de recuperação.

\subsubsection{Escores Inflamatórios e Índice de Atividade da Doença (IAD)}

Os escores inflamatórios e o IAD são importantes ferramentas para o conhecimento do grau de comprometimento da doença. Para sua determinação foram utilizadas as seguintes variáveis: análise diária da consistência das fezes e presença de sangue nas fezes, que foram pontuadas conforme os valores presentes na Tabela 6 .

O IAD foi calculado diariamente conforme descrito por Sanchez-Fidalgo et al. (2013) através de diferentes parâmetros: porcentagem de perda do peso corporal, consistência fecal e presença de sangue nas fezes. A descrição de cada um desses parâmetros utilizados estão descritos na tabela abaixo: 
Tabela 6 - Critérios utilizados para o cálculo do Índice de Atividade da Doença.

\begin{tabular}{|c|c|c|c|}
\hline Score & Consistência & Presença de Sangue & \% Perda de Peso Corporal \\
\hline 0 & Normal & Ausente & $<2 \%$ \\
\hline 1 & $\begin{array}{l}\text { Mole/gruda no fundo } \\
\text { da caixa }\end{array}$ & Quase imperceptível & $>=2 \%-<5 \%$ \\
\hline 2 & Pastosa/sem formato & Visível & $>=5 \%-<10 \%$ \\
\hline 3 & $\begin{array}{c}\text { Diarreia intensa } \\
\text { (aguada) }\end{array}$ & $\begin{array}{l}\text { Sangue por todo o cólon } \\
\text { e fezes }\end{array}$ & $>=10 \%-<15 \%$ \\
\hline
\end{tabular}

\subsubsection{Atividade da Mieloperoxidase}

A atividade da mieloperoxidase (MPO), importante marcador de estado inflamatório, foi realizada a partir de uma amostra de $0.5 \mathrm{~cm}$ de cólon obtido no dia da eutanásia. Os tecidos foram homogeneizados em uma solução de HTAB (i.e., hexadecyltrimethylammonium bromide) $0,5 \%$, pH 6.0. A uma alíquota de $50 \mu \mathrm{L}$ desse homogenato foram adicionados $200 \mathrm{ml}$ de uma solução com o-dianisidina. O cálculo foi realizado através da mudança na absorbância a $460 \mathrm{~nm}$ no período de $10 \mathrm{~min}$.

\subsubsection{Histologia}

Foi utilizado corte de $2 \mathrm{~cm}$ do cólon distal, que foi fixado com solução de paraformoldeído a $10 \%$ por 24 horas. Após esse período as amostras permaneceram submersas em uma solução de álcool a 75\%. A fixação e coloração feitas, hematoxilinaeosina (HE), foram realizadas por um laboratório especializado que fica situado no Hospital Cochin, Paris, França e a avaliação histológica foi realizada por um físiologista, cego para os grupos experimentais. Os cortes foram avaliados através de escores de lesão epitelial e inflamação, conforme proposto por Jia et al. (2008), descritos na Tabela 7. 
Tabela 7 - Escores de lesão tecidual e inflamação utilizados para avaliação dos cortes histológicos.

\begin{tabular}{cl}
\hline \hline Escores & Inflamatório \\
\hline 0 & Presença ocasional de células inflamatórias na lâmina própria \\
1 & Aumentado número de células inflamatórias na lâmina própria \\
2 & Confluência de células inflamatórias, estendendo-se por toda a submucosa \\
3 & Células inflamatórias completamente infiltradas \\
Escores & Lesão Tecidual \\
\hline 0 & Sem lesão na mucosa \\
1 & Discreta lesão linfoepitelial \\
2 & Erosão da superfície da mucosa ou ulceração focal \\
3 & Extensa lesão da mucosa a níveis mais profundos da parede intestinal \\
\hline \hline
\end{tabular}

\subsubsection{Expressão Gênica}

Foi realizada a análise da expressão gênica por RT-PCR da interleucina 10 (IL-10), fator de necrose tumoral- $\alpha$ (TNF- $\alpha$ ), IL-6, IL-1 $\beta$, ocludina (OCLN), Claudina (CLDN), interferon- $\gamma$ (IFNg) e tight junction protein 1 (TJP1). A extração de RNA foi realizada na porção distal do cólon conforme método Trizol ${ }^{\circledR}$.

O RNA total foi extraído com o reagente Trizol ${ }^{\circledR}\left(100 \mathrm{mg}\right.$ de tecido/ $1 \mathrm{ml}$ Trizol $\left.{ }^{\circledR}\right)$, homogeneizado em aparelho Politron e incubado por 10 minutos à temperatura ambiente. As amostras foram precipitadas com $200 \mu \mathrm{L}$ de clorofórmio e centrifugadas por 15 minutos a 12000rpm a $4^{\circ} \mathrm{C}$ para a obtenção do RNA total (Fase superior). Este RNA total foi precipitado com $500 \mu \mathrm{L}$ de álcool isopropílico e incubado por 10 minutos à temperatura ambiente. Os pellets, agora visíveis, foram lavados com etanol 75\% e as amostras centrifugadas por 5 minutos a $7500 \mathrm{rpm}$, a $4{ }^{\circ} \mathrm{C}$. O álcool foi então removido e os pellets secos à temperatura ambiente por 15 minutos. Após essa etapa as amostras foram solubilizadas em água-DEPC. Para avaliação da concentração e pureza do RNA total, foi

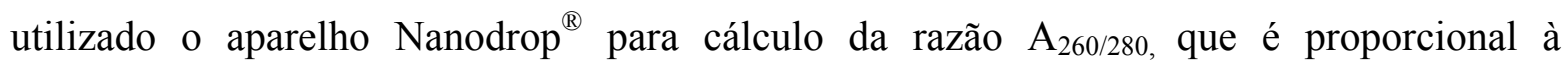
concentração de RNA total na amostra (Sambrook et al., 1989).

Foi então gerado o cDNA por transcrição reversa: incubação de $2 \mu \mathrm{g}$ de OligoDTs $(0,05 \mu \mathrm{g} / \mu \mathrm{L})$ e $2 \mu \mathrm{L}$ de transcriptase reversa (M-ML Reverse Transcriptase 20U, Gibco), completando com Água-DEPC para $20 \mu \mathrm{L}$ de volume total da reação, por 10 minutos a $4^{\circ} \mathrm{C}$, em termociclador (Gene Amp®, PCR system 9700). 
Em seguida, o cDNA foi amplificado a partir da adição do Mix de dNTPs Mix, RT MMLV, M DTT e 5x Buffer (M-MLV RT) (Promega, WI, EUA) às amostras e incubando-as em termociclador, a $42^{\circ} \mathrm{C}$ por 60 minutos (união dos nucleotídeos para formação e amplificação de cDNA) e a $95^{\circ} \mathrm{C}$ por 10 minutos (inativação da enzima RT).

Para a realização do PCR, $2.5 \mu \mathrm{l}$ de cDNA, foram adicionados a 7,5mix $\mu 1 \mathrm{com}$ SYBR-Green (Life Technologies, CA, EUA), primer sense e antisense e água. Todas as reações de amplificação foram realizadas em termociclador Rotor Gene-Q (Quiagen). O valor de $\triangle \mathrm{CT}$ foi obtido pela subtração do valor de CT do gene de interesse pelo valor de CT de HPRT (gene de referência). Para cada gene, o valor médio dos $\triangle \mathrm{CT}$ no tempo PRE (média de todos os sujeitos) foi então subtraído do valor de $\Delta \mathrm{CT}$ de cada sujeito, gerando o valor de $\Delta-\Delta \mathrm{CT}$. A expressão do gene foi então avaliada pelo fold do gene $\left(2^{-\Delta-\Delta \mathrm{C}} \mathrm{T}\right)$.

\subsubsection{Análise Estatística}

Para aferir consumo de DSS, peso corporal, consumo calórico e escores inflamatórios, foi realizada análise de variância conforme critérios Schwarz Bayesian para medidas repetidas, Mixed Models para 2 fatores (dieta e tempo), seguido por teste post hoc de Tukey, quando necessário. Para as demais análises foi realizado o GLM (general linear model de 1 fator - dieta), em função do número amostral ser desigual entre os grupos. Os dados foram expressos na forma de média \pm erro padrão $(\mathrm{SEM})$ e os resultados foram considerados significantes quando $\mathrm{p} \leq 0,05$. As análises foram realizados com o auxílio do software SAS 9.1.

\subsection{Resultados}

\subsubsection{Consumo de DSS}

A retrocolite ulcerativa foi induzida através de uma solução de DSS que foi oferecida por 5 dias consecutivos e, houve diferença no consumo entre os grupos, apenas no quarto dia, no qual o grupo CON consumiu uma quantidade significativamente maior de DSS quando comparado aos grupos SAT e PUFA ( $<<0.002$, Figura 19). 
Figura 19 - Efeito de diferentes dietas hiperlipídicas no consumo de DSS.

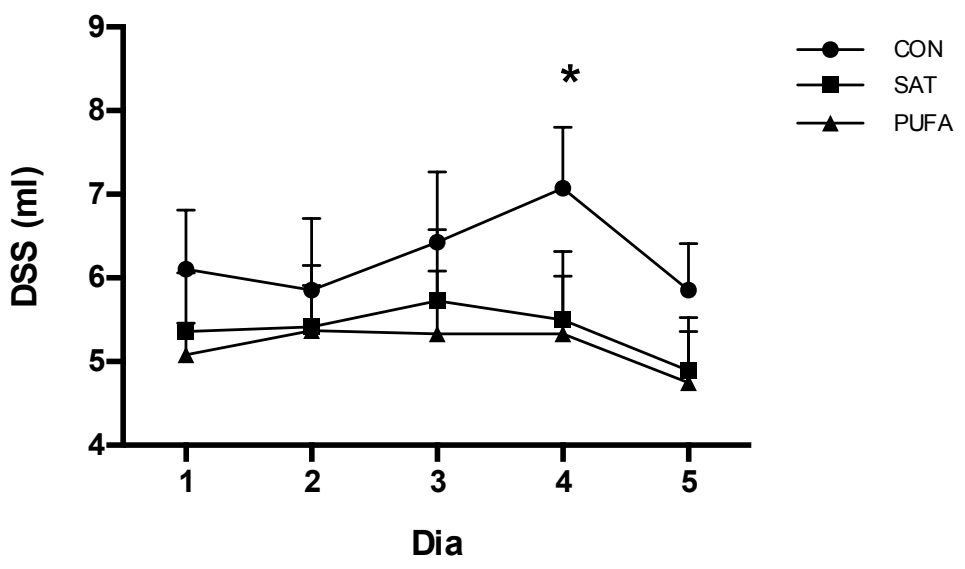

${ }^{*} \mathrm{p}<0.002 \mathrm{CON}$ versus SAT e PUFA. Dados apresentados como média $\pm \mathrm{SEM}$, (SAT= dieta hiperlipídica rica em gordura saturada, $\mathrm{PUFA}=$ dieta hiperlipídica rica em gordura poli-insaturada, $\mathrm{CON}=$ dieta controle).

\subsubsection{Sobrevida}

Todos os grupos iniciaram com o mesmo número de camundongos $(\mathrm{n}=16)$. No entanto, com a progressão da doença foi verificada uma diferença significativa $(p<0.05)$ do efeito da dieta na qual o grupo PUFA apresentou menor sobrevida, 56.25\%, quando comparado aos demais grupos: $75 \%$ para o grupo SAT e $87,5 \%$ para o grupo CON (Figura 20). 
Figura 20 - Efeitos de diferentes dietas hiperlipídicas na sobrevida de camundongos com retrocolite ulcerativa induzida por DSS.

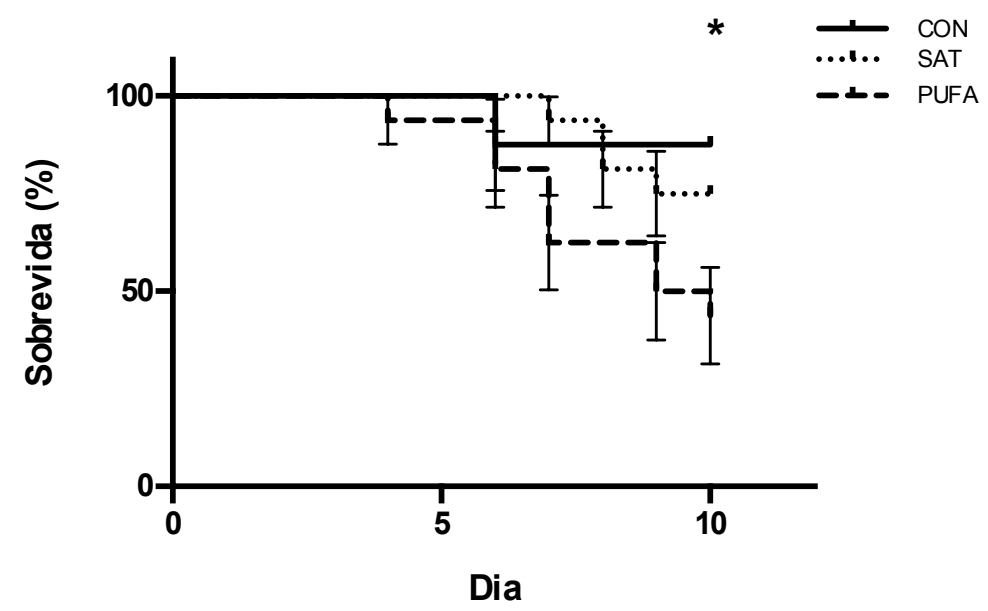

* $\mathrm{p}<0.05$ PUFA versus SAT e CON. Dados apresentados como média $\pm \mathrm{SEM}$ (PUFA= dieta rica em gordura poli-insaturada, $\mathrm{SAT}=$ dieta rica em gordura saturada, $\mathrm{CON}=$ dieta controle).

\subsubsection{Consumo Alimentar e Peso Corporal}

O consumo alimentar e o peso corporal foram aferidos diariamente. O consumo calórico foi relativizado conforme o peso corporal e se manteve similar entre os grupos durante grande parte do experimento, apresentando diferença significativa apenas no nono dia, no qual o grupo PUFA apresentou consumo significativamente menor quando comparado ao grupo $\mathrm{CON}(\mathrm{p}=0.01$, Figura 21$)$. 
Figura 21 - Efeitos de diferentes dietas hiperlipídicas no consumo alimentar de camundongos com retrocolite ulcerativa induzida por DSS.

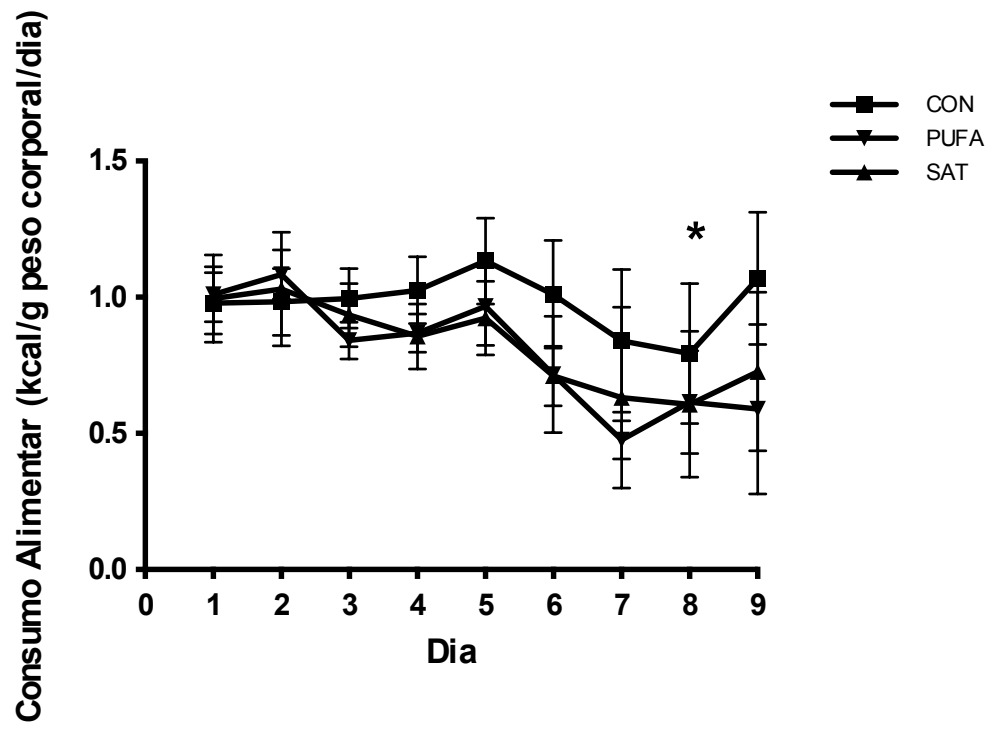

${ }^{*} \mathrm{p}=0.01$ PUFA versus CON. Dados apresentados como média $\pm \mathrm{SEM}$ (PUFA $=$ dieta rica em gordura poliinsaturada; $\mathrm{SAT}=$ dieta rica em gordura saturada; $\mathrm{CON}=$ dieta controle).

Sendo esta uma doença altamente debilitante, o principal foco com relação ao peso corporal foi verificar se algum procedimento seria capaz de alterar sua perda. Sendo assim, o peso corporal está expresso em porcentagem de perda de peso corporal diário. Neste quesito o grupo PUFA apresentou maior perda de peso no nono dia quando comparado aos demais grupos $(\mathrm{p}=0.0001$, Figura 22). 
Figura 22 - Efeitos de diferentes dietas hiperlipídicas na perda de peso corporal de camundongos com retrocolite ulcerativa induzida por DSS.

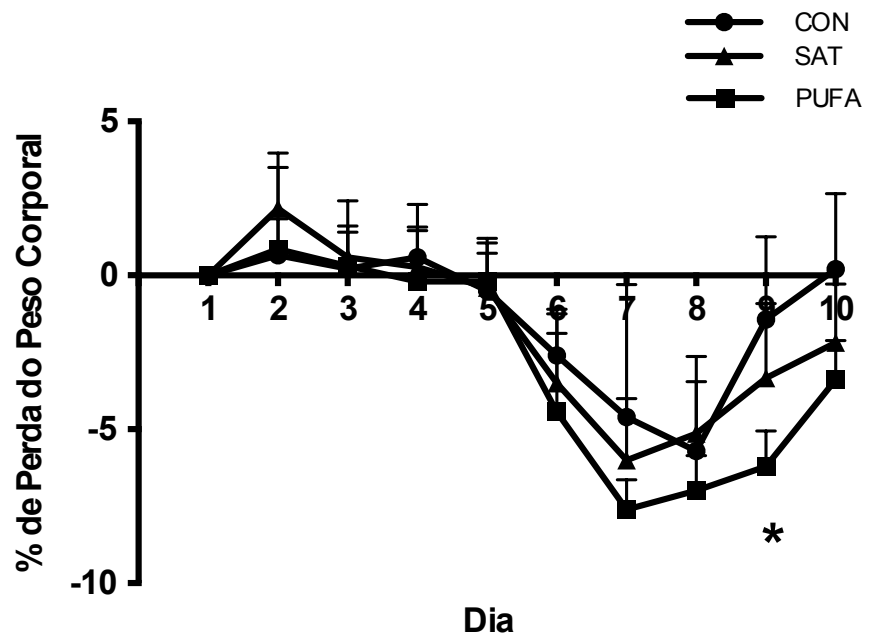

* $\mathrm{p}=0.0001$ PUFA versus SAT e CON. Dados apresentados como média \pm SEM (PUFA $=$ dieta rica em gordura poli-insaturada, $\mathrm{SAT}=$ dieta rica em gordura saturada, $\mathrm{CON}=$ dieta controle).

3.4.4 Escores Inflamatórios e Índice de Atividade da Doença

Com o objetivo de avaliar o grau de comprometimento da doença, foi realiza análise diária das consistências das fezes (Painel A, Figura 23), presença de sangue (Painel C, Figura 23) e, após o término, foi feito o cálculo da área abaixo da curva para os dois parâmetros (Painéis B - Consistência e Painel D - Presença de Sangue). 
Figura 23 - Efeito de diferentes tipos de dieta hiperlipídica em escores inflamatórios de camundongos com retrocolite ulcerativa induzida por DSS.
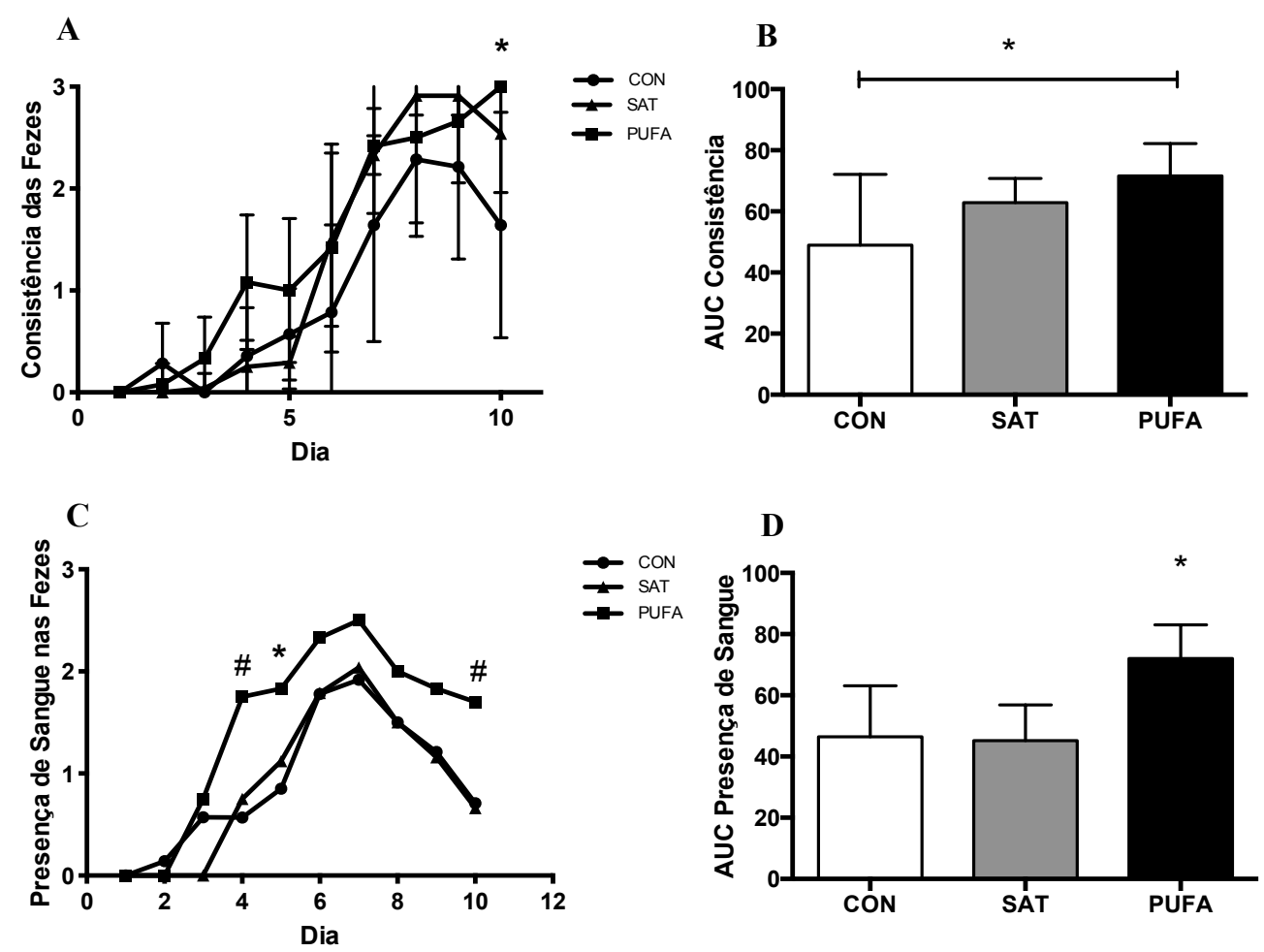

Painel A - Escore diário da consistência das fezes, *p $<0.05$ PUFA versus CON. Painel B - AUC da consistência das fezes, * ${ }^{*}<0.02$ PUFA versus CON, Painel C - Escore diário da presença de sangue nas fezes, $\# \mathrm{p}<0.05$ PUFA versus CON e SAT e, ${ }^{*} \mathrm{p}<0.05$ PUFA versus CON. Painel D - AUC da presença de sangue nas fezes, $* \mathrm{p}<0.05$ PUFA versus SAT e CON. Dados apresentados como média \pm SEM (PUFA= dieta rica em gordura poli-insaturada, $\mathrm{SAT}=$ dieta rica em gordura saturada, $\mathrm{CON}=$ dieta controle).

Assim como nos escores inflamatórios isolados, o grupo PUFA também apresentou um pior IAD, sendo, no quarto dia, significativamente maior $(\mathrm{p}<0.05)$ que os dos demais grupos. No oitavo dia o IAD deste grupo permaneceu aumentado apenas quando comparado ao grupo $\mathrm{CON}$ ( $\mathrm{p}=0.04$, Figura 24 - Painel A). Ao realizarmos a análise do impacto geral do IAD através do cálculo da área abaixo da curva, foi observado que o grupo PUFA apresentou um índice significativamente mais elevado do que quando comparado aos demais grupos ( $p<0.005$ Figura $24-$ Painel B). 
Figura 24 - Efeitos de diferentes dietas hiperlipídicas no Índice de Atividade da Doença (IAD) de camundongos com retrocolite ulcerativa induzida por DSS.
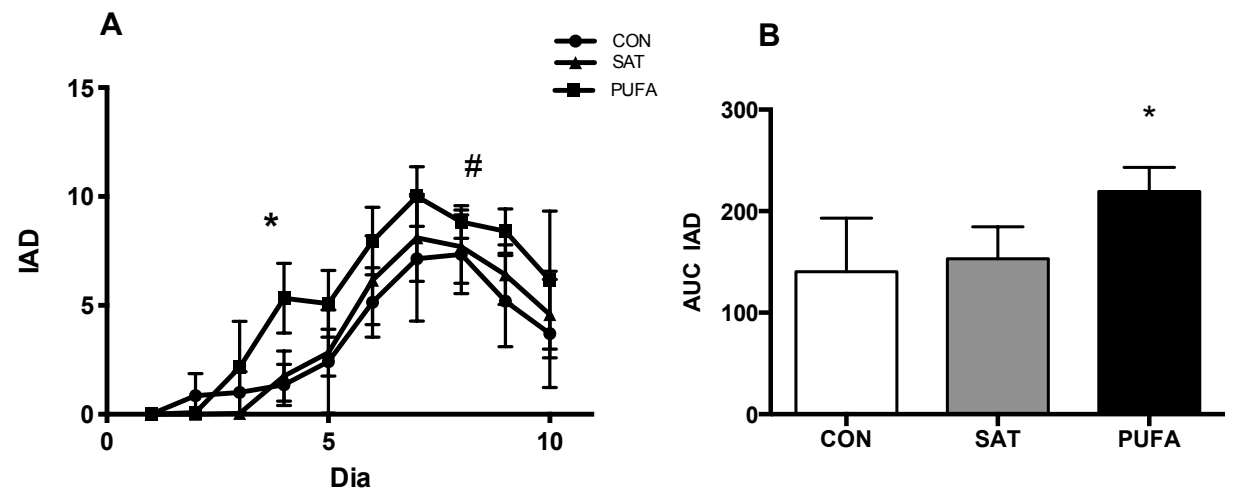

Painel A: IAD, ${ }^{*} \mathrm{p}=0.0001$ PUFA versus $\mathrm{SAT}$ e $\mathrm{CON}$ e $\# \mathrm{p}<0.05$ PUFA versus $\mathrm{CON}$. Painel $\mathrm{B}=$ Área abaixo da curva do IAD, ${ }^{*} \mathrm{p}=0.005$ PUFA versus $\mathrm{SAT}$ e CON. Dados apresentados como média $\pm \mathrm{SEM}$ (PUFA= dieta rica em gordura poli-insaturada, $\mathrm{SAT}=$ dieta rica em gordura saturada, $\mathrm{CON}=$ dieta controle).

\subsubsection{Comprimento e Peso do Cólon}

Os dados morfológicos do cólon são importantes indicadores do estado de sua estrutura e função. A dieta rica em PUFA resultou em um cólon significativamente maior quando comparado aos demais grupos (Figura 25 - Painel A, $<<0.03$ ). No entanto, este mesmo cólon estava também significativamente mais leve (Figura 25 - Painel A, $\mathrm{p}<0.03$ ). 
Figura 25 - Efeitos de diferentes dietas hiperlipídicas no comprimento e peso do cólon de camundongos com retrocolite ulcerativa induzida por DSS.

A

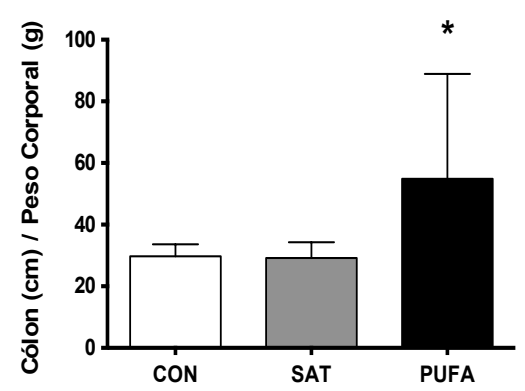

B

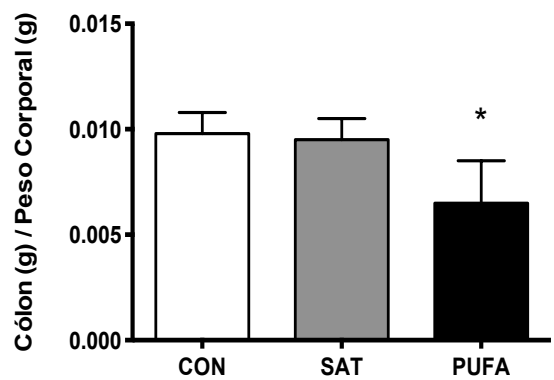

Painel A - Comprimento do cólon relativo ao peso corporal, * ${ }^{*}<0.03$ PUFA versus SAT e CON. Painel B Peso do cólon relativo ao peso corporal, ${ }^{*} \mathrm{p}<0.05$ PUFA versus SAT e CON. Dados apresentados como média \pm SEM (PUFA $=$ dieta rica em gordura poli-insaturada, $\mathrm{n}=6$; $\mathrm{SAT}=$ dieta rica em gordura saturada, $\mathrm{n}=11$; $\mathrm{CON}=$ dieta controle, $\mathrm{n}=7$ ).

\subsubsection{Atividade da Mieloperoxidase}

A dieta rica em gordura saturada ocasionou um aumento significativo $(p<0,03)$ da atividade MPO (Figura 26, Painel A) comparado aos demais grupos, quando relativo à quantidade de proteínas presentes no cólon. Já quando essa atividade foi expressa relacionada ao peso do cólon, esse aumento da atividade foi significativo apenas quando comparado ao grupo CON ( $p=0,04$; Figura 26, Painel B). 
Figura 26 - Efeitos de diferentes dietas hiperlipídicas na atividade da mieloperoxidase de camundongos com retrocolite ulcerativa induzida por DSS.
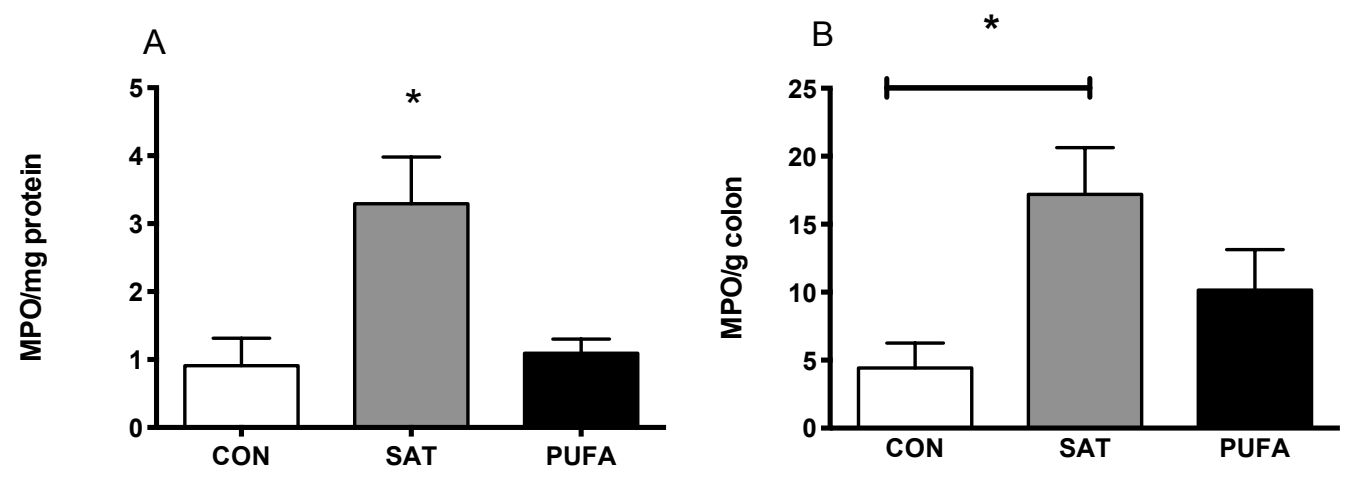

Painel A - MPO/mg de proteínas, *p $<0.05$ SAT versus PUFA e CON; Painel B - MPO/g cólon, * $<<0.05$ SAT versus $\mathrm{CON}$ (PUFA $=$ dieta rica em gordura poli-insaturada, $\mathrm{n}=6$; $\mathrm{SAT}=$ dieta rica em gordura saturada, $\mathrm{n}=11$; $\mathrm{CON}=$ dieta controle, $\mathrm{n}=7$ ).

\subsubsection{Expressão Gênica}

A avaliação da expressão gênica realizada no cólon demonstrou que o grupo que consumiu dieta rica em gordura saturada apresentou piores marcadores inflamatórios quando comparados ao grupo controle $(\mathrm{TNF}-\alpha$, IL-6; $\mathrm{p}<0,05)$ ou quando comparados a ambos os grupos CON e PUFA (INF- $\gamma ; \mathrm{p}<0,04)$ 
Figura 27 - Efeitos de diferentes dietas hiperlipídicas na expressão gênica de citocinas inflamatórias em camundongos com retrocolite ulcerativa induzida por DSS.
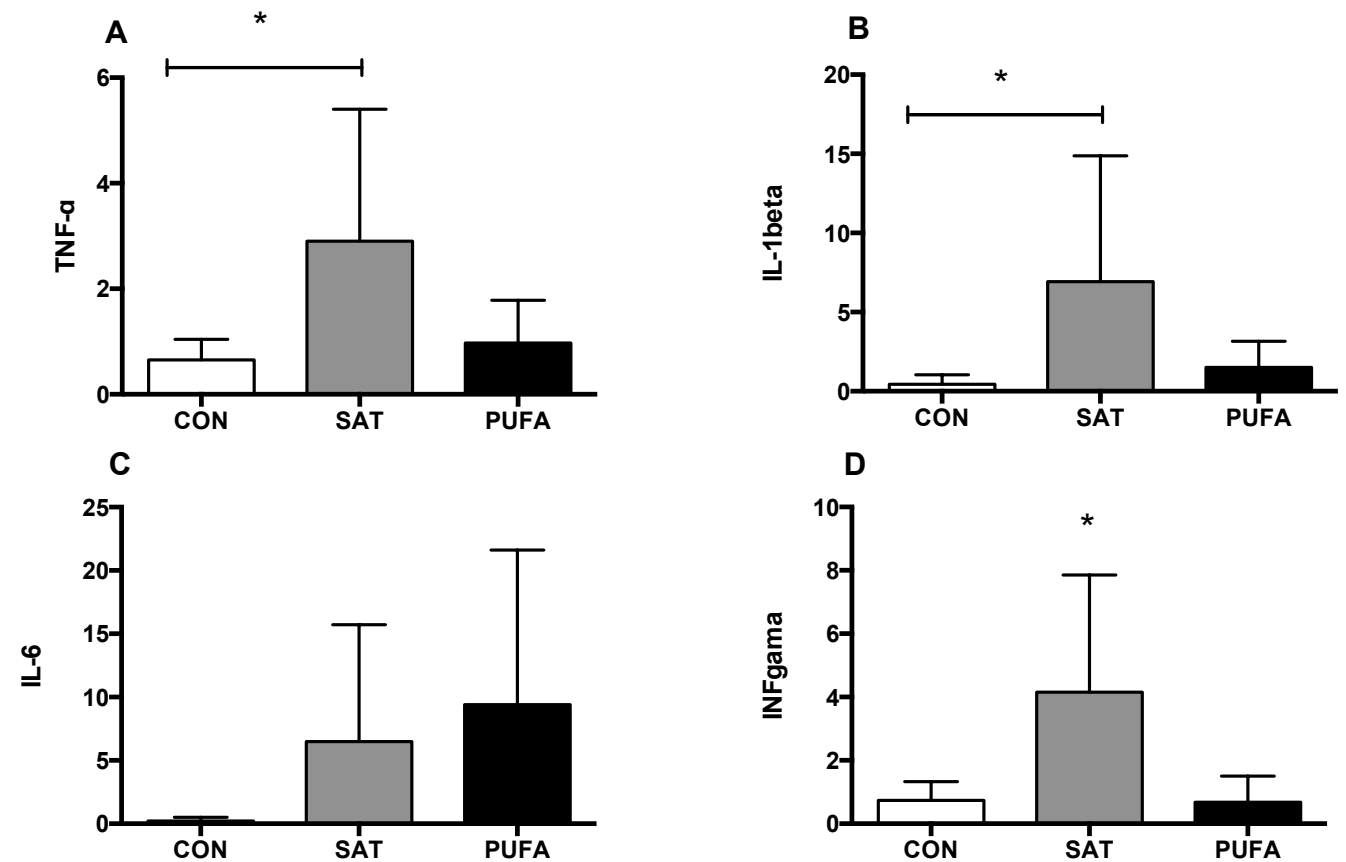

Painel A - TNF- $\alpha,{ }^{*} \mathrm{p}<0.05$ SAT versus CON; Painel B - IL-1 $\beta,{ }^{*} \mathrm{p}<0.05$ SAT versus CON; Painel C - IL-6, sem diferença significativa; Painel D - INF- $\gamma,{ }^{*}$ p $<0.04$ SAT versus CON e PUFA (PUFA $=$ dieta rica em gordura poli-insaturada, $\mathrm{n}=6 ; \mathrm{SAT}=$ dieta rica em gordura saturada, $\mathrm{n}=8 ; \mathrm{CON}=$ dieta controle, $\mathrm{n}=6$ ).

$\mathrm{Na}$ análise da expressão gênica dos marcadores de permeabilidade intestinal foi verificado que o grupo CON apresentou expressão gênica significativamente maior de TJP-1 quando comparado ao grupo SAT $(\mathrm{p}<0,05)$. 
Figura 28 - Efeitos de diferentes dietas hiperlipídicas na expressão gênica de marcadores de permeabilidade intestinal em camundongos com retrocolite ulcerativa induzida por DSS.
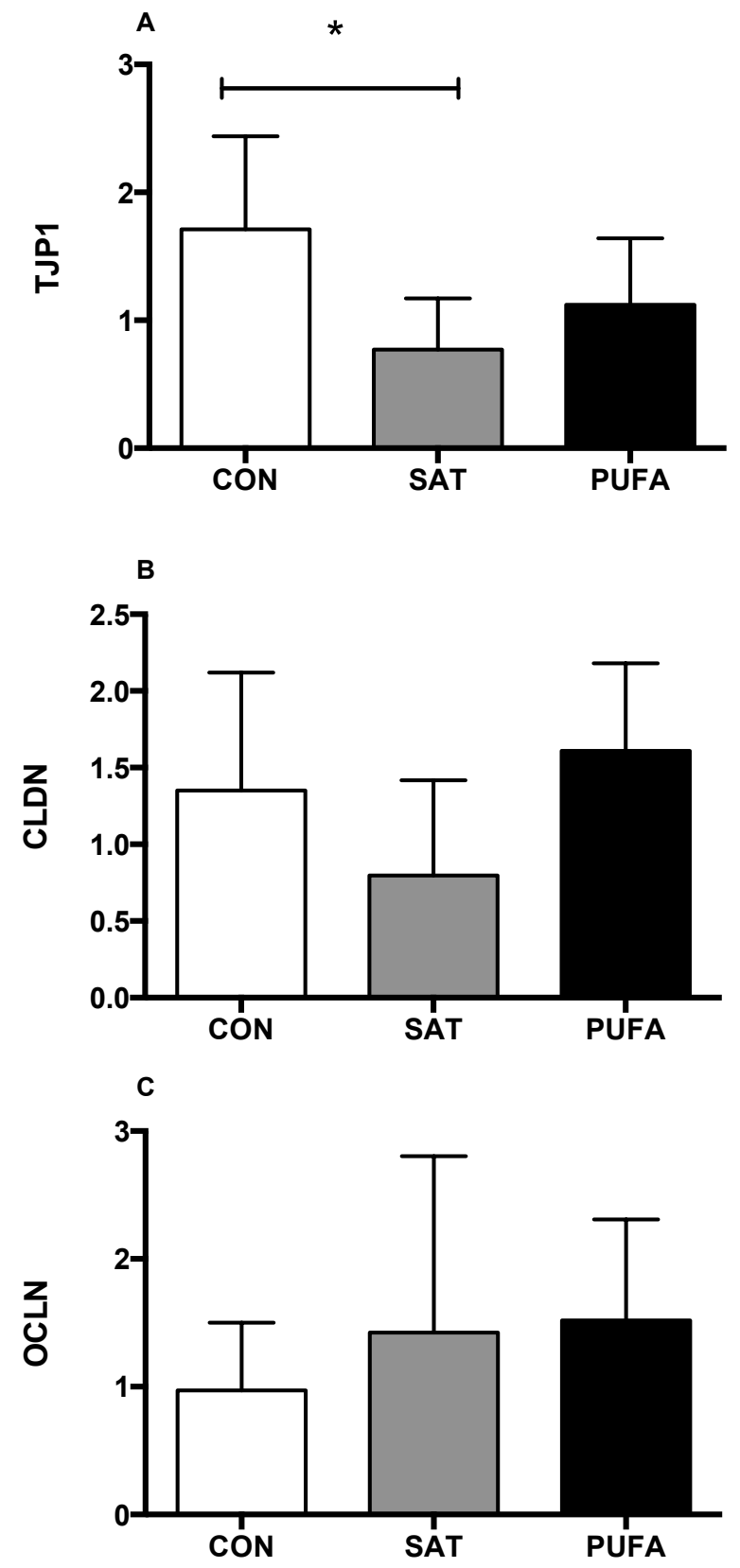

Painel A - Tight Junction Proteins ${ }^{*} \mathrm{p}<0.05$ CON versus SAT; Painel B - Claudina, sem diferença significativa; Painel C - Oclunina, sem diferença significativa (PUFA= dieta rica em gordura poli-insaturada, $\mathrm{n}=6 ; \mathrm{SAT}=$ dieta rica em gordura saturada, $\mathrm{n}=8 ; \mathrm{CON}=$ dieta controle, $\mathrm{n}=6$ ). 


\subsubsection{Histologia}

A avaliação histológica demonstrou que a dieta rica em PUFA ocasionou grande prejuízo colônico: criptas ausentes ou malformadas, redução do número de células goblet e moderada infiltração de células inflamatórias (Figura 29). Através dos escores histológicos foi verificado que o grupo PUFA, apesar de não obter diferença significativa no escore inflamatório $(\mathrm{p}>0,2)$, apresentou importante aumento de lesão tecidual quando comparado ao grupo SAT ( $\mathrm{p}=0,01$; Figura 30 ).

Figura 29 - Efeitos de diferentes dietas hiperlipídicas nos cortes histológicos de camundongos com retrocolite ulcerativa induzida por DSS.

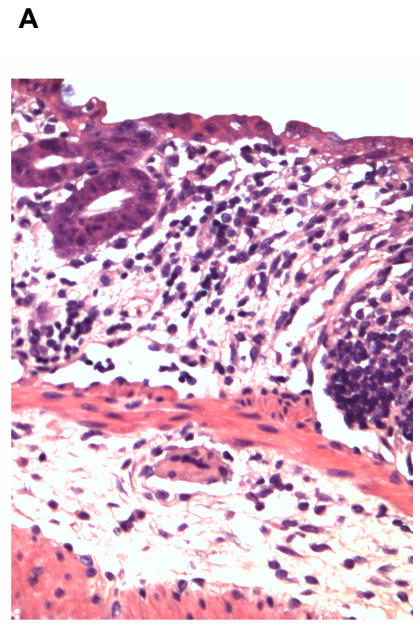

B

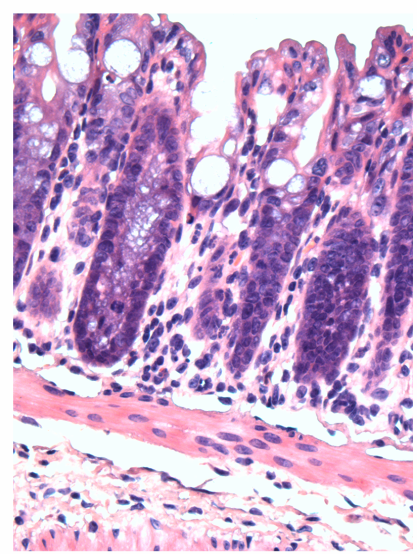

C

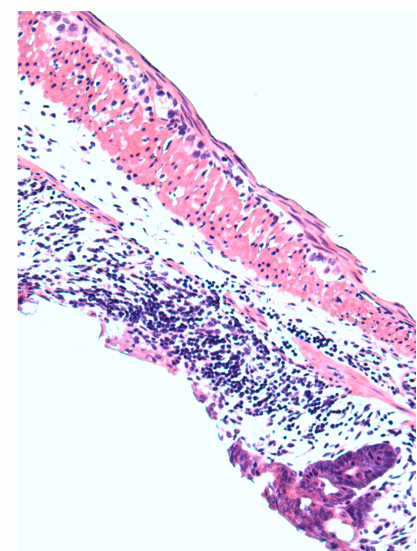

Painel A - dieta controle ( $\mathrm{n}=7)$; Painel B - dieta rica em gordura saturada $(\mathrm{n}=7)$; Painel C - dieta rica em gordura poli-insaturada $(n=6)$. Imagens com aumento de $40 X$. 
Figura 30 - Efeitos de diferentes dietas hiperlipídicas nos escores histológicos de camundongos com retrocolite ulcerativa induzida por DSS.
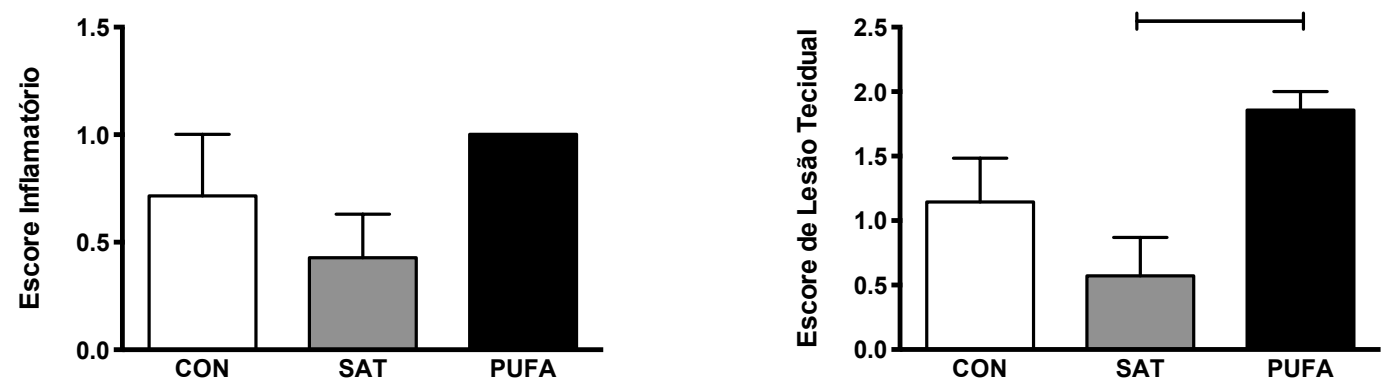

Painel A - Escore Inflamatório, sem diferença significativa; Painel B - Escore de Lesão Tecidual, ${ }^{*} \mathrm{p}<0,05$ PUFA versus SAT (PUFA= dieta rica em gordura poli-insaturada, $\mathrm{n}=5 ; \mathrm{SAT}=$ dieta rica em gordura saturada, $\mathrm{n}=6 ; \mathrm{CON}=$ dieta controle, $\mathrm{n}=6$ ).

\subsection{Discussão}

Este estudo teve como objetivo avaliar o efeito do consumo de diferentes dietas hiperlipídicas na progressão da doença e no perfil inflamatório de camundongos com retrocolite ulcerativa induzida por DSS.

O principal achado do presente estudo foi que, ao contrário do esperado, o grupo de animais ao qual foi administrada a dieta rica em gordura poli-insaturada apresentou piora dos escores inflamatórios e, até mesmo, maior incidência de óbito, quando comparado aos demais.

A retrocolite ulcerativa (RU) é uma doença inflamatória do intestino grosso que compromete grande parte do reto e cólon. É uma doença crônica, altamente debilitante, proveniente de uma desregulação e uma exacerbação da resposta inflamatória alternada com fases de remissão da doença (Ordás et al., 2012). Devido à dificuldade de seu estudo, modelos experimentais de indução da retrocolite são comumente utilizados. Dentre eles, a utilização de DSS é uma das mais bem aceitas e estudadas (Melgar et al., 2005).

No presente estudo, apenas no quarto dia de indução da doença o consumo de DSS foi maior no grupo CON quando comparado aos demais grupos. Apesar dessa diferença, o consumo de DSS foi suficiente para a indução da RU, conforme pode ser verificado pelos escores inflamatórios, que consistiam em aferição da perda de peso corporal, consistência das fezes e presença de sangue. Com relação a progressão da doença, verificamos que o 
grupo PUFA apresentou maior comprometimento quando comparado aos demais grupos, fato este que pode ser observado devido ao menor consumo calórico e à maior perda de peso corporal (Barrett et al., 2013; Huang et al., 2013; Sann et al., 2013).

Os escores inflamatórios, como consistência das fezes e presença de sangue, demonstram que o grupo PUFA de fato apresentou piores parâmetros quando comparados ao grupo NP - dado ratificado pelo IAD, que também demonstrou que o grupo PUFA estava com maior comprometimento da doença. Deste modo verificamos um efeito negativo do consumo de uma dieta rica em PUFA nesse animais. Em função dessas alterações, reflexos da progressão da doença, este grupo apresentou óbito de $43.75 \%$. Tal dado não era esperado, uma vez que alguns estudos verificam benefícios do uso de PUFA em animais com RU (Camuesco et al., 2006; Grimstad et al., 2012; ). Por isso, na expectativa de verificar/corrigir algum eventual erro, o experimento foi repetido e, os mesmos resultados foram mantidos.

Interessante dado encontrado em nosso estudo foi que, ao associarmos os dados morfológicos de comprimento e peso do cólon verificamos que, apesar do cólon do grupo PUFA estar significativamente mais comprido que o dos demais grupos, este tecido estava também com menor massa. Um dos efeitos da colite insuzida pelo DSS é diminuir o tamanho do cólon, o que indica a progressão da doença. Outros estudos demonstraram que o n-3 possui a capacidade de minimizar este efeito (Grimstad et al., 2012), mas apenas no presente estudo verificamos que este cólon aumentado apresentava menor massa tecidual. Estes dados demonstram o aumentado grau de fragilidade tecidual e de perda funcional que a dieta rica em PUFA ocasionou.

Outro dado interessante verificado neste estudo foi que, apesar de todos os resultados indicarem um efeito negativo do consumo de uma dieta rica em PUFA associada à retrocolite ulcerativa induzida pelo consumo de DSS, esse mesmo grupo não apresentou aumentada atividade da mieloperoxidase quando comparado aos demais grupos. Este é um importante marcador inflamatório e uma menor quantidade desta enzima está relacionada diretamente a um efeito anti-inflamatório. De fato, diversos estudos já demonstraram a habilidade dos ácidos graxos ômega-3 em diminuir a atividade dessa enzima em animais com retrocolite ulcerativa (Camuesco et al., 2006; Kono et al., 2012). No entanto considerando-se que ao analisarmos os escores inflamatórios (fezes, atividade da doença) verificamos um pior perfil neste grupo, seria esperado que a atividade dessa enzima também estivesse aumentada, o que não aconteceu. Logo, esta análise nos leva a concluir que estes animais não estavam apresentando uma resposta inflamatória aumentada.

O grupo SAT apresentou maior atividade dessa enzima, indicando maior resposta 
inflamatória. Além disso apresentou também expressão gênica significativamente aumentada de IL-1 $\beta$ e TNF- $\alpha$ quando comparado ao grupo CON, e de INF- $\gamma$ quando comparado tanto ao grupo CON quanto ao grupo PUFA. Estas três citocinas possuem atividade pró-inflamatória e corroboram os dados da mieloperoxidase, nos levando a supor que este grupo estivesse, de fato, com maior inflamação que os demais.

Apesar de ter sido verificado aumento da expressão gênica dessas citocinas no presente estudo, este resultado não foi comprovado por outros. Monk et al. (2012) estudaram os efeitos da retrocolite ulcerativa em camundongos com obesidade induzida por dieta hiperlipídica que podia ser acrescida, ou não, de óleo de peixe, e também não verificaram diferença na expressão gênica de TNF- $\alpha$.

O INF- $\gamma$ é uma das citocinas pró-inflamatórias que atua de diversas maneiras, prejudicando a barreira intestinal: aumenta a permeabilidade intestinal, prejudica o processo de cicatrização da mucosa através de um prejuízo na função proteínas de adesão, prejudica a migração de células epiteliais e também a comunicação intracelular (Beaurepaire et al., 2009). No estudo de Monk et al. (2012) verificou-se que a dieta hiperlipídica aumentou as concentrações dessa citocina quando comparado ao grupo PUFA.

Com relação à IL-1 $\beta$, seus efeitos são diversos nas DII: ao mesmo tempo que ela pode exacerbar as respostas inflamatórias, ela também estimula a migração celular que é necessária para a cicatrização tecidual (Coccia et al., 2012). Um dado interessante foi que o grupo SAT apresentou maior expressão gênica da TJP-1, proteína que caracteriza um complexo de proteínas que selam os espaços entre os colonócitos, promovendo assim uma adequada reparação tecidual (D'Alessio et al., 2013). Sendo assim, nosso dados demonstram que o grupo que consumiu dieta rica em SAT apresentou maior expressão gênica de citocinas pró-inflamatórias - lembrando que algumas delas são necessárias no estímulo da cicatrização tecidual.

Com relação aos cortes histológicos, é importante notar que, qualitativamente, o grupo que consumiu dieta rica em gordura saturada apresentou melhor estrutura colônica quando comparado aos demais grupos, sendo possível notar maior regeneração epitelial. Em oposição ao nosso estudo, Monk et al (2012) verificaram que uma dieta hiperlipídica padrão ocasionou piora dos escores de lesão e inflamação quando comparado com grupo suplementado com krill. Barros et al. (2011) utilizaram ratos wistar com obesidade induzida por diferentes dietas hiperlipídicas: dois grupos com dieta controle - um com indução e o outro sem - e três grupos com diferentes tipos de dieta hiperlipídica - adicionada ou de óleo de peixe, ou de óleo de soja ou a mistura dos dois óleos. Dez dias depois da indução da RU 
por meio do DSS, o grupo que consumiu a mistura de óleos apresentou maior preservação das criptas quando comparado aos grupos com retrocolite, inclusive o grupo que consumiu dieta controle. Interessante destacar que o grupo que consumiu a mistura de óleos apresentou uma razão ômega-6:ômega-3 de 2:1, muito parecida com a dieta rica em gordura poliinsaturada do presente estudo.

No entanto, nem todos estudos verificam melhora de fato: Bosco et al. (2013) utilizaram a suplementação com óleo de peixe prévia à indução da doença e, após quatro semanas de recuperação, verificaram que apesar do grupo suplementado ter apresentado uma diminuição nas concentrações de eicosanóides pró-inflamatórios, isso não ocasionou diferenças nos parâmetros histológicos e nem nos escores inflamatórios.

Os cortes histológicos são uma importante ferramenta de estudo nas DIIs, pois demonstram, de fato, a resposta final do tecido aos diferentes procedimentos. Ao contrário do observado em outros estudos, nossos resultados demonstram que a dieta rica em SAT ocasionou uma melhor resposta adaptativa. Estes resultados nos levam a concluir que, talvez, a resposta inflamatória observada nesse grupo não estivesse exacerbada e tenha sido fundamental no processo de cicatrização da doença observado. Além disso, apesar de muitos estudos observarem efeitos benéficos associados ao consumo de PUFA e as DIIs, os resultados obtidos neste estudo foram inesperados.

Uma possível explicação para a disparidade dos resultados pode ser o desenho experimental. No presente estudo as diferentes dietas começaram a ser oferecidas concomitantemente com a indução da doença. E, com exceção do estudo de Varnalidis et al. (2011), comentado abaixo, no qual o consumo de n-3 se iniciou após a indução da doença, em todos os outros estudos a suplementação foi realizada antes da indução, denotando assim o efeito protetor deste nutriente, diminuindo a atividade/gravidade da doença (Grimstad et al. 2012; Monk et al., 2012) .

Analisamos os dados de estudos realizados em humanos, na tentativa de encontrar resultados que coincidissem com os nossos, uma vez que esses estudos normalmente utilizam pacientes que possuem a doença. Apenas o estudo de Dichi et al. (2000) encontrou efeitos negativos. Neste estudo, cross-over, 10 pacientes com RU moderada receberam, por dois meses, tratamento ou com sulfasalazina (medicamento anti-inflamatório intestinal, $2 \mathrm{~g} / \mathrm{da})$ ou óleo de peixe $(5,4 \mathrm{~g} / \mathrm{dia})$. Após os tratamentos, foi verificado que a suplementação com n-3 ocasionou aumento das concentrações de proteína $\mathrm{C}$ reativa e da taxa de sedimentação eritrocitária (marcador de turnover proteico, quanto mais alto, maior a atividade da doença). Portanto, neste estudo em humanos, a suplementação com ômega-3 
ocasionou, assim como no presente estudo, uma piora do quadro metabólico quando comparado ao estado pré-tratamento e ao tratamento com sulfazalazina.

Diversas revisões realizadas a partir de estudos em humanos concluíram que não há evidências suficientes para a utilização dessa suplementação. MacLean et al. (2005) em sua revisão sistemática avaliaram os estudos, classificando-os conforme os escores de Jadad, que variam de $0-5$, sendo que os estudos com escore acima de 3 seriam considerados de alta qualidade. Nessa revisão os autores relatam que os estudos com este alto escore não demonstraram, de fato, benefícios da suplementação de ômega-3 nas DIIs. Já Cabré et al. (2012), utilizaram, em sua revisão sistemática, o índice de Oxford para avaliar qualitativamente os estudos e também concluíram que não há evidências que suportem a indicação da suplementação de ômega-3 para pacientes com doenças inflamatórias intestinais. Feagan et al. (2008), analisaram os dados do estudo canadense EPIC (Epanova Program in Crohn's Study), no qual pacientes com DC consumiram, durante 58 semanas, $4 \mathrm{~g} /$ dia de ômega-3. Como resultado não foi observado efeito benéfico da suplementação em marcadores de atividade da doença e tempo de remissão. No entanto, tanto BassaganyaRiera et al. (2006) quanto Turner et al. (2011) afirmaram em seus estudos que o ômega-3 possuiria a capacidade de prevenir ou trazer efeitos benéficos nas DII. Apesar da falta de consenso, vale ressaltar que em apenas um dos estudos avaliados (Dichi et al., 2012), a suplementação ocasionou efeitos negativos. Em todos os demais ou houve ausência de efeitos positivos, ou os efeitos foram modestos.

Em animais, um recente estudo também verificou efeito negativo associado ao consumo de dietas ricas em PUFA. Turk et al., 2013) avaliaram os efeitos do EPA e do DHA em camundongos com retrocolite ulcerativa induzida por DSS e verificaram que o tanto o grupo EPA, quanto o grupo DHA apresentaram maior perda de peso corporal quanto comparados ao grupo controle deste estudo, que recebeu a mesma dose de lipídios, mas de óleo de milho. Além disso, o escore de lesão tecidual do grupo EPA apresentou aumento três dias após o término da indução da doença, enquanto que no grupo DHA este escore se apresentou aumentado somente seis dias depois. No entanto, apenas o grupo submetido à dieta rica em EPA apresentou maior taxa de óbito do que os demais grupos. Interessante notar que ambos os grupos apresentavam menor quantidade de AA no cólon, quando comparados ao grupo controle. Este, que foi postulado ser um efeito benéfico, não demonstrou ser tão eficiente neste estudo. Portanto, há controvérsias quanto aos efeitos negativos deste ácido na RU. Ramakers et al. (2008), estudaram os efeitos da RU induzida por DSS em camundongos submetidos, por seis semanas, a uma dieta ou rica em ômega-3 
ou rica em ômega-6, especialmente em ácido araquidônico. O grupo que consumiu a dieta rica em AA apresentou melhores resultados de consistência das fezes e peso corporal, quando comparado ao grupo submetido a uma dieta rica em óleo de peixe.

Além disso, Turk et al. (2013) também verificaram que o EPA, mas não o DHA, foi capaz de inibir a ativação de uma proteína-chave do processo de cicatrização, o EGFR (i.e., receptor do fator de crescimento epidérmico), o que ocasionou atraso no processo de cicatrização. Outra hipótese verificada foi a menor proliferação celular induzida pelo EPA quando comparado aos demais grupos. Nas DIIs ocorre uma perda de células epiteliais, fazendo com que micro-organismos presentes no lúmen entrem em contato com a lâmina própria. Em lesões leves e moderadas, a recomposição da mucosa é possível devido a essa migração de células epiteliais e a um subsequente aumento da proliferação destas células. Deste modo, esta proliferação é um passo necessário para a cicatrização da mucosa (Osterman, 2013).

Varnalidis et al. (2011) estudaram a suplementação de ômega-3 em ratos wistar com RU induzida por DSS. Diferentemente dos demais estudos já citados, o objetivo foi avaliar o efeito do n-3 após a indução da doença, como tratamento. Foi observado que, apesar do quadro geral da doença ter apresentado melhora com a suplementação, foi observado neste grupo um aumento da infiltração de neutrófilos.

Vale ressaltar que alguns estudos indicam que, ao passo que a infiltração de neutrófilos pode exercer um efeito negativo na reparação tecidual, chegando a produzir compostos bio-ativos que podem até mesmo acelerar o dano tecidual (Dovi et al., 2004), ela possui também o importante papel de mediar a ativação de fatores de transcrição que irão estimular a regeneração tecidual (Theilgaard-Mönch et al., 2005).

Os neutrófilos compõem a reposta imunológica inata, que é essencial na proteção contra patógenos e também minimizam possíveis efeitos deletérios que poderiam ser ocasionados por células danificadas. No entanto, um excesso nessa migração e ativação leva a uma liberação excessiva de produtos citotóxicos, estimulando uma massiva migração trans-epitelial que resultará em uma grande alteração morfológica das criptas e agravará a lesão na mucosa (Fournier et al., 2012). Através dos cortes histológicos podemos perceber que os animais do grupo PUFA de fato apresentaram uma exacerbada infiltração de neutrófilos que, ao que tudo indica, estaria relacionada com o aumento dos escores de lesão tecidual e com o agravamento da doença neste grupo.

Outro efeito exacerbado que não foi alvo do presente estudo, mas que pode ter ocorrido, foi relatado por Fan et al. (2011), que demonstraram que os ácidos graxos ômega- 
3 possuem a capacidade de induzir a apoptose dos colonócitos. Esta variável é utilizada como marcador de risco de câncer do cólon, uma vez que altos níveis de apoptose significam aumentada remoção de células "doentes/alteradas". Este efeito é derivado de sua habilidade de oxidar fosfolipídeos (Hofmanová et al., 2012), peroxidação lipídica, e do acúmulo de cálcio, estimulando a liberação de proteínas inter-membranas. Somados, estes efeitos ocasionam uma perda do potencial de membrana, prejudicando assim sua permeabilidade e, induzindo sua apoptose (Kolar et al., 2011). Se exacerbado, este efeito da suplementação de ômega-3 pode ter sido responsável até mesmo pela maior infiltração de neutrófilos observada neste grupo.

Levando em consideração todos os estudos analisados face aos resultados obtidos, concluímos que, no modelo utilizado, o consumo de uma dieta rica em ácidos graxos poliinsaturados exacerbou os efeitos da retrocolite ulcerativa, resultando em piora absoluta do perfil inflamatório da doença, inclusive com elevada taxa de óbito. Destacamos, ainda, que a resposta com característica mais pró-inflamatória observada no grupo que consumiu a dieta rica em gordura saturada foi fundamental para estimular as respostas necessárias para o processo de cicatrização. No entanto, mais estudos similares ao nosso são necessários para confirmar estes resultados. 


\section{CAPÍTULO 4 - CONSIDERAÇÕES FINAIS}

Os dados do presente estudo demonstraram distintos desfechos do consumo de dietas ricas em ácidos graxos saturados ou poli-insaturados. Quando associada a uma dieta rica em gordura saturada, a lipectomia ocasionou prejuízo metabólico com aumento das concentrações de colesterol total, pior sensibilidade à insulina e acúmulo hepático de gordura. Estas alterações estão provavelmente relacionadas ao crescimento compensatório do depósito retroperitoneal e a um aumento no perfil pró-inflamatório verificados nos animais do grupo submetido a essa dieta.

Um importante resultado encontrado foi que a dieta rica em gordura poli-insaturada preveniu todos os efeitos negativos supracitados. Esta resposta parece ter sido derivada do aumento do tecido adiposo marrom e de um melhor perfil inflamatório verificados nesse grupo, comparado ao submetido a dieta rica em gordura saturada.

No entanto, embora no primeiro estudo a dieta rica em gordura poli-insaturada tenha apresentado efeitos protetores, essa resposta foi diferente em ratos com retrocolite ulcerativa. Esta dieta, considerada anti-inflamatória, desencadeou uma resposta exacerbada à doença, ocasionando uma piora generalizada nos escores de lesão tecidual e inflamatórios, inclusive com aumento nas taxas de óbito desses animais. Já a dieta rica em gordura saturada permitiu a produção de uma resposta inflamatória adequada e necessária, propiciando assim uma melhor regeneração colônica.

Com isso podemos concluir que mais importante do que o conteúdo total de lipídios da dieta, é sua composição - predominância de ácidos graxos saturados e poli-insaturados uma vez que estes ácidos podem exercer funções completamente distintas. Destacamos os efeitos verificados na ação dos ácidos graxos poli-insaturados. Estes, apesar de possuírem uma importante função anti-inflamatória que pode trazer inúmeros benefícios em doenças como a obesidade, devem ser utilizados com extrema cautela em algumas doenças inflamatórias como a retrocolite ulcerativa, até que mais estudos comprovem de fato seus efeitos. 


\section{REFERÊNCIAS ${ }^{1}$}

Ananthakrishnan AN. Personalizing therapy for inflammatory bowel disease. Expert Rev Gastroenterol Hepatol. 2013;7(6):9.

Asakura H, Suzuki K, Kitahora T, Morizane T. Is there a link between food and intestinal microbes and the occurrence of Crohn's disease and ulcerative colitis? J Gastroenterology and Hepatology. 2008;23(12):1794-801.

Awad AB, Bernardis LL, Fink CS. Failure to demonstrate an effect of dietary fatty acid composition on body weight, body composition and parameters of lipid metabolism in mature rats. J Nutr. 1990;120(11):1277-82.

Barrett CW, Singh K, Motley AK, et al. Dietary selenium deficiency exacerbates DSSinduced epithelial injury and AOM/DSS-induced tumorigenesis. PloS One. 2013;8(7):e67845.

Barros KV, Abreu GG, Xavier RA, et al. Effects of a high fat or a balanced omega 3/omega 6 diet on cytokines levels and DNA damage in experimental colitis. Nutrition. 2011;27(2):6.

Barzilai N, She L, Liu BQ, et al. Surgical removal of visceral fat reverses hepatic insulin resistance. Diabetes. 1999;48(1):94-8.

Bassaganya-Riera J, Hontecillas R. CLA and n-3 PUFA differentially modulate clinical activity and colonic PPAR-responsive gene expression in a pig model of experimental IBD. Clin Nutr. 2006;25(3):454-65.

Beaurepaire C, Smyth D, McKay DM. Interferon-gamma regulation of intestinal epithelial permeability. J Interferon Cytokine Res. 2009;29(3):9.

Berg AH, Scherer PE. Adipose tissue, inflammation, and cardiovascular disease. Circ Res. 2005;96(9):939-49.

Bi L, Chiang JY, Ding WX, Dunn W, Roberts B. Saturated fatty acids activate ERK signaling to downregulate hepatic sortilin 1 in obese and diabetic mice. J Lipid Res. 2013;52(10):8.

Bjorndal B, Burri L, Staalesen V, Skorve J, Berge RK. Different adipose depots: their role in the development of metaboli syndrome and mutochondrial response to hypolipidemic agents. J Obes. 2011;2011:1-39.

Borst SE, Lee Y, Conover CF, Shek EW, Bagby GJ. Neutralization of tumor necrosis factoralpha reverses insulin resistance in skeletal muscle but not adipose tissue. Am J Physiol Endocrinol Metab. 2004; 287(5): E934-8.

\footnotetext{
${ }^{1}$ De acordo com:

International Committee of Medical Journal Editors. [Internet]. Uniform requirements for manuscripts submitted to Biomedical Journal: sample references. [updated $2011 \mathrm{Jul}$ 15]. Available from: http://www.icmje.org
} 
Bosco N, NBrahmbhatt V, Oliveira M, et al. Effects of increase in fisj oil intake on intestinal eicosanoids ans inflammation in a mouse model of colitis. Lipids in Health Dise. 2013;12:13.

Bozzetto L, Prinster A, Mancini M, et al. Liver fat in obesity: role of type 2 diabetes mellitus and adipose tissue distribution. Eur J Clin Invest. 2011;41(1):39-44.

Bray GA, Popkin, BM. Dietary fat intake does affect obesity. Am J Clin Nutr. 1998;68:1156-73.

Brunner EJ, Wunsch H, Marmot MG. What is an optimal diet? Relationship of macronutrient intake to obesity, glucose tolerance, lipoprotein cholesterol levels and the metabolic syndrome in the Whitehall II study. Int $\mathrm{J}$ Obes Relat Metab Disord. 2001;25(1):45-53.

Bueno AA, Oyama LM, Estadella D, Habitante CA, Bernardes BS, Riberiro EB, Oller do Nascimento CM. Lipid metabolism of monosodium glutamate obese rats after partial removal of adipose tissue. Physiol Res. 2005; 54(1): 57-65.

Bueno AA, Habitante CA, Oyama LM, et al. White adipose tissue re-growth after partial lipectomy in high fat diet induced obese Wistar rats. J Physiol Sci. 2011;61(1):55-63.

Bunea R, El Farrah K, Deutsch L. Evaluation of the effects of Neptune Krill Oil on the clinical course of hyperlipidemia. Altern Med Rev. 2004;9(4):8.

Cabre E, Manosa M, Gassull MA. Omega-3 fatty acids and inflammatory bowel diseases - a systematic review. Br J Nutr. 2012;107 Suppl 2:S240-52.

Calder PC. Polyunsaturated fatty acids, inflammatory processes and inflammatory bowel diseases. Mol Nutr Food Res. 2008;52(8):885-97.

Camuesco D, Comalada M, Concha $\mathrm{A}$, et al. Intestinal anti-inflammatory activity of combined quercitrin and dietary olive oil supplemented with fish oil, rich in EPA and DHA (n-3) polyunsaturated fatty acids, in rats with DSS-induced colitis. Clin Nutr. 2006;25(3):466-76.

Chan DC, Watts GF, Sussekov AV, et al. Adipose tissue compartments and insulin resistance in overweight-obese Caucasian men. Diab Res Clin Pract. 2004;63(2):77-85.

Chapkin RS, Kim W, Lupton JR, McMurray DN. Dietary docosahexaenoic and eicosapentaenoic acid: emerging mediators of inflammation. Prostl Leuk Essent Fatty Acids. 2009;81(2-3):187-91.

Chen A, Mumick S, Zhang C, et al. Diet induction of monocyte chemoattractant protein-1 and its impact on obesity. Obes Res. 2005;13(8):1311-20.

Clarke SD. Polyunsaturated fatty acid regulation of gene transcription: a molecular mechanism to improve the metaboli syndrome. J Nutr. 2001;131:3. 
Coccia M, Harrison OJ, Schiering C, et al. Il-1beta mediates chronic intestinal inflammation by promoting the accumulation of IL-17A secreting innate lymphoid cells and CD4(+) Th17 cells. J Exp Med. 2012;209(9):14.

Coelho DF, Gualano B, Artioli GG, et al. Exercise Training attenuates lipctomy-induced glucose tolerance in rats. Endocr Regul. 2009.

Costa CA, Carlos AS, Gonzalez Gde P, et al. Diet containing low n-6/n-3 polyunsaturated fatty acids ratio, provided by canola oil, alters body composition and bone quality in young rats. Eur J Nutr. 2012;51(2):191-8.

D'Alessio DA, Tacconi C, Fiocchi C, Danese S. Advances in therapeutic interventions targeting the vascular an lymphatic endothelium in inflammatory bowel disease. Curr Opin Cell Biol. 2013;29(6):5.

De Silva P, Ananthakrishnan AN. Vitamin D and IBD: more pieces to the puzzle, still no complete picture. Infl Bowel Dis. 2012;18(7):1391-3.

DeLany JP, Windhauser MM, Champagne CM, Bray GA. Differential oxidation of individual dietary fatty acids in humans. Am J Clin Nutr. 2000;72(4):905-11.

Dichi If, P., Dichi JB, Correa CR, et al. Comparison of w-3 fatty acids and sulfasalazine in ulcerative colitis. Nutr. 2000;16(3):87.

Dovi, AM S, LA D. Neutrophil function in the healing wound: adding insult to injury? Thromb Haemost. 2004;92:275:8.

Drewnowski A. The real contribution of added sugars and fats to obesity. Epid Rev. 2007;29:160-71.

Duca FA, Sakar Y, Covasa M. The modulatory role of high fat feeding on gastrointestinal signals in obesity. J Nutr Biochem. 2013;24(10):1663-77.

Einstein FH, Atzmon G, Yang XM, et al. Differential responses of visceral and subcutaneous fat depots to nutrients. Diabetes. 2005;54(3):672-8.

Endo M, Masaki T, Seike M, Yoshimatsu K. TNF-alpha induces hepatic steatosis in mice by enhancing gene expression of sterol regulatory element binding protein-1c (SREBP-1c). Exp Biol Med (Maywood). 2007;232(4):7.

Enerback S. Brown adipose tissue in humans. Int J Obes (London). 2010;34(suppl 1):S3642.

Fain JN, Madan AK, Hiler ML, Cheema P, Bahouth SW. Comparison of the release of adipokines by adipose tissue, adipose tissue matrix, and adipocytes from visceral and subcutaneous abdominal adipose tissues of obese humans. Endocrinol. 2004;145(5):227382 . 
Fan YY, Ran Q, Toyokuni S, et al. Dietary fish oil promotes colonic apoptosis and mitochondrial proton leak in oxidatively stressed mice. Cancer Prev Res. 2011;4(8):126774.

Faust IM, HJohnson PR, Hirsch J. Adipose tissue regeneration following lipectomy. Science. 1977;31:3.

Feagan BG, Sandborn WJ, Mittmann U, et al. Omega-3 Free Fatty Acids for the Maintenance of Remission in Crohn Disease. The EPIC Randomized Controlled Trials. . JAMA. 2008;299(14):1690:19.

Fickova M, Hubert P, Crémel G, Leray C. Dietary (n-3) and (n-6) polyunsaturated fatty acids rapidly modify fatty acid composition and insulin effects in rat adipocytes. $J$ Nutr. 1998;128:7.

Fiocchi C. IBD: advances in pathogenesis, complications, diagnosis, and therapy. Curr Opin Gastroenterol. 2012;28(4):297-300.

Flachs $\mathrm{P}$, Horakova $\mathrm{O}$, Brauner $\mathrm{P}$, et al. Polyunsaturated fatty acids of marine origin upregulate mitochondrial biogenesis and induce beta-oxidation in white fat. Diabetologia. 2005;48(11):2365-75.

Fonseca-Alaniz MH, Takada J, Alonso-Vale MI, Lima FB. O tecido adiposo como centro regulador do metabolismo. Arq bras Endocrinol Metab. 2006;50(2):216-29.

Foster MT, Shi H, Seeley RJ, Woods SC. Removal of intra-abdominal visceral adipose tissue improves glucose tolerance in rats: role of hepatic triglyceride storage. Physiol Behav. 2011a;104(5):845-54.

Foster MT, Shi H, Softic S, et al. Transplantation of non-visceral fat to the visceral cavity improves glucose tolerance in mice: investigation of hepatic lipids and insulin sensitivity. Diabetologia. 2011b;54(11):2890-9.

Fournier BM, Parkos CA. the role of neutrophils during intestinal inflammation. Nature. 2012;5(4).

Fruhbeck G, Gomez-Ambrosi J, Muruzabal FJ, Burrell MA. The adipocyte: a model for integration of endocrine and metabolic signaling in energy metabolism regulation. Am $\mathrm{J}$ Physiol Endocrinol Metab. 2001;280(6):E827-47.

Furnes MW, Zhao CM, Chen D. Development of obesity is associated with increased calories per meal rather than per day. A study of high-fat diet-induced obesity in young rats. Obes Surg. 2009;19:1430-38.

Gabriely I, Ma XH, Yang XM, et al. Removal of visceral fat prevents insulin resistance and glucose intolerance of aging: an adipokine-mediated process? Diabetes. 2002;51(10):2951-8.

Gaiva MH, Couto RC, Oyama LM, et al. Polyunsaturated fatty acid-rich diets: effect on adipose tissue metabolism in rats. Br J Nutr. 2001;86(3):371-7. 
Gerhardt CC, Romero IA, Cancello R, Camoin L, Strosberg AD. Chemokines control fat accumulation and leptin secretion by cultured human adipocytes. Mol Cell Endocrinol. 2001;175(1-2):81-92.

Gil C, Cubi R, Aguilera J. Shedding of the p75NTR neurotrophin receptor is modulated by lipid rafts. FEBS Lett. 2007;581(9):1851-8.

Giusti V, Suter M, Verdumo C, et al. Molecular determinants of human adipose tissue: differences between visceral and subcutaneous compartments in obese women. J Clin Endocrinol Metab. 2004;89(3):1379-84.

Gonzalez CA, Pera G, Quiros JR, et al. Types of fat intake and body mass index in a Mediterranean country. Pub Health Nutr. 2000;3(3):329-36.

Gonzalez-Périz A, Horrillo R, Ferré N, Gronert K et al. Obesity-induced insulin resistance and hepatic steatosis are alleviated by w-3 fatty acids: a role for resolvins and protectins. FASEB J. 2009;23:1946-57.

Goodpaster BH, Thaete FL, Kelley DE. Thigh adipose tissue distribution is associated with insulin resistance in obesity and in type 2 diabetes mellitus. Am $J$ Clin Nutr. 2000;71(4):885-92.

Grimstad T, Bjorndal B, Cacabelos D, et al. Dietary supplementation of krill oil attenuates inflammation and oxidative stress in experimental ulcerative colitis in rats. Scand $\mathrm{J}$ Gastroenterol. 2012;47(1):49-58.

Hamilton JM, Wade GN. Lipectomy does not impair fattening induced by short photoperiods or high-fat diets in female Syrian hamsters. Physiol Behav. 1988;43(1):85-92.

Harris RB, Leibel RL. Location, location, location. Cell Metabol. 2008;7(5):359-61.

Hausman DB, Lu J, Ryan DH, Flatt WP, Harris RB. Compensatory growth of adipose tissue after partial lipectomy: involvement of serum facotrs. Exp Biol Med (Maywood). 2004;229:8.

Hofmanová J, Ciganek M, Slavik J, et al. Lipid alterations in human colon epithelial cells induced to differentation and/or apoptosis by butyrate and polyunsaturated fatty acids. J Nutr Biochem. 2012;23(6):9.

Huang YT, Wen CC, Chen YH, et al. Dietary uptake of Wedelia chinensis extract attenuates dextran sulfate sodium-induced colitis in mice. PloS One. 2013;8(5):e64152.

Item F, Konrad D. Visceral fat and metabolic inflammation: the portal theory revisited. Obes Rev. 2012;13 Suppl 2:30-9.

Ito A, Suganami T, Miyamoto Y, et al. Role of MAPK phosphatase-1 in the induction of monocyte chemoattractant protein-1 during the course of adipocyte hypertrophy. J Biol Chem. 2007;282(35):25445-52. 
Jacobi SK, Moeser AJ, Corl BA, et al. Dietary long-chain PUFA enhance acute repais of ischemia-ijured intestine of suckling pigs. J Nutr. 2012;142(7):5.

James MJ, Gibson RA, Cleland LG. Dietary polyunsaturates fatty acids ans inflammatory mediator production. Am J Clin Nutr. 2000;71(1 Suppl):5.

Jeffery RW, Harnack LJ. Evidence implicating eating as a primary driver for the obesity epidemic. Diabetes. 2007;56(11):2673-6.

Jia Q, Lupton JR, Smith R, Weeks BR, Callaway E, Davidson LA, et al. Reduced colitisassociated colon cancer in fat-1 (n-3 fatty acid desaturase) transgenic mice. Cancer Res. 2008;69(10):3985-91.

Jia X, Naito $\mathrm{H}$, Yetti $\mathrm{H}$, et al. The modulation of hepatic adenosine triphosphate and inflammation by eicosapentaenoic acid during severe fibrotic progression in the SHRSP5/Dmcr rat model. Life sciences. 2012;90(23-24):934-43.

Jorgensen ME, Borch-Johnsen K, Bjerregaard P. Lifestyle modifies obesity-associated risk of cardiovascular disease in a genetically homogeneous population. Am $\mathrm{J}$ Clin Nutr. 2006;84(1):29-36.

Jove M, Planavila A, Sanchez RM, et al. Palmitate induces tumor necrosis factor-alpha expression in $\mathrm{C} 2 \mathrm{C} 12$ skeletal muscle cells by a mechanism involving protein kinase $\mathrm{C}$ and nuclear factor-kappaB activation. Endocrinology. 2006;147(1):552-61.

Jowett SL, Seal CJ, Pearce MS, et al. Influence of dietary factors on the clinical course of ulcerative colitis: a prospective cohort study. Gut. 2004;53(10):1479-84.

Juge-Aubry CE. Adipose tissue: a regulator of inflammation. Best Pra Res Clin Endocrinl Metab. 2005;19(4):547-566.

Karanth S, Tran VM, Kuberan B, Schlegel A. Polyunsaturated fatty acyl-Coenzyme A are inhibitors of cholesterol biosynthesis. Dis Model Mech. 2013.

Karki S, Chakrabarti P, Huang G, et al. The multi-level action of fatty acids on adiponectin production by fat cells. PloS One. 2011;6(11):e28146.

Kim YW, Kim JY, Lee SK. Surgical removal of visceral fat decreases plasma free fatty acid and increases insulin sensitivity on liver and peripheral tissue in monosodium glutamate (MSG)-obese rats. J Korean Med Sci. 1999;14(5):539-45.

Kirwan JP, del Aguila LF. Insulin signalling, exercise and cellular integrity. Biochem Soc Trans. 2003;31(Pt 6):1281-5.

Klein, S, Fontana, L, Young L, Coggan AR, Kilo C, Patterson BW. Mohammed, BS. Absence of an effect of liposuction on insulin action and risk factors for coronary heart disease. New Engl J Med. 2004;350(25):2549-57.

Ko JK, Auyeung KK. Inflammatory bowel disase: etiology, pathogenesis and current therapy. Curr Pharm Des. 2013. 
Kolar S, Barhoumi R, Jones CK, et al. Interactive effects of fatty acid and butyrate-induced mitochondrial $\mathrm{Ca}(2)(+)$ loading and apoptosis in colonocytes. Cancer. 2011;117(23):5294303.

Kono H, Fujii H, Ogiku M, et al. Enteral diets enriched with medium-chain triglycerides and N-3 fatty acids prevent chemically induced experimental colitis in rats. Translat Res. 2010;156(5):282-91.

Kozak LP, Koza RA, Anunciado-Koza R. Brown fat thermogenesis and body weight regulation in mice: relevance to humans. Int J Obes (Lond). 2010;34 Suppl 1:S23-7.

Krebs JD, Browning LM, McLean NK, et al. Additive benefits of long-chain n-3 polyunsaturated fatty acids and weight-loss in the management of cardiovascular disease risk in overweight hyperinsulinaemic women. Int J Obes (Lond). 2006;30(10):1535-44.

Kromhout D, Gelejinse JM, Menotti A, Jacobs DRJ. The confusion about dietary fatty acids recommendations for CHD prevention. Br J Nutr. 2011;105(5):6.

Lavau M, Fried SK, Susini C, Freychet P. Mechanism of insulin resistance in adipocytes of rats fed a high-fat diet. J Lipid Res, 1979; 20(1): 8-16.

Lebovitz HE, Banerji MA. Point: visceral adiposity is causally related to insulin resistance. Diab Care. 2005;28(9):2322-5.

Levy-Costa RB, Sichieri R, Pontes Ndos S, Monteiro CA. Household food availability in Brazil: distribution and trends (1974-2003). Rev Saúde Púb. 2005;39(4):530-40.

Lieberman LS. Dietary, evolutionary, and modernizing influences on the prevalence of the type 2 duabetes. Ann Rev Nutr. 2003;23:354-77.

Liu M, Wang J, Jiang B, et al. Increasing Prevalence of Metabolic Syndrome in a Chinese Elderly Population: 2001-2010. PloS One. 2013;8(6):e66233.

Lu J, Borthwick F, Hassanali Z, et al. Chronic dietary n-3 PUFA intervention improves dyslipidaemia and subsequent cardiovascular complications in the JCR:LA- cp rat model of the metabolic syndrome. Br J Nutr. 2011;105(11):1572-82.

Ludwig T, Worsch S, Heikenwalder M, et al. Metabolic and immunomodulatory effects of n-3 fatty acids are different in mesenteric and epididymal adipose tissue of diet-induced obese mice. Am J Physiol Endocrinol Metab. 2013;304(11):E1140-56.

MacLean CH, Mojica WA, Newberry SJ, et al. Systematic Review of the effects of n-3 fatty acids in inflammatory bowel disease. Am J Clin Nutr. 2005;82(3):8.

Madsen L, Petersen RK, Kristiansen K. Regulation of adipocyte differentiation and function by polyunsaturated fatty acids. Biochem et Biophys Acta. 2005;1740(2):266-86.

Martin TL, Alquier T, Asakura K, et al. Diet-induced obesity alters AMP kinase activity in hypothalamus and skeletal muscle. J Biol Chem. 2006;281(28):18933-41. 
Matsubara M, Katayose S, Maruoka S. Decreased plasma adiponectin concentrations in nondiabetic women with elevated homeostasis model assessment ratios. Eur J Endocrinol. 2003;148(3):343-50.

Matsuo T, Takeuchi H, Suzuki H, Suzuki M. Body fat accumulation is greater in rats fed a beef tallow diet than in rats fed a safflower or soybean oil diet. Asia Pacif J Clin Nutr. 2002;11(4):302-8.

Matthews JN, Altman DG, Campbell MJ, Royston P. Analysis of serial measurements in medical research. BMJ. 1990;300(6719):230-5.

Mauer MM, Bartness TJ. Body fat regulation after partial lipectomy in Siberian hamsters is photoperiod dependent and fat pad specific. Am J Physiol. 1994;266(3 Pt 2):R870-8.

Mauer MM, Bartness TJ. Fat pad-specific compensatory mass increases after varying degrees of lipectomy in Siberian hamsters. Am J Physiol. 1997;273(6 Pt 2):R2117-23.

McDonald SD, Pesarchuk E, Don-Wauchope A, El Zimaity H, Holloway AC. Adverse metabolic effects of a hypercaloric, high-fat diet in rodents precede observable changes in body weight. Nutr Res. 2011;31(9):707-14.

Melgar S, Karlsson A, Michaelsson E. Acute colitis induced by dextran sulfate sodium progresses to chronicity in $\mathrm{C} 57 \mathrm{BL} / 6$ but not in $\mathrm{BALB} / \mathrm{c}$ mice: correlation between symptoms and inflammation. Am J Physiol Gastrointest Liver Physiol. 2005;288(6):G132838.

Mercer SW, Trayhurn P. Effect oh high-fat diets on energy balance and thermogenesis in brown adipose tissue oof lean and genetically obese ob/ob mice. J Nutr. 1987;117(6):2147.

Michel C, Cabanac M. Lipectomy, body weight, and body weight set point in rats. Physiol Behav. 1999;66(3):473-9.

Middleton SJ, Naylor S, Woolner J, Hunter JO. A double-blind, randomized, placebocontrolled trial of essential fatty acid supplementation in the maintenance of remission of ulcerative colitis. Alimentary pharmacology \& therapeutics. 2002;16(6):3.

Mobbs CV, Mastaitis J, Yen K, et al. Low-carbohydrate diets cause obesity, lowcarbohydrate diets reverse obesity: a metabolic mechanism resolving the paradox. Appetite. 2007;48(2):135-8.

Mojiminiyi OA, Abdella NA. Effect of homeostasis model assessment cinoutational method on the definition and association of insulin resistance. Clin Chem Lab Med. 2010;48(11):5.

Monk JM, Hou TY, Turk HF, et al. Dietary n-3 polyunsaturated fatty acids (PUFA) decrease obesity-associated Th17 cell-mediated inflammation during colitis. PloS One. 2012;7(11):e49739.

Monteiro CA, Conde WL, Popkin BM. Income-specific trends in obesity in Brazil: 19752003. Am J Publ Health. 2007;97(10):1808-12. 
Moreno-Aliaga MJ, Lorente-Cebrian S, Martinez JA. Regulation of adipokine secretion by n-3 fatty acids. Proc Nutr Soc. 2010;69(3):324-32.

Mudter J. What's new about inflammatory bowel diseases in 2011. World J Gastroenterol. 2011; 17(27):3177-80.

Murumalla RK, Gunasekaran MK, Padhan JK, Bencharif K et al. Fatty acids do not pay the roll: effect os SFA and PUFA on human adipose tissue and mature adipocytes inflammation. Lipids Health Dis.2012;11:175-84.

Nakamura MT, Cheon Y, Li Y, Nara TY. Mechanisms of regulation of gene expression by fatty acids. Lipids. 2004;39(11):1077-83.

Negrao AB, Licinio J. Obesity: on the eve of a major conceptual revolution. Drug Discov Today. 2000;5(5):177-9.

Newman RE, Bryden WL, Fleck E, et al. Dietary n-3 and n-6 fatty acids alter avian metabolism: metabolism and abdominal fat deposition. Br J Nutr. 2007;88(01):11.

Nielsen S, Guo Z, Johnson CM, Hensrud DD, Jensen MD. Splanchnic lipolysis in human obesity. J Clin Invest. 2004;113(11):1582-8.

Nogalska A, Stelmanska E, Sledzinski T, Swierczynski J. Surgical removal of perirenal and epididymal adipose tissue decreases serum leptin concentration and increases lipogenic enzyme activities in remnant adipose tissue of old rats. Gerontol. 2009;55(2):224-8.

Nuernberg K, Breier BH, Jayasinghe SN, et al. Metabolic responses to high-fat diets rich in n-3 or n-6 long-chain polyunsaturated fatty acids in mice selected for either high body weight or leanness explain different health outcomes. Nutr Metab (Lond). 2011;8(1):56.

Ordás I, Eckmann L, Talamini M, Baumgart DC, Sandborn WJ. Ulcerative colitis. Lancet. 2012;380(9853):1606-19.

Osterman MT. Mucosal healing in inflammatory bowel disease. J Clin Gastroenterol. 2013;47(3):9.

Oudart H, Groscolas R, Calgari C, et al. Brown fat thermogenesis in rats fed high-fat diets enriched with n-3 polyunsaturated fatty acids. Int $J$ Obes Relat Metab Disord. 1997;21(7):955.

Pelletier-Neaumont E, Arsenault BJ, Améras N, Bergeron J et al. Normalization of visceral adiposity is required to normalize plasma apolipoprotein $\mathrm{B}$ levels in response to a healthy eating/physical activity lifestyle modification program in viscerally obese men. Atherosclerosis. 2012;221(2):577-82.

Popkin BM. The Nutrition Transition and Obesity in the Developing World. Asia Pacific J Cl Nutr 2001;10:5. 
Poudyal H, Panchal SK, Ward LC, Brown L. Effects of ALA, EPA and DHA in highcarbohydrtae, high-fat diet-induced metabolic syndrome in rats. J Nutr Biochem. 2013;26(6):12.

Prentice AM. Manipulation of dietary fat and enerdy density and subsequent effects on substrate flux and food intake. Am J Clin Nutr. 1998;67S:6.

Prunet-Marcassus B, Cousin B, Caton D, et al. From heterogeneity to plasticity in adipose tissues: site-specific differences. Exp Cell Res. 2006;312(6):727-36.

Queiroz JCF, Alonso-Vale MIC, Lima FB. Controle da adipogenese por ácidos graxos. Arq Bras Endocrinol Metabol. 2009;53(5):6.

Ramakers JD, Mensink RP, Verstege MI, te Velde AA, Plat J. An arachidonic acid-enriched diet does not result in more colonic inflammation as compared with fish oil- or oleic acidenriched diets in mice with experimental colitis. Br J Nutr. 2008;100(2):347-54.

Rangel-Huerta OD, Aguilera CM, Mesa MD, Gil A. Omega-3 long-chain polyunsaturated fatty acids supplementation on inflammatory biomakers: a systematic review of randomised clinical trials. Br J Nutr. 2012;107 Suppl 2:S159-70.

Raubenheimer PJ, Nyirenda MJ, Walker BR. A choline-deficient diet exacerbates fatty liver but attenuates insulin resistance and glucose intolerance in mice fed a high-fat diet. Diabetes. 2006;55(7):2015-20.

Reif S, Klein I, Farbstein M, Hallak A, Gilat T. Pre-illnes dietary factors in inflammatory bowel disease. Gut. 1997;40:6.

Rioux V, Legrand P. saturated fatty acids: simple molecular structures with comples cellular functions. Curr Op Clin Nutr Metab Care. 2007;10(6):16.

Rokling-Andersen MH, Rustan AC, Wensaas AJ, et al. Marine n-3 fatty acids promote size reduction of visceral adipose depots, without altering body weight and composition, in male Wistar rats fed a high-fat diet. Br J Nutr. 2009;102(7):995-1006.

Rolls BJ, Shide DJ. The influence of dietary fat on food intake and body weight. Nutr Rev. 1992;50:8.

Rondinone CM. Adipocyte-derived hormones, cytokes, and mediators. Endocrine. 2006;29(1):81-90.

Rosa EC, Zanella MT, Ribeiro AB, Kohlmann Junior O. Visceral obesity, hypertension and cardio-renal risk: a review. Arq Bras Endocrinol Metabol. 2005;49(2):196-204.

Ruan H, Hacohen N, Golub TR, Van Parijs L, Lodish HF. Tumor necrosis factor-alpha suppresses adipocyte-specific genes and activates expression of preadipocyte genes in 3T3L1 adipocytes: nuclear factor-kappaB activation by TNF-alpha is obligatory. Diabetes. 2002;51(5):1319-36. 
Rull A, Escola-Gil JC, Julve J, et al. Deficiency in monocyte chemoattractant protein-1 modifies lipid and glucose metabolism. Exp Mol Pathol. 2007;83(3):361-6.

Rustan AC, Hustvedt B, Drevon CA. Postprandial decrease in plasma unesterified fatty acids during ny3 fatty acid feeding is not caused by accumulation of fatty acis in adipose tissue. Biochem Biophys Acta. 1998;1390:12.

Ruthig DJ, Meckling-Gill KA. N-3 and n-6 fatty acids stimulate restitution by independent mechanisms in the IEC-6 model of intestinal wound healing. J Nutr Biochem. 2002;13(1):8.

Sadurskis A, Dicker A, Cannon B, Nedergaard J. Polyunsaturated fatty acids recruit brown adipose tissue: increased UCP content and NST capacity. Am J Physiol. 1995;269(2 Pt 1):9.

Sagher FA, Dodge JA, Johnston CF, et al. Rat small intestinal morphology and tissue regulatory peptides: effects of high dietary fat. Br J Nutr. 1991;65(1):21-8.

Saghizadeh M, Ong JM, Garvey WT, Henry RR, Kern PA. The expression of TNF alpha by human muscle. Relationship to insulin resistance. J Clin Invest. 1996;97(4):1111-6.

Sánchez-Fidalgo S, Cárdeno A, Sánchez-Hidalgo, Aparicio-Sato M, de la Lastra CA. Dietary extra virgin olive oil polyphenols supplementation modulates DSS-induced chronic colitis in mice. J NutrBiochem. 2013;24:1401-13.

Sanchez-Villegas A, Bes-Rastrollo M, Martinez-Gonzalez MA, Serra-Majem L. Adherence to a Mediterranean dietary pattern and weight gain in a follow-up study: the SUN cohort. Int J Obes (Lond). 2006;30(2):350-8.

Sann H, Erichsen J, Hessmann M, Pahl A, Hoffmeyer A. Efficacy of drugs used in the treatment of IBD and combinations thereof in acute DSS-induced colitis in mice. Life Sci. 2013;92(12):708-18.

Sato D, Nakamura T, Tsutsumi K, Shinzawa G et al. Site dependency of fatty acid composition in adipose triacylglycerol in rats and its absence as a result of high-fat feeding. Metabol Clin Exp. 2012:92-98.

Savastano DM, Covasa M. Adaptation to a high-fat diet leads to hyperphagia and diminished sensitivity to cholecystokinin in rats. J Nutr. 2005;135(8):1953-9.

Schmitz G, Ecker J. The opposing effects of n-3 and n-6 fatty acids. Prog Lip Res. 2008;47(2):8.

Sharma AM. Obesity is not a choice. Obes Rev. 2009;10(4):371-2.

Shi H, Bartness TJ. White adipose tissue sensory nerve denervation mimics lipectomyinduced compensatory increases in adiposity. Am J Physiol Regul Integr Comp Physiol. 2005;289(2):R514-R20.

Shi H, Strader AD, Woods SC, Seeley RJ. The effect of fat removal on glucose tolerance is depot specific in male and female mice. Am $J$ Physiol Endocrinol Metab. 2007;293(4):E1012-20. 
Shi Y, Burn P. Lipid metabolic enzymes: emerging drug targets for the treatment of obesity. Nature Rev Drug discovery. 2004;3(8):695-710.

Shiraev T, Chen H, Morris MJ. Differential effects of restricted versus unlimited high-fat feeding in rats on fat mass, plasma hormones and brain appetite regulators. $\mathrm{J}$ Neuroendocrinol. 2009;21(7):602-9.

Smorlesi A, Frontini A, Giordano A, Cinti S. The adipose organ: white-brown adipocyte plasticity and metabolic inflammation. Obes Rev. 2012;13 Suppl 2:83-96.

Sprong RC, Schonewille AJ, van der Meer R. Dietary cheese whey protein protects rats against mild dextran sulfate sodium-induced colitis: role of mucin and microbiota. J Dairy Sci. 2010;93(4):1364-71.

So M, Gaidhu MP, Maghdoori B, Ceddia RB. Analysis of time-dependent adaptations in whole-body energy balance in obesity induced by high-fat diet in rats. Lip Health Dis. 2011;10:99.

Spencer M, Finlin BS, Unal R, et al. Omega-3 fatty acids reduce adipose tissue macrophages in human subjects with insulin resistance. Diabetes. 2013;62:8.

Stanford KI, Middelbeek RJ, Townsend KL, et al. Brown adipose tissue regulates glucose homeostasis and insulin sensitivity. J Clin Invest. 2013;123(1):215-23.

Stansbie D, Brownsey RW, Crettaz M, Denton RM. Acute effects in vivo of anti-insulin serum on rates of fatty acid synthesis and activities of acetyl-coenzyme A carboxylase and pyruvate dehydrogenase in liver and epididymal adipose tissue of fed rats. Biochem $\mathrm{J}$. 1976;160(2):413-6.

Storlien LH, Higgins JA, Thomas TC, et al. Diet composition and insulin action in animal models. Br J Nutr. 2000;83(Suppl 1):5.

Suastika K. Update in the management of obesity. Acta Med Indones. 2006;38(4):231-7.

Suganami T, Yuan X, Shimoda Y, et al. Activaing transcription facotr 3 constitutes a negative feedback mechanism that attenuates saturated fatty acid/toll-like receptor 4 signalling and macrophage activation in obese adipose tissue. Circ Res. 2009;105(1):7.

Sundstrom J, Lind L, Vessby B, et al. Dyslipidemia and an Unfavorable Fatty Acid Profile Predict Left Ventricular Hypertrophy 20 Years Later. Circulation. 2001;103(6):836-41.

Takahashi Y, Ide T. Dietary n-3 fatty acids affect mRNA level of brown adipose tissue uncoupling protein 1, and white adipose tissue leptin and glucose transporter 4 in the rat. $\mathrm{Br}$ J Nutr. 2000;84(2):175-84.

Tchernof A, Despres JP. Pathophysiology of human visceral obesity: an update. Physiol Rev. 2013;93(1):359-404. 
Teran-Garcia M, Adamson AW, Yu G, et al. Polyunsaturated fatty acid suppression of fatty acid synthase (FASN): evidence for dietary modulation of NF-Y binding to the Fasn promoter by SREBP-1c. Biochem J. 2007;402(3):591-600.

Theilgaard-Mönch K, Jacobsen LC, Borup R, et al. The transcriptional activation program of human neutrophils in skin lesions supports their important role in wound healing. $\mathrm{J}$ Immunol. 2005;172(12):4.

Thomson AB, Keelan M, Garg M, Clandinin MT. Spectrum of effects of dietary long-chain fatty acids on rat intestinal glucose and lipid uptake. Can J Physiol Pharmacol. 1987;65(12):2459-65.

Tilg H, Moschen AR. Inflammatory mechanisms in the regulation of insulin resistance. Mol Med. 2008;14(3-4):222-31.

Todoric J, Loffler M, Huber J, et al. Adipose tissue inflammation induced by high-fat diet in obese diabetic mice is prevented by n-3 polyunsaturated fatty acids. Diabetol. 2006;49(9):2109-19.

Tran TT, Yamamoto Y, Gesta S, Kahn CR. Beneficial effects of subcutaneous fat transplantation on metabolism. Cell Metab. 2008; 7(5):410-20.

Trayhurn P, Beattie JH. Physiological role of adipose tissue: white adipose tissue as an endocrine and secretory organ. Proc Nutr Soc. 2001;60(3):329-39.

Tur JA, Bibiloni MM, Sureda A, Pons A. Dietary sources of omega 3 fatty acids: public health risks and benefits. Nr J Nutr. 2012;107(suppl 2):S23-52.

Turer AT, Khera A, Ayers CR, et al. Adipose tissue mass and location affect circulating adiponectin levels. Diabetol. 2011;54(10):2515-24.

Turk HF, Monk JM, Fan YY, et al. Inhibitory effects of omega-3 fatty acids on injuryinduced epidermal growth factor receptor transactivation contribute to delayed wound healing. American journal of physiology Cell physiology. 2013;304(9):C905-17.

Turner D, Shah PS, Steinhart AH, Zlotkin S, Griffiths AM. Maintenance of remission in inflammatory bowel disease using omega-3 fatty acids (fish oil): a systematic review and meta-analyses. Inflamm Bowel Dis. 2011;17(1):336-45.

Tyagi A, Kumar U, Reddy S, et al. Attenuation of colonic inflammation by partial replacement of dietary linoleic acid with alpha-linolenic acid in a rat model of inflammatory bowel disease. Br J Nutr. 2012;108(9):1612-22.

Uchiyama K, Odahara S, Nakamura M, et al. The fatty acid profile of the erythrocyte membrane in initial-onset inflammatory bowel disease patients. Dig Dis Sci. 2013;58(5):1235-43.

van den Heuvel JK, van Rozen AJ, Adan RA, la Fleur SE. An overview on how components of the melanocortin system respond to different high energy diets. Eur J Pharmacol. 2011;660(1):5. 
Van Harmelen V, Reynisdottir S, Eriksson P, et al. Leptin secretion from subcutaneous and visceral adipose tissue in women. Diabetes. 1998;47(6):913-7.

Varnalidis I, Ionnidis O, Karamanavi E, et al. Omega 3 fatty acids supplementation has an ameliorative effect in experimental ulcerative colitis despite increased colonic neutrophil infiltration Rev Esp Enferm Dig. 2011;103(10):7.

Vedana EHB, Peres MA, Neves J, Rocha GC, longo GZ. Prevalência de Obesidade e Fatores Potencialmente Causais em Adultos em Região do Sul do Brasil Arq Bras Endocrinol Metabol. 2008;52(7):6.

Vessby B, Uusitupa M, Hermansen K, et al. Substituting dietary saturated for monounsaturated fat impairs insulin sensitivity in healthy men and women: The KANWU Study. Diabetol. 2001;44(3):312-9.

Veyrat-Durebex C, Poher AL, Caillon A, Montet X, Rohner-Jeanrenaud F. Alterations in lipid metabolism and thermogenesis with emergence of brown adipocytes in white adipose tissue in diet-induced obesity-resistant Lou/C rats. Am J Physiol Endocrinol Metab. 2011;300(6):E1146-57.

Wajchenberg BL. Subcutaneous and visceral adipose tissue: their relation to the metabolic syndrome. Endocr Rev. 2000;21(6):697-738.

Wallace TM, Levy JC, Matthews DR. Use and abuse of HOMA modeling. Diab Care. 2004;27(6):1487-95.

Wang H, Storlien LH, Huang XF. Effects of dietary fat types on body fatness, leptin, and ARC leptin receptor, NPY, and AgRP mRNA expression. Am J Physiol Endocrinol Metab. 2002;282(6):E1352-9.

Weisberg SP, McCann D, Desai M, et al. Obesity is associated with macrophage accumulation in adipose tissue. J Clin Invest. 2003;112(12):1796-808.

Weiss EP, Brandauer J, Kulaputana O, et al. FABP2 Ala54Thr genotype is associated with glucoregulatory function and lipid oxidation after a high-fat meal in sedentary nondiabetic men and women. Am J Clin Nutr. 2007;85(1):102-8.

West DB, York B. Dietary fat, genetic predisposition, and obesity: lesson from animal models. Am J Clin Nutr. 1998;67(3S):7.

Wong $\mathrm{SH}, \mathrm{Ng} \mathrm{SC}$. What can we learn from inflammatory bowel disease in developing countries? Curr Gastroenterol Rep. 2013;15(3):313.

$\mathrm{Xu} \mathrm{H}$, Barnes GT, Yang Q, et al. Chronic inflammation in fat plays a crucial role in the development of obesity-related insulin resistance. J Clin Invest. 2003;112(12):1821-30.

Yamamoto T. Nutrition and diet in inflammatory bowel disease. Curr Op Gastroenterol. 2013;29(2):216-21. 
Yu R, Kim CS, Kwon BS, Kawada T. Mesenteric adipose tissue-derived monocyte chemoattractant protein-1 plays a crucial role in adipose tissue macrophage migration and activation in obese mice. Obesity (Silver Spring). 2006;14(8):1353-62.

Yu YH, Ginsberg HN. Adipocyte signaling and lipid homeostasis: sequelae of insulinresistant adipose tissue. Circ Res. 2005;96(10):1042-52. 
APÊNDICE - Artigo "Review of the association between meat consumption and risk of colorectal cancer" 
ANEXO - Laudo da análise bromatológica 
APÊNDICE - Artigo "Review of the association between meat consumption and risk of colorectal cancer" 


\title{
Review of the association between meat consumption and risk of colorectal cancer
}

\author{
Eunjung Kim ${ }^{a, *}$, Desire Coelho ${ }^{b}$, François Blachier $^{c}$ \\ a Department of Food Science and Nutrition, Catholic University of Daegu, Gyeongsan, Korea \\ b Laboratory of Applied Nutrition and Metabolism, University of São Paulo, Brazil \\ ${ }^{c}$ UMR 914 INRA/AgroParisTech, Nutrition Physiology and Ingestive Behavior, Paris, France
}

\section{A R T I C L E I N F O}

Article history:

Received 13 February 2013

Revised 2 July 2013

Accepted 24 July 2013

Keywords:

Colorectal cancer

Meat

Heme

Dietary protein

Microbiota

\begin{abstract}
A B S T R A C T
The incidence of colorectal cancer (CRC) is rapidly increasing in developing countries, especially among populations that are adopting Western-style diets. Several, but not all, epidemiological and experimental studies suggest that a high intake of meat, especially red and processed meat, is associated with increased CRC risk. Potential reasons for the association between high red and processed meat intake and CRC risk include the content of the meat (e.g. protein, heme) and compounds generated by the cooking process (e.g. $\mathrm{N}$-nitroso compounds, heterocyclic amines). These factors can affect the large intestine mucosa with genotoxicity and metabolic disturbances. Increased bacterial fermentation (putrefaction) of undigested protein and production of bacterial metabolites derived from amino acids may affect colon epithelial homeostasis and renewal. This correlates with the fact that most colonic cancers are detected in the distal colon and rectum where protein fermentation actively occurs. However, there are still large controversies on the relationship between red meat consumption and CRC risk. Therefore, the purpose of this review is to enhance the current understanding on the association between high red and processed meat intakes with CRC risk. A principal focus of this review will be to discuss the meatrelated components, such as proteins in the meat, heme, $\mathrm{N}$-nitroso compounds, and heterocyclic amines, and the effects they have upon the large intestine mucosa and the intestinal gut microbiota.
\end{abstract}

ㄷ 2013 Elsevier Inc. All rights reserved.

\section{Colorectal cancer and diet}

Colorectal cancer (CRC) is one of the leading global causes of cancer-related death. It is estimated that more than 1 million cases and 600,000 deaths occur every year [1]. CRC incidence has been rapidly increasing, especially in economically developed countries [2,3]. The etiology of CRC includes both genetic and environmental factors. Among CRC, only approximately $20 \%$ can be attributed to heritable gene variations [4], thus suggesting that the largest fraction of sporadic CRC cases is linked to environmental causes [5]. A subclass of CRC has emerged that is correlated to colitis and chronic inflammatory bowel diseases [6]. A classical model for the genetic changes that occur during colorectal tumorigenesis was proposed in

Abbreviations: ACF, aberrant crypt foci; BCFAs, branched chain fatty acids; CRC, Colorectal cancer; HAAs, heterocyclic aromatic amines; HP, high protein; NOCs, N-nitroso compounds; NP, normal protein; SCFAs, short chain fatty acids; SRB, sulfate-reducing bacteria; UC, ulcerative colitis.

* Corresponding author. Department of Food Science and Nutrition, Catholic University of Daegu, 13-13 Hayang-ro, Hayang-eup, Gyeongsan-si, Gyeongbuk, 712-702, Korea. Tel.: +82 53850 3523; fax: +82 538503516.

E-mail address: kimeunj@cu.ac.kr (E. Kim). 
1990 by Fearon and Vogelstein [7]. These genetic and epigenetic alterations impact the normal process of large intestine epithelium renewal [8]. Briefly, these abnormalities interfere with the process of normal epithelial cell division, differentiation, migration, and apoptosis as well as with cell signaling in response to extracellular and intracellular regulators [9-12].

Among the environmental factors that are involved in the modulation of CRC risk, dietary parameters are presumed to play a significant role [13]. The variation of cancer incidence between countries appears largely associated with differences in dietary habits [14]. Several epidemiological and experimental studies have suggested that consumption of a typical Western-style diet that is high in fat and protein significantly increases CRC risk [15], but a high intake of fruits, vegetables, and whole grains is shown to be protective against CRC [16]. However, it is only fair to say that epidemiological studies are markedly dependent on the methodologies used to obtain and analyze dietary and lifestyle information and this can contribute to the variability of the results obtained. Furthermore, epidemiological studies cannot establish causal relationships between a given dietary parameter and the endpoint measured, eg, CRC [17]. Nevertheless, the occurrence of CRC is shown to be significantly increased in Japanese people who have migrated to the United States and adopted a more Western-style diet/lifestyle compared with those living in Japan [18]. This strongly suggests a significant role of the environment in the development of CRC. More recently though, the incidence of CRC has dramatically increased in Japan, which coincides with an overall increased consumption of the Westernized diet $[19,20]$.

\section{Meat consumption and CRC}

Among all cancers, colon cancer appears to have the strongest association with meat consumption $[14,21]$. Meat is an important source of dietary protein and essential nutrients, including iron, zinc, and vitamin $\mathrm{B}_{12}$, if consumed in non-excessive amounts. Some of these nutrients (such as iron) are deficient in the diets of many people in numerous countries [22].

Although there is heterogeneity between the different studies [13], several population studies suggest that a high meat intake, especially of red and processed meat, increases CRC risk in a dose-dependent manner [23-25]. Daniel et al found that CRC risk increased linearly with an increased consumption of red/processed meats at up to $140 \mathrm{~g} / \mathrm{d}$ [26], and the frequency of red meat consumption was more strongly associated with a risk of colorectal carcinogenesis than the amount of meat consumed [27]. However, when the total meat intake was constant, a $10 \mathrm{~g} / 1000 \mathrm{kcal}$ increase in white meat consumption was associated with a significant reduction in the risk of cancer of the colon and rectum [28]. The World Cancer Research Fund and American Institute of Cancer Research report, which is based on an extensive review of the existing evidence by an international panel of experts, concluded that a high intake of red or processed meats is a convincing and probable cause of CRC. The risk of CRC was estimated to increase by $29 \%$ for every $100 \mathrm{~g} /$ day increase in red meat and by $21 \%$ for every $50 \mathrm{~g} /$ day increase in processed meat consumption [13]. In a recent prospective study of Danish men and women, the risk for rectal cancer was elevated with a higher intake of pork, while the risk for colon cancer was elevated with a higher intake of lamb. However, no overall association was found between intake of red meat, processed meat, or poultry for colon and rectal cancer [29].

It should be mentioned that the relationship between red meat consumption and CRC is still the subject of intense scientific debate. Recent reviews of prospective epidemiologic studies have concluded that the association between red meat consumption and CRC, when detected, is generally rather weak $[30,31]$. In a multiethnic cohort with 165,717 participants, it was concluded that there was no role for meat in the etiology of colorectal cancer [32]. Similarly, another study found no association between colorectal cancer risk and intake of meat [33]. Alexander et al also found a lack of a clear dose-response relationship between red meat intake and CRC in an analysis of more than 35 prospective studies [31]. Therefore, it appears that currently available epidemiologic evidence is still not sufficient enough to support an independent positive association between red meat consumption and CRC [34]. However, there is the possibility that an overall association may be modified or confounded by other dietary factors (eg, high intake of refined sugars and alcohol, or low intake of fruits and vegetables) and/ or behavioral factors (eg, low physical activity and smoking). Abundant epidemiological evidence has shown a lower risk of colorectal cancer with higher overall levels of physical activity, although the effect on rectal cancer is less clear than the effect on colon cancer [13].

\section{The mechanisms of action of meat-related components on CRC development}

Several plausible mechanisms to explain the association between meat, and particularly red or processed meat, consumption and CRC risk have been suggested [35-38]. These mechanisms implicate proteins in the meat, heme iron, $\mathrm{N}$-nitroso compounds (NOCs), and heterocyclic aromatic amines (HAAs) (Fig. 1). Notably, these different parameters

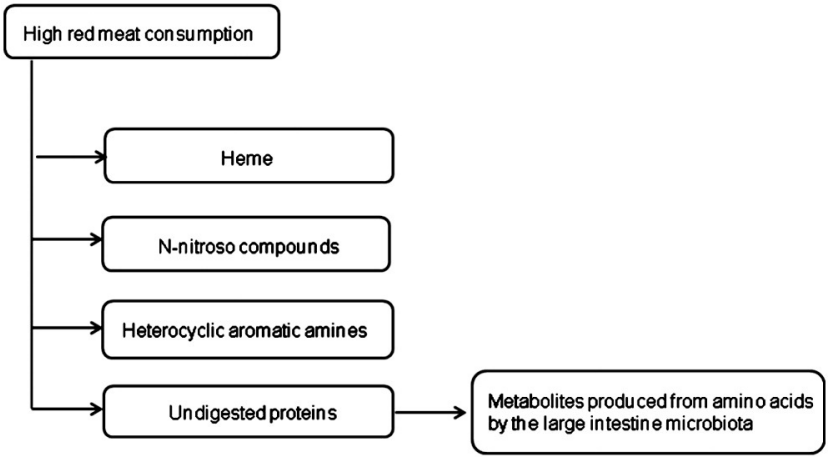

Fig. 1 - Schematic view of compounds associated with high meat consumption which may impact colonic epithelial cell physiology. 
may act synergistically in increasing CRC risk. Furthermore, although experimental evidence is limited, it is tempting to postulate that compounds linked to high meat consumption, which are not absorbed by the small intestine and thus transferred into the large intestine lumen, may have deleterious effects on the large intestine epithelial cells when present in excess [39]. In terms of genotoxicity and metabolic disturbances, these compounds may be active as is or after conversion to bacterial metabolites by the microbiota.

\subsection{Protein}

Protein is a major constituent of meat. In red meat, the amount of protein is between $20 \mathrm{~g} / 100 \mathrm{~g}$ (beef) and $33 \mathrm{~g} / 100 \mathrm{~g}$ (roe deer). In poultry, the amount of proteins varies from $20 \mathrm{~g} /$ $100 \mathrm{~g}$ (quail) up to $37 \mathrm{~g} / 100 \mathrm{~g}$ (pigeon). In Western Europe and the United States of America, protein consumption averages 1.5-2.0 times the recommended intakes $\left(0.83 \mathrm{~g} \mathrm{~kg}^{-1} \mathrm{~d}^{-1}\right)$ [40]. The levels of protein consumption throughout other countries all around the world, however, are vastly different according to the level of socio-economic development, food availability, and cultural dietary habits $[39,41]$.

As reviewed by McIntosh and Le Leu [42], experimental studies with animal models of chemically induced colonic preneoplastic or neoplastic lesions have shown that dietary proteins can influence cancer risk, depending on their quantity and quality. Some of these have a promotional influence and others a preventive effect relative to an arbitrarily established standard. However, the data are sometimes difficult to interpret. For instance, high-protein (HP) diets usually depress food intake, and this may represent a confounding factor [43].

The association between high protein intake and CRC risk can, in some studies, be explained by the induction of genetic damage in colonocytes. When rats were fed a HP diet comprised of casein (25\%), soybean protein $(25 \%)$, or white or red meat ( 25 or $35 \%$, respectively), genetic damage in colon cells, as well as the level of fecal p-cresol, significantly increased compared to that in rats fed a normal-protein diet (15\% casein) [44-47]. Toden et al showed that animal-derived proteins (casein and red meat) increased colonocyte DNA damage and induced a thinning of the mucus barrier in rats $[44,45]$. They also showed that increasing the level of dietary casein from $15 \%$ to $25 \%$ induced greater DNA damage (measured as comet tail moments indicating DNA strand breakage) in isolated colonocytes and thinner colonic mucus layer [46]. The $25 \%$ soybean protein diet induced even greater colonocyte DNA damage compared to the HP casein diet, but mucus layer thickness was not affected by an increase in soybean protein intake. These data suggest that total protein content is more important to CRC risk than the source of protein, i.e. animal-derived (casein) or plant-derived (soybean) protein. However, the source of protein cannot be completely excluded from consideration. In one study, whey protein did not affect DNA damage or mucus layer thickness, while the level of DNA damage was substantially reduced in rats fed white meat (chicken) compared to rats fed red meat [47]. Winter et al also found that the induction of the promutagenic adduct $O(6)$-methyl-2-deoxyguanosine and fecal $p$-cresol levels were significantly higher in rats fed red meat than in rats fed casein [48].
In contrast, Andriamihaja et al found that the whole luminal content and water content mass was significantly higher in rats fed a HP diet than in rats fed a normal-protein diet (53\% vs. $14 \%$ whole milk proteins, respectively) [49]. The levels of ammonia, short-chain fatty acids (SCFAs), and branched-chain fatty acids (BCFAs) in colonic luminal content were also significantly increased with a HP diet. Although SCFAs from luminal origin are known to be a major energy source for colonic epithelial cells for oxidative metabolism [50], ammonia in excess has been shown to decrease colonocyte mitochondrial oxygen consumption [49]. The protease activities in the colon content also increased nearly 3-fold, and the heights of the brush-border membranes, maybe as a consequence of impaired oxidative energy metabolism, were drastically reduced in HP-fed animals [49]. In this study, however, the morphology of tight junctions and the overall colonic mucosa were not affected by a HP diet.

Although alimentary protein digestion followed by amino acid and oligopeptide absorption in the small intestine is an efficient process, substantial amounts of nitrogenous compounds from both exogenous and endogenous origins can enter the large intestine through the ileocecal junction [51]. When present in the large intestine luminal content, this material is mixed with the microbiota and undergoes proteolysis, resulting in peptide and amino acid release, which is followed by the production of numerous bacterial metabolites (Fig. 2) [52].

The amount of protein entering the colon depends on the amount and digestibility of protein in food rather than the source of the protein [53]. Overall, animal and dairy proteins are somewhat more digestible than plant proteins (over $90 \%$ vs $70 \%-90 \%$ ) [54]. Undigested or endogenous protein in the colon is then hydrolyzed to small peptides and free amino acids by the residual pancreatic [55] and bacterial proteases [56] that are more active at the neutral-to-slightly alkaline $\mathrm{pH}$ of the distal parts of the colon. Rats fed with cooked casein had cecal ammonia levels 2 to 3 times higher than animals fed other proteins, including natural casein, keratin (hydrolyzed or not), and bovine serum albumin (oxidized or not) [57]. This suggests that a decrease in protein digestibility increases the amount of protein reaching the colon and the rate of protein fermentation by colonic bacteria. In contrast to carbohydrates, protein fermentation has been suggested to be detrimental for the gut. This is because potentially toxic bacterial metabolites produced in excess from amino acids may promote DNA damage and metabolic alterations in colonic epithelial cells, which could hamper the normal renewal of the epithelium and its homeostasis. Whether this plays a significant role in the colorectal carcinogenesis is an important question that remains to be answered. In approximately $60 \%$ of CRC cases, the tumor is located in the distal colon or rectum, where protein fermentation mainly occurs [15].

The products of protein fermentation, which have been identified, include ammonia $\left(\mathrm{NH}_{4}^{+} / \mathrm{NH}_{3}\right)$, phenolic and indolic compounds, BCFAs, and hydrogen sulfide $\left(\mathrm{H}_{2} \mathrm{~S}\right)$.

\subsubsection{Ammonia}

Ammonia is produced during amino acid deamination and urea hydrolysis by colonic bacteria and bacterial urease, respectively [39]. Approximately $25 \%$ of the daily excreted 


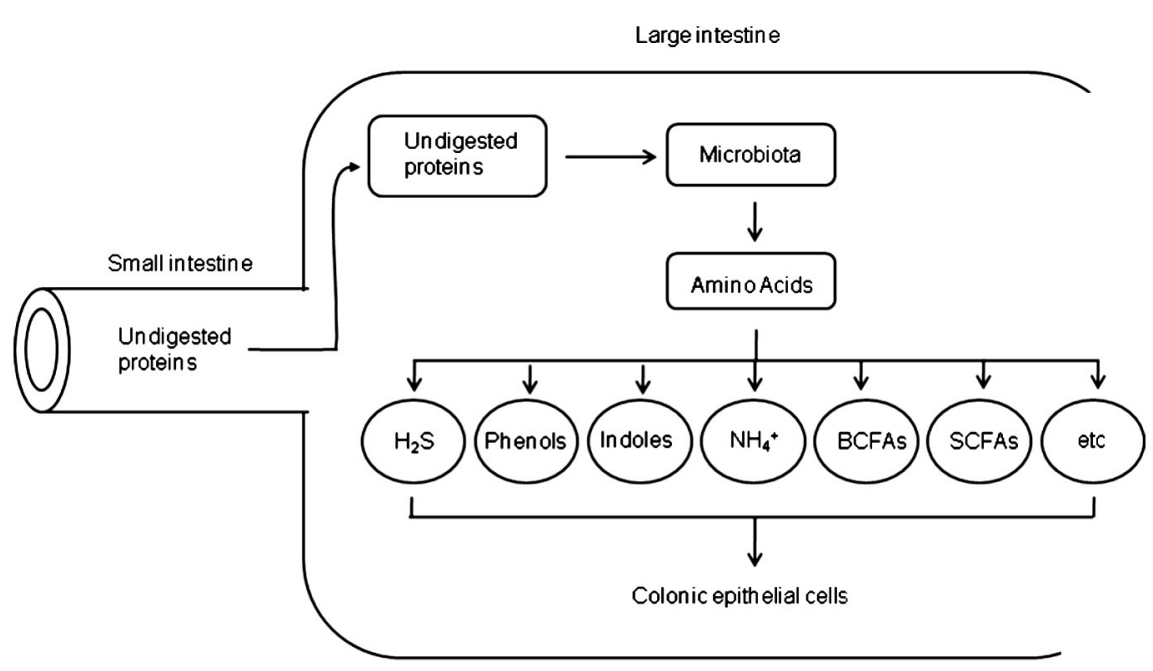

Fig. 2-Schematic view of the metabolism of undigested proteins in the large intestine. Alimentary and endogenous undigested proteins undergo the activities of the microbiota leading to the release of amino acids and further metabolism resulting in the production of a complex mixture of metabolic end-products that may enter into the colonocytes and exert deleterious effects when present in excess.

urea, which is synthesized in the liver, reaches the intestine and is hydrolyzed to ammonia and carbon dioxide $\left(\mathrm{CO}_{2}\right)$ by bacterial urease [58]. Ammonia is also produced from endogenous nitrogen recycling. Initially, it was thought that endogenous urea hydrolysis by the gut microflora was the main source of ammonia. However, the amount of ammonia produced by urea hydrolysis in the colon is probably minor [59] when compared with amino acid deamination. Regardless, the ammonia concentration in the large intestine increases as protein intake increases [60].

One-week supplementation with protein-rich food in men and women significantly increased levels of fecal SCFAs, ammonia, volatile organic compounds, and urinary $p$-cresol [61]. Bacteria can also use ammonia for their own metabolism and protein synthesis. Unused ammonia is then excreted in feces or absorbed by colonocytes and converted to urea in the liver urea cycle. Interestingly, in colonocytes, ammonia can be detoxified by two metabolic pathways. First, ammonia can be condensed with bicarbonate leading to the synthesis of carbamyl phosphate through the activity of carbamylphosphate synthetase, followed by the condensation of carbamylphosphate with L-ornithine through the activity of ornithine transcarbamylase, and leading to the synthesis of the end-product L-citrulline (Fig. 3) [62,63]. A second, more recent method for ammonia detoxification involves the conversion of ammonia and L-glutamate into L-glutamine through the glutamine synthetase activity in colonic epithelial cells [64]. The glutamine synthetase activity in colonocytes is relatively high, representing more than 10 times the activity measured in small intestine enterocytes [49].

Excessive amounts of ammonia have been reported to alter cell viability and nucleic acid synthesis, and stimulate growth of cancerous cells in preference to noncancerous cells in tissue culture [65]. Clinton et al reported that intrarectal infusion of a high concentration of ammonium acetate in rats significantly increased tumor incidence, number of highgrade dysplasia lesions, and the total number of adenocarci- nomas in a model of N-methyl-N'-nitro-N-nitrosoguanidineinduced colon carcinogenesis [58]. Perfusion of ammonium acetate or ammonium chloride also caused histological damage and loss of mucus in the rat colon [66]. In the human colon adenocarcinoma cell line HT-29 Glc(-/+), administration of increasing doses of ammonium chloride suppressed cell proliferation without affecting cell viability, cellular differentiation, or cell cycle distribution [67]. This suggests that ammonia in the colon may alter colonic epithelial cell growth. However, since ammonia was not metabolized into carbamoyl-phosphate and L-citrulline in these cells, it is possible that the growth inhibitory effect of ammonia in HT-29 Glc(-/+) cells was related to the inability of these cells to metabolize ammonia.

\subsubsection{Phenolic and indolic compounds and BCFAs}

Phenolic and indolic compounds are produced from aromatic amino acids (tyrosine, tryptophan, and phenylalanine) during degradation by bacteria [17]. Tyrosine is degraded into 4hydroxyphenylpyruvate and 4-hydroxyphenylacetate, which themselves are finally degraded to phenol, 4-ethylphenol, and $p$-cresol. Degradation products of tryptophan include indole, indole acetate, and 3-methyl indole (skatole). Phenylalanine is degraded to phenylpropionate and phenylacetate. In vitro, phenol can react with nitrite to produce $p$-diazoquinone, which has mutagenic activity [68]. These phenolic and indolic compounds are largely absorbed and detoxified in the colon and excreted in the urine as $p$-cresol [69]. Skatole concentration increases in the large intestine lumen after a high meat diet or when luminal fermentation is increased due to an increase in intestinal stasis [70]. In rats, increasing the protein dietary intake results in increased $p$-cresol fecal concentration [44]. To the best of our knowledge, there is no available information on the effects of phenolic and indolic compounds in excess on colonic epithelial cells.

Branched chain amino acids are fermented to BCFAs by bacteria. Valine, leucine, and isoleucine are fermented to 


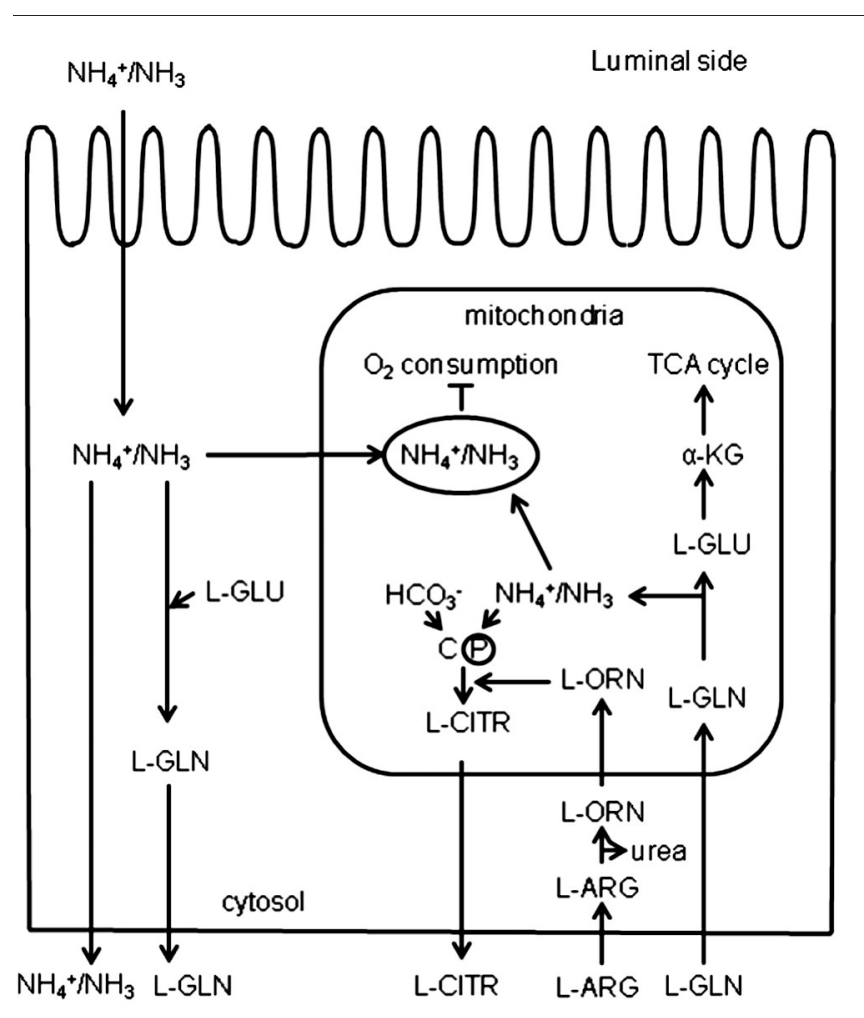

Apical side

Fig. 3 - Schematic view of the detoxification of ammonia in colonic epithelial cells. The conversion of ammonia into L-glutamine in the cytosol and into L-citrulline in the mitochondria is presented. L-ARG, L-arginine; L-CITR, L-citrulline; L-GLN; L-glutamine; L-GLU, L-glutamate; L-ORN, L-ornithine; $\alpha$-KG, $\alpha$-ketoglutarate; CP, carbamyl phosphate.

isobutyrate, isovalerate, and 2-methylbutyrate, respectively [71]. Little information is available regarding the effects of BCFAs on colonic epithelial cells, other than their effects on electrolyte absorption and secretion [39]. Since human enzymes cannot produce phenols, indoles, and BCFAs, the levels of these metabolites in urine or feces are considered markers for bacterial protein fermentation in the colon [61].

\subsubsection{Hydrogen sulfide}

$\mathrm{H}_{2} \mathrm{~S}$ is another metabolite produced by bacterial fermentation of sulfur-containing amino acids (methionine, cystine, cysteine, and taurine), with a reported deleterious effect on colonocytes [72]. $\mathrm{H}_{2} \mathrm{~S}$ is mainly produced by indigenous sulfate-reducing bacteria (SRB) as an end product of anaerobic respiration [73]. The concentration of $\mathrm{H}_{2} \mathrm{~S}$ ranges from 0.2 to 1 $\mathrm{mmol} / \mathrm{L}$ and 0.3 to $3.4 \mathrm{mmol} / \mathrm{L}$ in mouse intestine and human feces, respectively [74,75].

The toxicity of $\mathrm{H}_{2} \mathrm{~S}$ was reported by Ramazzini in 1750 [76] and has been shown to be comparable to that of cyanide [77]. $\mathrm{H}_{2} \mathrm{~S}$ can damage the intestinal epithelium, and thus, may contribute to chronic inflammation [78,79], decreased cell growth [80], and perturbation of the balance between apoptosis, proliferation, and differentiation of intestinal epithelial cells [79]. Moreover, $\mathrm{H}_{2} \mathrm{~S}$ by itself is genotoxic. It can directly cause DNA strand breaks and nuclear genomic DNA damage in the ovary cells of Chinese hamsters, even at concentrations as low as $1 \mu \mathrm{mol} / \mathrm{L}$ [81,82]. These data are consistent with the results of previously reported clinical studies, which have shown that $\mathrm{H}_{2} \mathrm{~S}$ or SRB in the intestine is associated with a risk of ulcerative colitis (UC) and CRC $[83,84]$. However, Pitcher et al did not find differences in fecal SRB levels between UC patients and control subjects [85]. This suggests that the bioavailability of precursors for hydrogen sulfide production by the large intestine bacteria may be what determines the concentration of luminal sulfide. Recent studies have shown that colonic epithelial cells are equipped with an enzymatic complex that allows them to detoxify sulfide by oxidizing it in the mitochondrial respiratory chain $[86,87]$. This enzymatic system, called the sulfide oxidizing unit which contains sulfide quinone reductase, ETHE1 dioxygenase, and thiosulfate sulfur transferase, allows the conversion of sulfide into thiosulfate in mitochondria with ATP production (Fig. 4) [88].

However, it is worthwhile to note that the composition of the luminal content in terms of bacterial metabolites is presumed to be extremely complex with only a few compounds having been identified. For instance, it has been shown that the thermolysis of casein substantially decreased its digestibility and increased colonic bacterial protein fermentation products such as ammonia, phenol, cresol, and indol-3-ol in fecal and urine samples of rats [89]. When rats were fed a less digestible protein, such as rice or potato protein, the production of cecal succinate was decreased compared with that in animals fed casein [90]. Notably, the levels of fermentation products were not well correlated with the degree of colon cancer promotion. One-hour thermolyzed protein induced the maximal levels of fermentation products, and levels decreased as thermolysis time was extended. In contrast, the size of aberrant crypt foci (ACF) continued to increase with thermolysis time, while the number of ACF was not affected by thermolysis. Furthermore, thermolysis of soy and egg-white proteins increased levels of protein fermentation products but not ACF size. Thermolyzed egg-white protein even decreased the size of ACF in rats. Clearly, more investigations are needed to elucidate the mechanism by which a high protein diet may increase CRC risk.

\subsection{Heme}

Heme is the iron-porphyrin pigment of red meat and induces cytotoxicity of gut contents, which damages the colon surface epithelium [91]. Ijssennagger et al showed that supplementation of heme $(0.5 \mu \mathrm{mol} / \mathrm{g})$ to a "Westernized" diet ( $40 \%$ fat) for 14 days in C57BL6/J mice increased colon epithelial hyperproliferation and decreased apoptosis, resulting in hyperplasia of the colon mucosa [91]. Similarly, supplementation of 0.5 $\mathrm{mmol}$ hemin (chloride of heme)/kg to a purified diet in rats for 14 days induced a 10- to 50-fold increase in cytotoxicity of the fecal water $[92,93]$. In this supplemented rats, there was a nearly $100 \%$ increase in cell proliferation and a 100 -fold decrease in host DNA excretion (almost total inhibition of exfoliation of the colonocytes), compared with rats fed a control diet. Furthermore, the surface of the colon epithelium was injured and the crypt depth was significantly increased by compensatory hyperproliferation of crypt cells, thus leading to epithelial hyperplasia which increases the risk of colon 


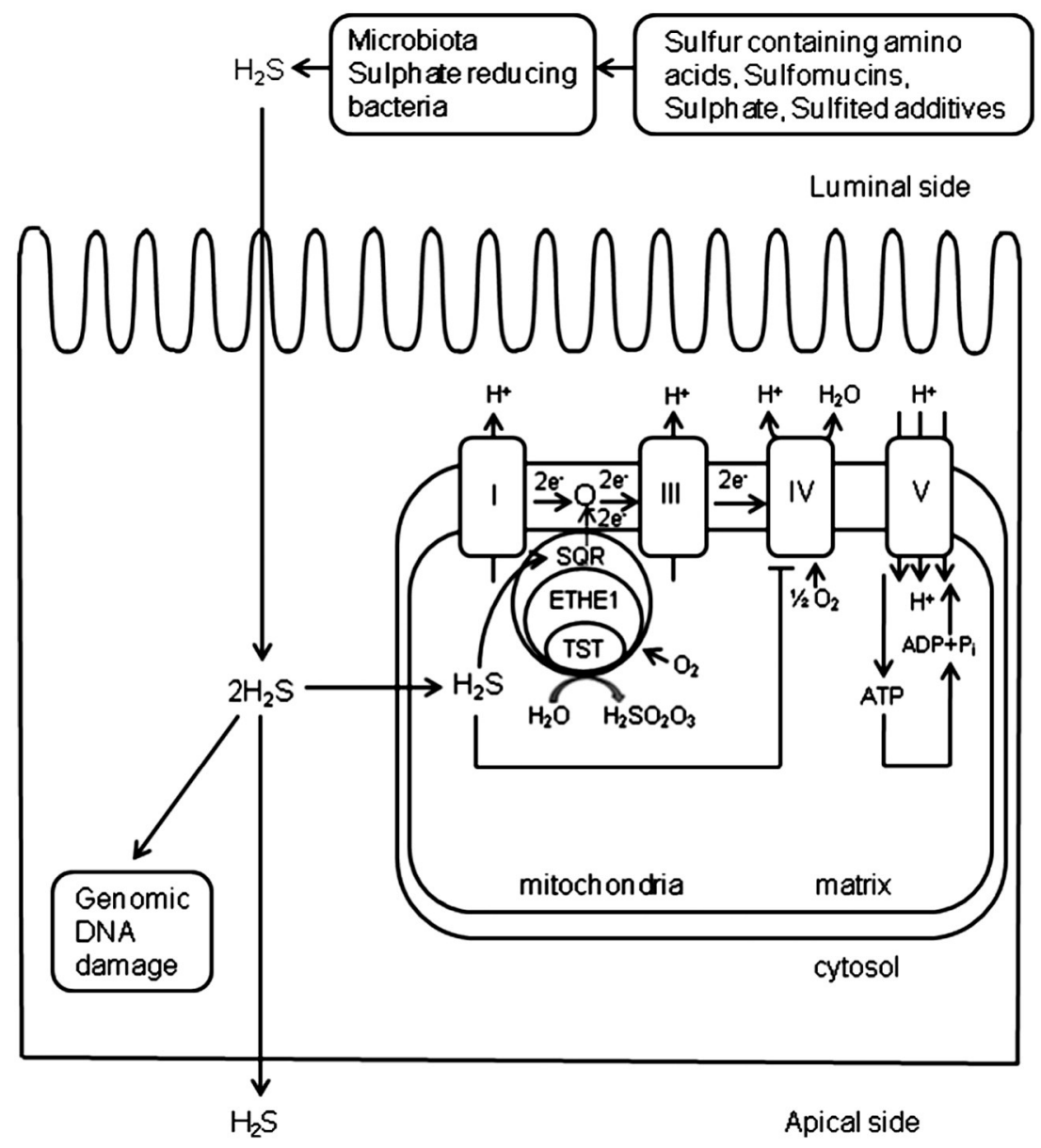

Fig. 4-Schematic view of the detoxification of hydrogen sulfide in colonic epithelial cells. The conversion of $\mathrm{H}_{2} \mathrm{~S}$ into thiosulfate is presented. SQR, sulfide quinone reductase; ETHE1, ETHE1 dioxygenase; TST, thiosulfate sulfur transferase.

cancer [92]. Colon microarray analysis revealed that the expression of mucosal pentraxin was approximately 30 -fold down-regulated by chloride hemin supplementation [94,95]. Since pentraxin is involved in the removal of old colonic epithelial cells, down-regulation of this gene may explain the hemin-induced inhibition of apoptosis and exfoliation of the colonocytes. Hemin also down-regulated the inhibitors of proliferation, Wnt inhibitory factor 1, Indian Hedgehog and bone morphogenetic protein 2, and interleukin (IL)-15 [91]. As the amount of hemin/heme was increased in the diet, the incidence of ACF and mucin-depleted foci also increased in rats $[96,97]$. In fact, hemoglobin/hemin is both genotoxic and cytotoxic in vitro to primary colonocytes and human colon tumor cells (HT29 clone 19A), as shown by increased DNA and membrane damage [98].

A meta-analysis of prospective cohort studies of colon cancer, in which heme intake had been estimated, showed that the relative risk of colon cancer was slightly increased at 1.18 (95\% confidence interval 1.06-1.32) for patients with the highest consumption of heme iron [99]. As another mechanism for heme-induced colon cancer, it has been suggested that heme catalyzes the lipid peroxidation reaction and produces lipid alkoxy radicals as well as heme oxyradicals, which can lead to cellular damage $[100,101]$. The tissue damage caused by these heme-catalyzed radicals is known to be similar to that of ionizing radiation [102]. This may be one of the mechanisms by which the high intake of vegetables and fruits containing various antioxidants protects against CRC. However, the Nurses' Health Study and Health Professionals Follow-up Study showed no strong correlation between consumption of heme iron and incidence of CRC in an analysis of 2,114 CRC cases during a 22-year period of follow-up [103]. In addition, Kabat et al also reported no association between intake of iron, heme iron, or iron from meat and CRC incidence in a cohort study of 49,654 Canadian women [104]. Therefore, these results make the association between heme consumption and increased CRC risk questionable.

\subsection{NOCs}

NOCs can be formed via nitrosation of organic compounds in meat by nitrite, one of the methods of preservation. Endogenous $\mathrm{N}$-nitrosation of amines forms nitrosamines [105]. Several NOCs are known carcinogens and can alkylate DNA leading to G-to-A mutations [106,107]. NOCs are synthesized endogenously in the gastrointestinal tract [108] and found in foods containing nitrites and nitrates, as well as in food that has been exposed to nitrogen oxide (such as processed meats) [109]. Heme iron, abundantly present in red meat, also has a catalytic effect on the endogenous formation of NOCs [110]. 
Bingham et al reported that increased levels of red meat consumption were highly correlated with the total amount of NOCs in fecal samples of volunteers [111]. A 7-day dietary red meat intervention study in volunteers showed that red meat intake significantly increased fecal water genotoxicity, but that the excretion of NOCs in feces was not affected [112]. The equivalent amount of white meat intake also had no effect on fecal NOCs [111].

\subsection{HAAs}

HAAs are formed on the surface of food with high protein content, such as meat exposed to high-temperature cooking [113]. Cooking over a direct flame also produces HAAs on the surface of meat [114]. More than 20 HAAs have been identified so far [115]. These compounds are not exclusively found in red and processed meat but are also found in poultry. A recent study suggested that diets high in poultry cooked at a high temperature were associated with an increased colorectal cancer risk [116]. HAAs are powerful carcinogens and induce tumors in multiple organs in experimental animal models [117]. Since prolonged cooking at high temperatures produces more HAAs, consumption of well-done grilled meat has been reported to be associated with the highest risk for CRC in a number of case-control studies [38,118,119]. However, not all human studies have shown a positive association between HAA intake and CRC risk $[120,121]$. Gunter et al reported that an increase of $10 \mathrm{~g}$ of barbecued red meat/day was associated with a $29 \%$ increased risk of adenoma, but oven-broiled red meat consumption was inversely related to adenoma risk, when compared with the data for control subjects (nonconsumers) [120]. In the multiethnic cohort study by Ollberding et al, no role of heterocyclic amines was suggested in the etiology of colorectal cancer [32]. In addition to HAAs, a variety of other potentially carcinogenic compounds, such as polycyclic aromatic hydrocarbons, NOCs, and lipid peroxides, are also found in cooked meats, making it difficult to distinguish between the effects of individual compounds. It is likely that the combinations of these compounds, depending on their respective doses, may be responsible for a putative increase of CRC risk [38].

\section{Gut microbiota and CRC risk}

Dietary modulation of CRC risk may be a result of the effects on the gut microbiota composition [122]. The colon microflora is composed primarily of bacteria, but it also includes fungi and protozoa [123]. Each individual is colonized by 300 to 500 different species of microbial organisms, collectively called the microbiota. The total number of organisms is estimated to be $10^{11}$ to $10^{12}$ cells/g luminal content, which is 10 -times more than the total number of eukaryotic cells in the human body [124]. The bacteria population in the gut can be classified into predominant $\left(>10^{9} \mathrm{CFU} / \mathrm{g}\right)$, subdominant $\left(10^{6}-10^{9} \mathrm{CFU} / \mathrm{g}\right)$, and transit $\left(<10^{6} \mathrm{CFU} / \mathrm{g}\right)$ bacteria [125]. The subdominant population is composed of endogenous or resident bacteria, whereas the transit population fluctuates according to the number of ingested bacteria. Among the microbiota, the genera Bifidobacterium and Lactobacillus have been considered potentially beneficial for the host [125]. However, the genera Clostridium, Staphylococcus, Fusobacterium, and Peptostreptococcus are supposed to be potentially harmful. Pseudomonas aeruginosa, Bacteroides, Eubacteria, Enterobacteria, and Escherichia coli can be either beneficial or harmful to the host health depending on the overall environment.

The balance between so-called "harmful" and "beneficial" bacteria may influence carcinogen bioactivation and, thus, cancer risk. For instance, Streptococcus bovis, Bacteriodes, Fusobacterium, Clostridia, and Helicobacter pylori have been implicated in tumor development [126-130]. However, some strains of bacteria, including Lactobacillus acidophilus, L. plantarum, and Bifidobacterium longum have been shown to inhibit colon carcinogenesis [131-133]. Moore and Moore found that the fecal concentrations of 15 bacterial species, including Bacteroides and Bifidobacterium, were higher in populations with high colon cancer risk (polyp patients and Japanese-Hawaiians) [127]. Concentrations of 6 bacterial species, including Lactobacillus and Eubacterium aerofaciens, were higher in populations with low colon cancer risk (rural native Japanese and rural native Africans) [127]. Still, it should be noted that no causal link between these parameters was established.

There is ample evidence to indicate that the diet has an impact in shaping gut microbiota. Significant differences in intestinal microbial composition have been demonstrated between children from Europe and Africa. African children showed greater levels of fecal Bacteroidetes and a lack of Firmicutes, compared with children from Europe [134]. This difference was correlated with the incidence of inflammatory bowel disease in the United Kingdom and Africa [135].

O'Keefe et al examined the dietary differences and colonic bacterial flora in native Africans (NAs), African Americans (AAs), and Caucasian Americans (CAs) [136]. Colon cancer is extremely rare in NAs, in whom the prevalence is $<1 / 100,000$. However, the life expectancy in this continent is lower than in Europe and America, and sporadic colon cancer is usually diagnosed in older individuals. In contrast, AAs have the highest prevalence $(65 / 100,000)$ of colon cancer of all other ethnic populations in the United States [137]. This difference may be partly related to environmental differences between the two regions, especially the diet. The dietary intake of AAs was not vastly different to that of CAs, but both consumed more energy, total and animal protein, saturated fat, cholesterol, folate, calcium, iron, vitamin C, vitamin A, and zinc than NAs. There was, however, no difference in fiber intake. Since NAs consumed significantly lower amounts of the so-called protective nutrients, including the antioxidant vitamins $\mathrm{A}$ and $\mathrm{C}$, folate, and calcium, the most powerful parameters associated with colon cancer risk were thought to be protein and fat intake [138]. Fasting breath methane concentrations, in response to oral lactulose which is an indicator of the mass of bacteria in the colon, were significantly higher in NAs than AAs and CAs, but the fecal colony counts of $7-\alpha$ dehydroxylating bacteria were highest in AAs. The counts of Lactobacillus were not significantly different between the 3 groups. Colonic epithelial proliferation rates measured by Ki-67 staining were significantly higher for AAs and CAs than for NAs throughout the entire colon.

The Lionetti group measured the gut microbiota of children 1 to 6 years of age, living in a village of Burkina Faso (BF) in 
rural Africa, who consumed a traditional rural African diet that was low in fat and animal protein and rich in starch and fiber. The microbiota measurements were compared with those of European (EU) children living in an urban area of Italy who ate a typical Western diet that was high in animal protein and fat and low in fiber [134]. High-throughput pyrosequencing with 16S rRNA revealed that Actinobacteria and Bacteroidetes counts were higher in BF children than in EU children, whereas Firmicutes and Proteobacteria were more abundant in EU than in BF children. In addition, Prevotella, Xylanibacter, Butyrivibrio, and Treponema (which ferment xylane, xylose, and carboxymethylcellulose to SCFAs) were found only in BF children. In fact, fecal SCFA concentrations were significantly higher in BF children than in EU children.

The bacterial species known to contribute to protein fermentation includes Clostridium, Bacteroides, Streptococcus, Propionibacterium, and Bifidobacterium [139,140]. Since meat protein contains abundant sulfur amino acids, the consumption of meat may also favor the growth of SRB (eg, Desulfovibrio vulgaris) and the production of $\mathrm{H}_{2} \mathrm{~S}[82,141]$.

Both the type of meat and the cooking process appears to influence the composition and fermentation profile of the human gut microbiota. Shen et al compared the effects of cooked (fried or boiled) meats (beef, chicken, and fish) on the human fecal microbiota using an in vitro fecal batch culture as a model of the gut microbiota [142]. The bacterial counts for the Clostridium histolyticum/perfringens group increased significantly over 48 hours with beef fermentation, either fried or boiled. The counts for the $C$. histolyticum/perfringens group were also significantly different with the different cooking methods. Compared to boiled meats, all the fried meats showed significantly higher numbers of this bacterial group. Bifidobacteria and Bacteroides numbers differed between meat types. At 24 and $48 \mathrm{~h}$ of fermentation, higher numbers of Bifidobacteria were found in chicken than in fish and beef, respectively.

An important, largely unresolved, question remains: how does the gut microbiota influence the risk of CRC or UC other than via the deleterious substances (including fermentation products) produced by the microbiota? Microbiota composition and/or diversity may contribute to colon cancer development by modulating intestinal inflammation. T-cell receptor (TCR)- $\beta /$ p53 double-knockout mice have been noted to spontaneously develop adenocarcinomas in the ileocecum and cecum [143]. However, when the mice were produced in germfree conditions, no adenocarcinomas were detected [143]. In addition, mice bred with targeted deletion of IL-10 or TCR- $\alpha$ have also been shown to spontaneously develop enterocolitis when exposed to bacterial colonization [144], while germ-free IL-10 or TCR- $\alpha$ knockout mice did not develop colitis $[145,146]$. This suggests that the gut microflora is necessary for the development of colonic colitis in these mice.

Recently, Sobhani and co-workers compared microbial dysbiosis from the stools of 60 CRC patients with that from 119 individuals with normal colonoscopy findings [147]. A significant elevation was observed for those that had Bacteroides/Prevotella in the CRC group compared to the control group, and this difference was not affected by general patient characteristics (eg, age, body mass index, or family history of polyps or cancer), by tumor size or location, or by disease stage. The elevation of Bacteroides/Prevotella levels in cancer patients was also associated with higher numbers of IL-17 immunostained cells in the colonic mucosa, compared with controls.

\section{Conclusions and future research}

Meat is an important source of several important dietary compounds, including protein and iron. In several epidemiological studies, high meat consumption was associated with an increased risk for CRC. However, there are other epidemiological studies that have not found an association between meat consumption and CRC risk. It is worth noting that the data presented are very mixed depending on the nature of the studies and on the source and amount of protein-rich foods examined. Given the complexity of the Western diet, it is not surprising that identifying the alimentary compounds that may impact the risk of CRC remains a difficult task. Recent studies suggest that altering the amount of dietary protein can result in marked modifications of the luminal environment of the colonic epithelial cells. Among the few identified metabolites produced by the microbiota from amino acids, it is clear that some of them can exert genotoxic and metabolically deleterious effects. However, detoxification processes in colonocytes are apparently able to control, up to a given level, the intracellular concentrations of bacterial metabolites, thus limiting their deleterious effects. The situation is further complicated by recent data showing that microbiota composition and diversity can be modified by alimentary changes.

Future research is needed to improve our understanding of colorectal cancer and meat and the investigations should address the following: (i) thoroughly characterize the chemical composition of the large intestinal luminal content following increased meat consumption, (ii) determine the genotoxic and metabolic effects of the metabolites generated by the microbiota from undigested (or not fully digested) dietary compounds, (iii) measure the effects of metabolites tested individually or in combination on biological processes involved in epithelial renewal, (iv) determine the metabolic capacity of colonocytes for detoxification of deleterious luminal compounds, and (v) To identify the dietary compounds able to bind to the deleterious bacterial metabolites in the luminal large intestine content thus allowing to decrease their bioactive concentration and toxicity towards epithelial stem cells.

\section{Acknowledgment}

We would like to thank Jaeyong Park, Aji Sutrisno (Catholic University of Daegu), and Joyce E. Rundhaug (University of Texas MD Anderson Cancer Center) for their critical reading and advice. This work was supported by research grants from the Catholic University of Daegu in 2010.

\section{R E F E R E N C E S}

[1] Jemal A, Bray F, Center MM, Ferlay J, Ward E, Forman D. Global cancer statistics. CA Cancer J Clin 2011;61(2):69-90.

[2] Parkin DM, Bray F, Ferlay J, Pisani P. Global cancer statistics, 2002. CA Cancer J Clin 2005;55(2):74-108. 
[3] Center MM, Jemal A, Smith RA, Ward E. Worldwide variations in colorectal cancer. CA Cancer J Clin 2009;59(6): 366-78.

[4] Grivennikov SI. Inflammation and colorectal cancer: colitisassociated neoplasia. Semin Immunopathol 2013;35(2): 229-44.

[5] Lichtenstein P, Holm NV, Verkasalo PK, et al. Environmental and heritable factors in the causation of cancer-analyses of cohorts of twins from Sweden, Denmark, and Finland. N Engl J Med 2000;343(2):78-85.

[6] Terzic J, Grivennikov S, Karin E, Karin M. Inflammation and colon cancer. Gastroenterology 2010;138(6):2101 e5-14 e5.

[7] Fearon ER, Vogelstein B. A genetic model for colorectal tumorigenesis. Cell 1990;61(5):759-67.

[8] Markowitz SD, Bertagnolli MM. Molecular origins of cancer: molecular basis of colorectal cancer. N Engl J Med 2009;361(25):2449-60.

[9] Wong WM, Mandir N, Goodlad RA, et al. Histogenesis of human colorectal adenomas and hyperplastic polyps: the role of cell proliferation and crypt fission. Gut 2002;50(2): 212-7.

[10] Lamprecht SA, Lipkin M. Migrating colonic crypt epithelial cells: primary targets for transformation. Carcinogenesis 2002;23(11):1777-80

[11] Romagnolo B, Berrebi D, Saadi-Keddoucci S, et al. Intestinal dysplasia and adenoma in transgenic mice after overexpression of an activated beta-catenin. Cancer Res 1999;59(16):3875-9.

[12] Merritt AJ, Potten CS, Watson AJ, et al. Differential expression of bcl-2 in intestinal epithelia. Correlation with attenuation of apoptosis in colonic crypts and the incidence of colonic neoplasia. J Cell Sci 1995;108(Pt 6):2261-71.

[13] World Cancer Research Fund/American Institute for Cancer Research. Food, nutrition, physical activity, and the prevention of cancer: a global perspective. Washington DC: AICR; 2007.

[14] Armstrong B, Doll R. Environmental factors and cancer incidence in different countries. Int J Cancer 1975;15: 617-31.

[15] Chao A, Thun MJ, Connell CJ, et al. Meat consumption and risk of colorectal cancer. JAMA 2005;293(2):172-82.

[16] Young GP, Le Leu RK. Preventing cancer: dietary lifestyle or clinical intervention? Asia Pac J Clin Nutr 2002;11(Suppl. 3): S618-31.

[17] Windey K, De Preter V, Verbeke K. Relevance of protein fermentation to gut health. Mol Nutr Food Res 2012;56(1): 184-96.

[18] Haenszel W, Kurihara M. Studies of Japanese migrants. I. Mortality from cancer and other diseases among Japanese in the United States. J Natl Cancer Inst 1968;40(1):43-68.

[19] Oba S, Shimizu N, Nagata C, et al. The relationship between the consumption of meat, fat, and coffee and the risk of colon cancer: a prospective study in Japan. Cancer Lett 2006;244(2):260-7.

[20] Takachi R, Tsubono Y, Baba K, et al. Red meat intake may increase the risk of colon cancer in Japanese, a population with relatively low red meat consumption. Asia Pac J Clin Nutr 2011;20(4):603-12.

[21] De Stefani E, Boffetta P, Ronco AL, et al. Processed meat consumption and risk of cancer: a multisite case-control study in Uruguay. Br J Cancer 2012;107(9):1584-8.

[22] Baltussen R, Knai C, Sharan M. Iron fortification and iron supplementation are cost-effective interventions to reduce iron deficiency in four subregions of the world. J Nutr 2004;134(10):2678-84.

[23] Sandhu MS, White IR, McPherson K. Systematic review of the prospective cohort studies on meat consumption and colorectal cancer risk: a meta-analytical approach. Cancer Epidemiol Biomarkers Prev 2001;10(5):439-46.
[24] Norat T, Lukanova A, Ferrari P, Riboli E. Meat consumption and colorectal cancer risk: dose-response meta-analysis of epidemiological studies. Int J Cancer 2002;98(2):241-56.

[25] Larsson SC, Wolk A. Meat consumption and risk of colorectal cancer: a meta-analysis of prospective studies. Int J Cancer 2006;119(11):2657-64.

[26] Chan DS, Lau R, Aune D, et al. Red and processed meat and colorectal cancer incidence: meta-analysis of prospective studies. PLoS One 2011;6(6):e20456.

[27] Smolinska K, Paluszkiewicz P. Risk of colorectal cancer in relation to frequency and total amount of red meat consumption. Systematic review and meta-analysis. Arch Med Sci 2010;6(4):605-10.

[28] Daniel CR, Cross AJ, Graubard BI, Hollenbeck AR, Park Y, Sinha R. Prospective investigation of poultry and fish intake in relation to cancer risk. Cancer Prev Res 2011;4(11):1903-11.

[29] Egeberg R, Olsen A, Christensen J, et al. Associations between red meat and risks for colon and rectal cancer depend on the type of red meat consumed. J Nutr 2013;143(4):464-72.

[30] Alexander DD, Miller AJ, Cushing CA, Lowe KA. Processed meat and colorectal cancer: a quantitative review of prospective epidemiologic studies. Eur J Cancer Prev 2010;19(5):328-41.

[31] Alexander DD, Cushing CA. Red meat and colorectal cancer: a critical summary of prospective epidemiologic studies. Obes Rev 2011;12(5):e472-93.

[32] Ollberding NJ, Wilkens LR, Henderson BE, Kolonel LN, Le Marchand L. Meat consumption, heterocyclic amines and colorectal cancer risk: the Multiethnic Cohort Study. Int J Cancer 2012;131(7):E1125-33.

[33] Parr CL, Hjartaker A, Lund E, Veierod MB. Meat intake, cooking methods and risk of proximal colon, distal colon and rectal cancer: The Norwegian Women and Cancer (NOWAC) cohort study. Int J Cancer 2013;133(5):1153-63.

[34] Alexander DD, Weed DL, Cushing CA, Lowe KA. Metaanalysis of prospective studies of red meat consumption and colorectal cancer. Eur J Cancer Prev 2011;20(4):293-307.

[35] Bingham SA. High-meat diets and cancer risk. Proc Nutr Soc 1999;58(2):243-8.

[36] Norat T, Riboli E. Meat consumption and colorectal cancer: a review of epidemiologic evidence. Nutr Rev 2001;59(2):37-47.

[37] Cross AJ, Sinha R. Meat-related mutagens/carcinogens in the etiology of colorectal cancer. Environ Mol Mutagen 2004;44(1):44-55.

[38] Cross AJ, Ferrucci LM, Risch A, et al. A large prospective study of meat consumption and colorectal cancer risk: an investigation of potential mechanisms underlying this association. Cancer Res 2010;70(6):2406-14.

[39] Blachier F, Mariotti F, Huneau JF, Tome D. Effects of amino acid-derived luminal metabolites on the colonic epithelium and physiopathological consequences. Amino Acids 2007;33(4):547-62.

[40] Rand WM, Pellett PL, Young VR. Meta-analysis of nitrogen balance studies for estimating protein requirements in healthy adults. Am J Clin Nutr 2003;77(1):109-27.

[41] Schonfeldt HC, Gibson Hall N. Dietary protein quality and malnutrition in Africa. Br J Nutr 2012;108(Suppl 2):S69-76.

[42] McIntosh GH, Le Leu RK. The influence of dietary proteins on colon cancer risk. Nutr Res 2001;21(7):1053-66.

[43] Visek WJ. Dietary protein and experimental carcinogenesis. Adv Exp Med Biol 1986;206:163-86.

[44] Toden S, Bird AR, Topping DL, Conlon MA. Resistant starch attenuates colonic DNA damage induced by higher dietary protein in rats. Nutr Cancer 2005;51(1):45-51.

[45] Toden S, Bird AR, Topping DL, Conlon MA. Resistant starch prevents colonic DNA damage induced by high dietary cooked red meat or casein in rats. Cancer Biol Ther 2006;5(3) 267-72. 
[46] Toden S, Bird AR, Topping DL, Conlon MA. Differential effects of dietary whey, casein and soybean on colonic DNA damage and large bowel SCFA in rats fed diets low and high in resistant starch. Br J Nutr 2007;97(3):535-43.

[47] Toden S, Bird AR, Topping DL, Conlon MA. High red meat diets induce greater numbers of colonic DNA double-strand breaks than white meat in rats: attenuation by highamylose maize starch. Carcinogenesis 2007;28(11):2355-62.

[48] Winter J, Nyskohus L, Young GP, et al. Inhibition by resistant starch of red meat-induced promutagenic adducts in mouse colon. Cancer Prev Res 2011;4(11):1920-8.

[49] Andriamihaja M, Davila AM, Eklou-Lawson M, et al. Colon luminal content and epithelial cell morphology are markedly modified in rats fed with a high-protein diet. Am J Physiol 2010;299(5):G1030-7.

[50] Thibault R, Blachier F, Darcy-Vrillon B, de Coppet P, Bourreille A, Segain JP. Butyrate utilization by the colonic mucosa in inflammatory bowel diseases: a transport deficiency. Inflamm Bowel Dis 2010;16(4):684-95.

[51] Evenepoel P, Claus D, Geypens B, et al. Amount and fate of egg protein escaping assimilation in the small intestine of humans. Am J Physiol 1999;277(5 Pt 1):G935-43.

[52] Davila AM, Blachier F, Gotteland M, et al. Intestinal luminal nitrogen metabolism: role of the gut microbiota and consequences for the host. Pharmacol Res 2013;68(1):95-107.

[53] Silvester KR, Cummings JH. Does digestibility of meat protein help explain large bowel cancer risk? Nutr Cancer 1995;24(3):279-88.

[54] Gilbert JA, Bendsen NT, Tremblay A, Astrup A. Effect of proteins from different sources on body composition. Nutr Metab Cardiovasc Dis 2011;21(Suppl 2):B16-31.

[55] Genell S, Gustafsson BE, Ohlsson K. Quantitation of active pancreatic endopeptidases in the intestinal contents of germfree and conventional rats. Scand J Gastroenterol 1976;11(8):757-62.

[56] Gustafsson BE. The physiological importance of the colonic microflora. Scand J Gastroenterol Suppl 1982;77:117-31.

[57] Corpet DE, Bellier R, Petrowitsch S, Vigouroux Y. Digestion and fermentation of proteins in rats fed keratin, albumin, cooked casein and antibiotics. Reprod Nutr Dev 1994;34(1): 57-64.

[58] Clinton SK, Bostwick DG, Olson LM, Mangian HJ, Visek WJ. Effects of ammonium acetate and sodium cholate on $\mathrm{N}$ methyl-N'-nitro-N-nitrosoguanidine-induced colon carcinogenesis of rats. Cancer Res 1988;48(11):3035-9.

[59] Wrong OM, Vince AJ, Waterlow JC. The contribution of endogenous urea to faecal ammonia in man, determined by $15 \mathrm{~N}$ labelling of plasma urea. Clin Sci (Lond) 1985;68(2): 193-9.

[60] Lin HC, Visek WJ. Large intestinal $\mathrm{pH}$ and ammonia in rats: dietary fat and protein interactions. J Nutr 1991;121(6): 832-43.

[61] Geypens B, Claus D, Evenepoel P, et al. Influence of dietary protein supplements on the formation of bacterial metabolites in the colon. Gut 1997;41(1):70-6.

[62] Mouille B, Morel E, Robert V, Guihot-Joubrel G, Blachier F. Metabolic capacity for L-citrulline synthesis from ammonia in rat isolated colonocytes. Biochim Biophys Acta 1999;1427(3):401-7.

[63] Mouille B, Robert V, Blachier F. Adaptative increase of ornithine production and decrease of ammonia metabolism in rat colonocytes after hyperproteic diet ingestion. Am J Physiol 2004;287(2):G344-51.

[64] Eklou-Lawson M, Bernard F, Neveux N, et al. Colonic luminal ammonia and portal blood L-glutamine and L-arginine concentrations: a possible link between colon mucosa and liver ureagenesis. Amino Acids 2009;37(4):751-60.

[65] Visek WJ. Diet and cell growth modulation by ammonia. Am J Clin Nutr 1978;31(10 Suppl):S216-20.
[66] Lin HC, Visek WJ. Colon mucosal cell damage by ammonia in rats. J Nutr 1991;121(6):887-93.

[67] Mouille B, Delpal S, Mayeur C, Blachier F. Inhibition of human colon carcinoma cell growth by ammonia: a noncytotoxic process associated with polyamine synthesis reduction. Biochim Biophys Acta 2003;1624(1-3):88-97.

[68] Kikugawa K, Kato T. Formation of a mutagenic diazoquinone by interaction of phenol with nitrite. Food Chem Toxicol 1988;26(3):209-14.

[69] Hughes R, Magee EA, Bingham S. Protein degradation in the large intestine: relevance to colorectal cancer. Curr Issues Intest Microbiol 2000;1(2):51-8.

[70] Yokoyama MT, Carlson JR. Microbial metabolites of tryptophan in the intestinal tract with special reference to skatole. Am J Clin Nutr 1979;32(1):173-8.

[71] Smith EA, Macfarlane GT. Dissimilatory amino acid metabolism in human colonic bacteria. Anaerobe 1997;3(5):327-37.

[72] Blachier F, Davila AM, Mimoun S, et al. Luminal sulfide and large intestine mucosa: friend or foe? Amino Acids 2010;39(2):335-47.

[73] Beerens H, Romond C. Sulfate-reducing anaerobic bacteria in human feces. Am J Clin Nutr 1977;30(11):1770-6.

[74] Deplancke B, Finster K, Graham WV, Collier CT, Thurmond JE, Gaskins HR. Gastrointestinal and microbial responses to sulfate-supplemented drinking water in mice. Exp Biol Med 2003;228:424-33.

[75] Magee EA, Richardson CJ, Hughes R, Cummings JH. Contribution of dietary protein to sulfide production in the large intestine: an in vitro and a controlled feeding study in humans. Am J Clin Nutr 2000;72(6):1488-94.

[76] Ramazzini B. On the diseases of artificers (De morbis artificum diatriba), 1713. JamesLondon: Whiston J; 1750.

[77] Reiffenstein RJ, Hulbert WC, Roth SH. Toxicology of hydrogen sulfide. Annu Rev Pharmacol Toxicol 1992;32:109-34.

[78] Babidge W, Millard S, Roediger W. Sulfides impair short chain fatty acid beta-oxidation at acyl-CoA dehydrogenase level in colonocytes: implications for ulcerative colitis. Mol Cell Biochem 1998;181(1-2):117-24.

[79] Deplancke B, Gaskins HR. Hydrogen sulfide induces serumindependent cell cycle entry in nontransformed rat intestinal epithelial cells. FASEB J 2003;17(10):1310-2.

[80] Leschelle X, Goubern M, Andriamihaja M, et al. Adaptative metabolic response of human colonic epithelial cells to the adverse effects of the luminal compound sulfide. Biochim Biophys Acta 2005;1725(2):201-12.

[81] Attene-Ramos MS, Wagner ED, Plewa MJ, Gaskins HR. Evidence that hydrogen sulfide is a genotoxic agent. Mol Cancer Res 2006;4(1):9-14.

[82] Attene-Ramos MS, Wagner ED, Gaskins HR, Plewa MJ. Hydrogen sulfide induces direct radical-associated DNA damage. Mol Cancer Res 2007;5(5):455-9.

[83] Levitt MD, Furne J, Springfield J, Suarez F, DeMaster E. Detoxification of hydrogen sulfide and methanethiol in the cecal mucosa. J Clin Invest 1999;104(8):1107-14.

[84] Huycke MM, Gaskins HR. Commensal bacteria, redox stress, and colorectal cancer: mechanisms and models. Exp Biol Med 2004;229:586-97.

[85] Pitcher MC, Beatty ER, Cummings JH. The contribution of sulphate reducing bacteria and 5 -aminosalicylic acid to faecal sulphide in patients with ulcerative colitis. Gut 2000;46(1):64-72.

[86] Bouillaud F, Blachier F. Mitochondria and sulfide: a very old story of poisoning, feeding, and signaling? Antioxid Redox Signal 2011;15(2):379-91.

[87] Goubern M, Andriamihaja M, Nubel T, Blachier F, Bouillaud F. Sulfide, the first inorganic substrate for human cells. FASEB J 2007;21(8):1699-706.

[88] Mimoun S, Andriamihaja M, Chaumontet C, et al. Detoxification of $\mathrm{H}(2) \mathrm{S}$ by differentiated colonic epithelial cells: 
implication of the sulfide oxidizing unit and of the cell respiratory capacity. Antioxid Redox Signal 2012;17(1): 1-10.

[89] Corpet DE, Yin Y, Zhang XM, et al. Colonic protein fermentation and promotion of colon carcinogenesis by thermolyzed casein. Nutr Cancer 1995;23(3):271-81.

[90] Morita T, Kasaoka S, Kiriyama S. Physiological functions of resistant proteins: proteins and peptides regulating large bowel fermentation of indigestible polysaccharide. J AOAC Int 2004;87(3):792-6.

[91] Ijssennagger N, Rijnierse A, de Wit N, et al. Dietary heme stimulates epithelial cell turnover by downregulating feedback inhibitors of proliferation in murine colon. Gut 2012;61(7):1041-9.

[92] de Vogel J, van-Eck WB, Sesink AL, Jonker-Termont DS, Kleibeuker J, van der Meer R. Dietary heme injures surface epithelium resulting in hyperproliferation, inhibition of apoptosis and crypt hyperplasia in rat colon. Carcinogenesis 2008;29(2):398-403.

[93] de Vogel J, Jonker-Termont DS, Katan MB, van der Meer R. Natural chlorophyll but not chlorophyllin prevents hemeinduced cytotoxic and hyperproliferative effects in rat colon. J Nutr 2005;135(8):1995-2000.

[94] Van Der Meer-Van Kraaij C, Van Lieshout EM, Kramer E, Van Der Meer R, Keijer J. Mucosal pentraxin (Mptx), a novel rat gene 10-fold down-regulated in colon by dietary heme. FASEB J 2003;17(10):1277-85.

[95] Van Der Meer-Van Kraaij C, Kramer E, Jonker-Termont D, Katan MB, van der Meer R, Keijer J. Differential gene expression in rat colon by dietary heme and calcium. Carcinogenesis 2005;26(1):73-9.

[96] Pierre F, Tache S, Petit CR, Van der Meer R, Corpet DE. Meat and cancer: hemeoglobin and hemein in a low-calcium diet promote colorectal carcinogenesis at the aberrant crypt stage in rats. Carcinogenesis 2003;24(10):1683-90.

[97] Pierre F, Freeman A, Tache S, Van der Meer R, Corpet DE. Beef meat and blood sausage promote the formation of azoxymethane-induced mucin-depleted foci and aberrant crypt foci in rat colons. J Nutr 2004;134(10):2711-6.

[98] Glei M, Klenow S, Sauer J, Wegewitz U, Richter K, Pool-Zobel BL. Hemoglobin and hemin induce DNA damage in human colon tumor cells HT29 clone 19A and in primary human colonocytes. Mut Res 2006;594(1-2):162-71.

[99] Bastide NM, Pierre FH, Corpet DE. Heme iron from meat and risk of colorectal cancer: a meta-analysis and a review of the mechanisms involved. Cancer Prev Res 2011;4(2):177-84.

[100] Tappel A. In: Schultz H, editor. Hematin compounds and lipoxidase as biocatalysts. Westport: Avi Publ; 1962. p. 122-38.

[101] Ishikawa S, Tamaki S, Ohata M, Arihara K, Itoh M. Heme induces DNA damage and hyperproliferation of colonic epithelial cells via hydrogen peroxide produced by heme oxygenase: a possible mechanism of heme-induced colon cancer. Mol Nutr Food Res 2010;54(8):1182-91.

[102] Tappel A. Heme of consumed red meat can act as a catalyst of oxidative damage and could initiate colon, breast and prostate cancers, heart disease and other diseases. Med Hypotheses 2007;68(3):562-4.

[103] Zhang X, Giovannucci EL, Smith-Warner SA, et al. A prospective study of intakes of zinc and heme iron and colorectal cancer risk in men and women. Cancer Causes Control 2011;22(12):1627-37.

[104] Kabat GC, Miller AB, Jain M, Rohan TE. A cohort study of dietary iron and heme iron intake and risk of colorectal cancer in women. Brit J Cancer 2007;97(1):118-22.

[105] Nyangale EP, Mottram DS, Gibson GR. Gut microbial activity, implications for health and disease: the potential role of metabolite analysis. J Proteome Res 2012;11(12): 5573-85.
[106] Joosen AM, Kuhnle GG, Aspinall SM, et al. Effect of processed and red meat on endogenous nitrosation and DNA damage. Carcinogenesis 2009;30(8):1402-7.

[107] Hall CN, Badawi AF, O'Connor PJ, Saffhill R. The detection of alkylation damage in the DNA of human gastrointestinal tissues. Brit J Cancer 1991;64(1):59-63.

[108] Bingham SA, Pignatelli B, Pollock JR, et al. Does increased endogenous formation of $\mathrm{N}$-nitroso compounds in the human colon explain the association between red meat and colon cancer? Carcinogenesis 1996;17(3):515-23.

[109] Hotchkiss JH. Preformed N-nitroso compounds in foods and beverages. Cancer Surv 1989;8(2):295-321.

[110] Cross AJ, Pollock JR, Bingham SA. Heme, not protein or inorganic iron, is responsible for endogenous intestinal $\mathrm{N}$-nitrosation arising from red meat. Cancer Res 2003;63(10): 2358-60.

[111] Bingham SA, Hughes R, Cross AJ. Effect of white versus red meat on endogenous $\mathrm{N}$-nitrosation in the human colon and further evidence of a dose response. J Nutr 2002;132(11 Suppl):3522S-5S.

[112] Hebels DG, Sveje KM, de Kok MC, et al. Red meat intakeinduced increases in fecal water genotoxicity correlate with pro-carcinogenic gene expression changes in the human colon. Food Chem Toxicol 2012;50(2):95-103.

[113] Lipkin M, Reddy B, Newmark H, Lamprecht SA. Dietary factors in human colorectal cancer. Annu Rev Nutr 1999;19: 545-86.

[114] Sinha R, Rothman N, Brown ED, et al. Pan-fried meat containing high levels of heterocyclic aromatic amines but low levels of polycyclic aromatic hydrocarbons induces cytochrome P4501A2 activity in humans. Cancer Res 1994;54(23):6154-9.

[115] Turesky RJ. Formation and biochemistry of carcinogenic heterocyclic aromatic amines in cooked meats. Toxicol Lett 2007;168(3):219-27.

[116] Wang J, Joshi AD, Corral R, et al. Carcinogen metabolism genes, red meat and poultry intake, and colorectal cancer risk. Int J Cancer 2012;130(8):1898-907.

[117] Sugimura T, Wakabayashi K, Nakagama H, Nagao M. Heterocyclic amines: mutagens/carcinogens produced during cooking of meat and fish. Cancer Sci 2004;95(4): 290-9.

[118] Nowell S, Coles B, Sinha R, et al. Analysis of total meat intake and exposure to individual heterocyclic amines in a casecontrol study of colorectal cancer: contribution of metabolic variation to risk. Mut Res 2002;506-507:175-85.

[119] Sinha R, Chow WH, Kulldorff M, et al. Well-done, grilled red meat increases the risk of colorectal adenomas. Cancer Res 1999;59(17):4320-4.

[120] Gunter MJ, Probst-Hensch NM, Cortessis VK, Kulldorff M, Haile RW, Sinha R. Meat intake, cooking-related mutagens and risk of colorectal adenoma in a sigmoidoscopybased case-control study. Carcinogenesis 2005;26(3): 637-42.

[121] Shin A, Shrubsole MJ, Ness RM, et al. Meat and meatmutagen intake, doneness preference and the risk of colorectal polyps: the Tennessee Colorectal Polyp Study. Int J Cancer 2007;121(1):136-42.

[122] Gill CI, Rowland IR. Diet and cancer: assessing the risk. Br J Nutr 2002;88(Suppl 1):S73-87.

[123] Mai V. Dietary modification of the intestinal microbiota. Nutr Rev 2004;62(6 Pt 1):235-42.

[124] Bengmark S. Ecological control of the gastrointestinal tract. The role of probiotic flora. Gut 1998;42(1):2-7.

[125] Bourlioux P, Koletzko B, Guarner F, Braesco V. The intestine and its microflora are partners for the protection of the host: report on the Danone Symposium "The Intelligent Intestine," held in Paris, June 14, 2002. Am J Clin Nutr 2003;78(4): 675-83. 
[126] Gold JS, Bayar S, Salem RR. Association of Streptococcus bovis bacteremia with colonic neoplasia and extracolonic malignancy. Arch Surg 2004;139(7):760-5.

[127] Moore WE, Moore LH. Intestinal floras of populations that have a high risk of colon cancer. Appl Environ Microbiol 1995;61(9):3202-7.

[128] Nakamura J, Kubota Y, Miyaoka M, Saitoh T, Mizuno F, Benno Y. Comparison of four microbial enzymes in Clostridia and Bacteroides isolated from human feces. Microbiol Immunol 2002;46(7):487-90.

[129] Peek Jr RM, Blaser MJ. Helicobacter pylori and gastrointestinal tract adenocarcinomas. Nat Rev 2002;2(1):28-37.

[130] Kostic AD, Gevers D, Pedamallu CS, et al. Genomic analysis identifies association of Fusobacterium with colorectal carcinoma. Genome Res 2012;22(2):292-8.

[131] Rowland IR, Bearne CA, Fischer R, Pool-Zobel BL. The effect of lactulose on DNA damage induced by DMH in the colon of human flora-associated rats. Nutr Cancer 1996;26(1):37-47.

[132] McIntosh GH, Royle PJ, Playne MJ. A probiotic strain of L. acidophilus reduces $\mathrm{DMH}$-induced large intestinal tumors in male Sprague-Dawley rats. Nutr Cancer 1999;35(2):153-9.

[133] Paolillo R, Romano Carratelli C, Sorrentino S, Mazzola N, Rizzo A. Immunomodulatory effects of Lactobacillus plantarum on human colon cancer cells. Int Immunopharmacol 2009;9(11):1265-71.

[134] De Filippo C, Cavalieri D, Di Paola M, et al. Impact of diet in shaping gut microbiota revealed by a comparative study in children from Europe and rural Africa. Proc Natl Acad Sci 2010;107(33):14691-6.

[135] Farrokhyar F, Swarbrick ET, Irvine EJ. A critical review of epidemiological studies in inflammatory bowel disease. Scand J Gastroenterol 2001;36(1):2-15.

[136] O'Keefe SJ, Chung D, Mahmoud N, et al. Why do African Americans get more colon cancer than Native Africans? J Nutr 2007;137(1 Suppl):175S-82S.

[137] Ashktorab H, Smoot DT, Carethers JM, et al. High incidence of microsatellite instability in colorectal cancer from African Americans. Clin Cancer Res 2003;9(3):1112-7.
[138] O'Keefe SJ, Kidd M, Espitalier-Noel G, Owira P. Rarity of colon cancer in Africans is associated with low animal product consumption, not fiber. Am J Gastroenterol 1999;94(5): 1373-80.

[139] Macfarlane GT, Cummings JH, Allison C. Protein degradation by human intestinal bacteria. J Gen Microbiol 1986;132(6): 1647-56.

[140] Van der Meulen R, Camu N, Van Vooren T, Heymans C, De Vuyst L. In vitro kinetic analysis of carbohydrate and aromatic amino acid metabolism of different members of the human colon. Int J Food Microbiol 2008;124(1):27-33.

[141] Roediger WE, Duncan A, Kapaniris O, Millard S. Sulphide impairment of substrate oxidation in rat colonocytes: a biochemical basis for ulcerative colitis? Clin Sci (Lond) 1993;85(5):623-7.

[142] Shen Q Chen YA, Tuohy KM. A comparative in vitro investigation into the effects of cooked meats on the human faecal microbiota. Anaerobe 2010;16(6):572-7.

[143] Kado S, Uchida K, Funabashi H, et al. Intestinal microflora are necessary for development of spontaneous adenocarcinoma of the large intestine in T-cell receptor beta chain and p53 double-knockout mice. Cancer Res 2001;61(6): 2395-8.

[144] Berg DJ, Davidson N, Kuhn R, et al. Enterocolitis and colon cancer in interleukin-10-deficient mice are associated with aberrant cytokine production and CD4(+) TH1-like responses. J Clin Invest 1996;98(4):1010-20.

[145] Sellon RK, Tonkonogy S, Schultz M, et al. Resident enteric bacteria are necessary for development of spontaneous colitis and immune system activation in interleukin-10deficient mice. Infect Immun 1998;66(11):5224-31.

[146] Dianda L, Hanby AM, Wright NA, Sebesteny A, Hayday AC, Owen MJ. T cell receptor-alpha beta-deficient mice fail to develop colitis in the absence of a microbial environment. Am J Pathol 1997;150(1):91-7.

[147] Sobhani I, Tap J, Roudot-Thoraval F, et al. Microbial dysbiosis in colorectal cancer (CRC) patients. PLoS One 2011;6(1): e16393. 
ANEXO - Laudo da análise bromatológica 


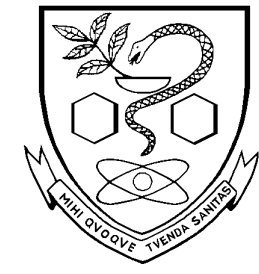

Laudo de análise: 02/13

$\grave{A}$

Escola de Educação Física e Esportes - USP

A/C: Desire Coelho

Amostras de ração:

1. Ração controle

2. Ração saturada

3. Ração PUFA

Condições de análise

Método de extração dos lípides e derivatização: ASSOCIATION OF OFFICIAL ANALYTICAL CHEMISTS. Official Methods of Analysis, Arlington, Official Method. n. 996.06, cap. 41, p. 20-24A, 2002, com modificações. Foram utilizados os fatores de resposta teóricos do FID (flame ionization detector), do método Ce 1j-07 da AOCS.

\section{Condições Cromatográficas:}

- Cromatógrafo a gás GC 2012 plus Shimadzu/ software GC solution.

- Coluna cromatográfica de sílica fundida SP-2560 (biscianopropil polisiloxana) de $100 \mathrm{~m}$ e $0.25 \mathrm{~mm}$. de d.i.

- Programação de temperatura da coluna: isotérmico a $140^{\circ} \mathrm{C}$ por 5 min. e então aquecimento a $4^{\circ} \mathrm{C} / \mathrm{min}$. até $240^{\circ} \mathrm{C}$, permanecendo nesta temperatura por $30 \mathrm{~min}$.

- Temperatura do vaporizador: $250^{\circ} \mathrm{C}$.

- Temperatura de detector: $260^{\circ} \mathrm{C}$.

- Gás de arraste: Hélio (1 ml/min.).

- Razão de divisão da amostra: 1/50. 


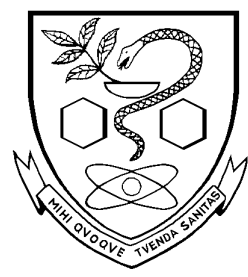

UNIVERSIDADE DE SÃO PAULO

Faculdade de Ciências Farmacêuticas

Departamento de Alimentos e Nutrição Experimental

\section{Resultados}

Os teores de ácidos graxos obtidos são apresentados em g/100 g de amostra, e em porcentagem do total de ácidos graxos e representam a média de três determinações.

\begin{tabular}{|c|c|c|c|c|c|c|c|}
\hline Fórmula & Nome & Controle & Saturada & Polinsaturada & Controle & Saturada & Polinsaturada \\
\hline & & \multicolumn{3}{|c|}{ g/100 g de ração } & \multicolumn{3}{|c|}{ \% Ac graxos } \\
\hline $12: 0$ & Láurico & - & - & - & - & - & - \\
\hline $14: 0$ & Mirístico & $0,01 \pm 0,00$ & $0,22 \pm 0,01$ & $0,25 \pm 0,01$ & $0,14 \pm 0,00$ & $1,14 \pm 0,03$ & $1,25 \pm 0,01$ \\
\hline 15:0 & Pentadecanóico & - & - & $0,02 \pm 0,00$ & - & - & $0,08 \pm 0,00$ \\
\hline $16: 0$ & Palmítico & $0,51 \pm 0,01$ & $4,38 \pm 0,24$ & $2,50 \pm 0,08$ & $13,29 \pm 0,06$ & $21,89 \pm 0,24$ & $11,93 \pm 0,04$ \\
\hline $16: 1$ & Hexadecenóico & & $0,34 \pm 0,02$ & $0,44 \pm 0,02$ & $0,11 \pm 0,01$ & $1,71 \pm 0,03$ & $2,10 \pm 0,01$ \\
\hline $17: 0$ & Margárico & $0,01 \pm 0,00$ & $0,08 \pm 0,00$ & $0,03 \pm 0,00$ & $0,11 \pm 0,01$ & $0,39 \pm 0,01$ & $0,13 \pm 0,00$ \\
\hline $17: 1$ & Heptadecenóico & - & $0,06 \pm 0,00$ & $0,02 \pm 0,00$ & - & $0,28 \pm 0,01$ & $0,10 \pm 0,00$ \\
\hline $18: 0$ & Esteárico & $0,15 \pm 0,00$ & $2,25 \pm 0,14$ & $0,74 \pm 0,02$ & $3,88 \pm 0,01$ & $10,97 \pm 0,21$ & $3,45 \pm 0,01$ \\
\hline $18: 1$ t (n-9) & Elaídico & - & - & - & - & - & - \\
\hline $18: 1(n-9)$ & Oleico & $0,87 \pm 0,02$ & $7,89 \pm 0,42$ & $9,86 \pm 0,44$ & $21,92 \pm 0,29$ & $38,22 \pm 0,41$ & $45,66 \pm 0,46$ \\
\hline $18: 1(n-11)$ & Vacênico & $0,05 \pm 0,01$ & $0,47 \pm 0,02$ & $0,40 \pm 0,02$ & $1,33 \pm 0,25$ & $2,26 \pm 0,04$ & $1,86 \pm 0,06$ \\
\hline $18: 2 \mathrm{t}$ & Linolelaídico & - & - & - & $0,11 \pm 0,01$ & - & - \\
\hline $18: 2(n-6)$ & Linoleico & $2,15 \pm 0,04$ & $4,46 \pm 0,09$ & $5,30 \pm 0,08$ & $53,91 \pm 0,09$ & $21,49 \pm 0,63$ & $24,40 \pm 0,48$ \\
\hline $20: 0$ & Eicosanóico & $0,01 \pm 0,00$ & - & $0,06 \pm 0,00$ & $0,33 \pm 0,01$ & - & $0,29 \pm 0,00$ \\
\hline $18: 3 \gamma$ & $\gamma$ Linolênico & - & - & - & $0,12 \pm 0,01$ & - & - \\
\hline $20: 1(n-9)$ & Eicosenóico & - & - & $0,19 \pm 0,01$ & - & - & $0,88 \pm 0,00$ \\
\hline $18: 3(n-3)$ & Linolênico & $0,17 \pm 0,00$ & $0,34 \pm 0,03$ & $0,44 \pm 0,02$ & $4,19 \pm 0,04$ & $1,63 \pm 0,24$ & $2,00 \pm 0,03$ \\
\hline $20: 2$ & Eicosadienóico & - & - & - & - & - & - \\
\hline $18: 4(n-3)$ & Octadecatetraenóico & - & - & $0,10 \pm 0,01$ & - & - & $0,47 \pm 0,01$ \\
\hline $22: 0$ & Docosanóico & $0,01 \pm 0,00$ & - & $0,04 \pm 0,00$ & $0,31 \pm 0,00$ & - & $0,17 \pm 0,01$ \\
\hline $20: 3(n-6)$ & Eicosatrienóico & & - & $0,02 \pm 0,00$ & - & - & $0,09 \pm 0,00$ \\
\hline $22: 1$ & Docosenóico & - & - & - & - & - & - \\
\hline $20: 3(n-3)$ & Eicosatrienóico & - & - & - & - & - & $0,09 \pm 0,00$ \\
\hline $20: 4(n-6)$ & Araquidônico & - & - & $0,03 \pm 0,00$ & - & - & $0,14 \pm 0,01$ \\
\hline $20: 4(n-3)$ & Eicosatetraenóico & - & - & $0,05 \pm 0,00$ & - & - & $0,22 \pm 0,00$ \\
\hline $24: 0$ & Lignocérico & $0,01 \pm 0,00$ & - & - & $0,25 \pm 0,00$ & - & - \\
\hline $20: 5(n-3)$ & Eicosapentaenóico & - & - & $0,48 \pm 0,02$ & - & - & $2,04 \pm 0,02$ \\
\hline $22: 5(n-6)$ & Docosapentaenóico & - & - & $0,03 \pm 0,00$ & - & - & $0,11 \pm 0,00$ \\
\hline $22: 5(n-3)$ & Docosapentaenóico & - & - & $0,20 \pm 0,01$ & - & - & $0,89 \pm 0,01$ \\
\hline $22: 6(n-3)$ & Docosahexaenóico & - & - & $0,40 \pm 0,02$ & 一 & 一 & $1,74 \pm 0,01$ \\
\hline \multirow{4}{*}{ Totais } & Saturados & $0,71 \pm 0,01$ & $6,93 \pm 0,39$ & $3,64 \pm 0,12$ & $18,31 \pm 0,09$ & $34,39 \pm 0,48$ & $17,30 \pm 0,04$ \\
\hline & Monoinsaturados & $0,93 \pm 0,02$ & $8,67 \pm 0,47$ & $10,92 \pm 0,48$ & $23,36 \pm 0,06$ & $42,46 \pm 0,43$ & $50,60 \pm 0,48$ \\
\hline & Polinsaturados & $2,32 \pm 0,04$ & $4,80 \pm 0,07$ & $7,05 \pm 0,15$ & $58,22 \pm 0,06$ & $23,12 \pm 0,86$ & $32,10 \pm 0,45$ \\
\hline & Trans & - & - & - & $0,11 \pm 0,01$ & - & - \\
\hline \% gordura & & $4,20 \pm 0,05$ & $21,93 \pm 0,96$ & $22,96 \pm 0,79$ & & & \\
\hline
\end{tabular}

*A determinação de gordura foi calculada, a partir do triglicerídeo do ácido tridecanóico, que foi utilizado como padrão interno. 


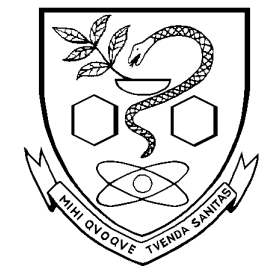

UNIVERSIDADE DE SÃO PAULO

Faculdade de Ciências Farmacêuticas

Departamento de Alimentos e Nutrição Experimental

São Paulo, 15 de abril de 2013.

Atenciosamente

Farm-Bioq. Rosângela Pavan

Visto: Prof. Titular Jorge Mancini Filho

Observações:

As amostras foram fornecidas pelo interessado. O conteúdo e as condições aqui apresentados são de exclusiva responsabilidade dos autores e não refletem necessariamente, as opiniões da Universidade de São Paulo. 